\title{
NEET In-Pile Ultrasonic Sensor Enablement-FY 2012 Status Report
}

\author{
J. Daw \\ J. Rempe \\ P. Ramuhalli \\ R. Montgomery \\ H. T. Chien \\ B. Tittman \\ B. Reinhardt
}

September 2012

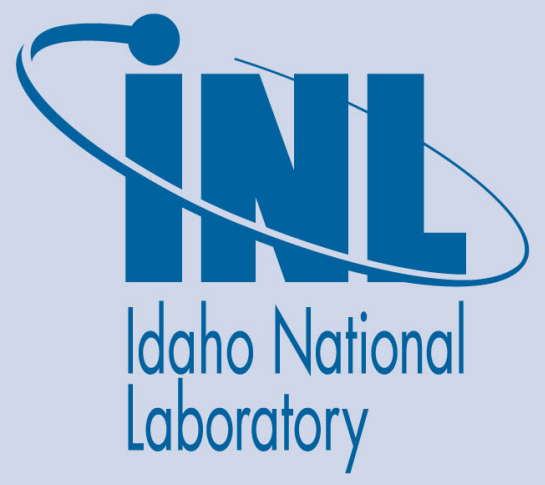

The INL is a U.S. Department of Energy National Laboratory operated by Battelle Energy Alliance 
INL/EXT-12-27233

\title{
NEET In-Pile Ultrasonic Sensor Enablement-FY 2012 Status Report
}

\author{
J. Daw \\ J. Rempe \\ P. Ramuhalli \\ R. Montgomery \\ H. T. Chien \\ B. Tittmann \\ B. Reinhardt
}

September 2012

\section{Idaho National Laboratory Idaho Falls, Idaho 83415}

http://www.inl.gov

Prepared for the U.S. Department of Energy Office of Nuclear Energy Under DOE Idaho Operations Office

Contract DE-AC07-05ID14517 


\section{DISCLAIMER}

This information was prepared as an account of work sponsored by an agency of the U.S. Government. Neither the U.S. Government nor any agency thereof, nor any of their employees, makes any warranty, expressed or implied, or assumes any legal liability or responsibility for the accuracy, completeness, or usefulness, of any information, apparatus, product, or process disclosed, or represents that its use would not infringe privately owned rights. References herein to any specific commercial product, process, or service by trade name, trade mark, manufacturer, or otherwise, does not necessarily constitute or imply its endorsement, recommendation, or favoring by the U.S. Government or any agency thereof. The views and opinions of authors expressed herein do not necessarily state or reflect those of the U.S. Government or any agency thereof.

\section{PRODUCT DISCLAIMER}

References herein to any specific commercial product, process, or service by trade name, trademark, manufacturer, or otherwise, does not necessarily constitute or imply its endorsement, recommendation, or favoring by the U.S. Government, any agency thereof, or any company affiliated with the Idaho National Laboratory. 
This page intentionally left blank. 


\section{SUMMARY}

Several programs funded by the Department of Energy Office of Nuclear Energy (DOE-NE), such as the Fuel Cycle Research and Development, Advanced Reactor Concepts, Light Water Reactor Sustainability, and Next Generation Nuclear Plant programs, are investigating new fuels and materials for advanced and existing reactors. A key objective of such programs is to understand the performance of these fuels and materials when irradiated. The Nuclear Energy Enabling Technology (NEET) Advanced Sensors and Instrumentation (ASI) in-pile instrumentation development activities are focused upon addressing cross-cutting needs for DOE-NE irradiation testing by providing higher fidelity, real-time data, with increased accuracy and resolution from smaller, compact sensors that are less intrusive.

Ultrasonic technologies offer the potential to measure a range of parameters, including geometry changes, temperature, crack initiation and growth, gas pressure and composition, and microstructural changes, under harsh irradiation test conditions. There are two primary issues that current limit in-pile deployment of ultrasonic sensors. The first is transducer survivability. The ability of ultrasonic transducer materials to maintain their useful properties during an irradiation must be demonstrated. The second issue is signal processing. Ultrasonic testing is typically performed in a lab or field environment, where the sensor and sample are accessible. Due to the harsh nature of in-pile testing, and the variety of measurements that are desired, an enhanced signal processing capability is needed to make in-pile ultrasonic sensors viable. The NEET ASI program is funding the Ultrasonic Transducer Irradiation and Software Enhancements project, which is a collaborative effort between the Idaho National Laboratory, the Pacific Northwest National Laboratory, and the Argonne National Laboratory, and the Pennsylvania State University, to address these issues. As summarized below, significant progress was made toward addressing each issue during FY2012.

- Transducer Irradiation Test - The first task of this project supports efforts to develop a test capsule design and define irradiation conditions for evaluating most promising candidate piezoelectric and magnetostrictive transducer materials and designs. The collaborative project team supported development of a PSU-led proposal for irradiating ultrasonics transducers. In June 2012, the ATR NSUF announced that this proposal was selected, and the irradiation would occur in the MIT Research Reactor (MITR). Subsequent project efforts have focused on developing a capsule design and on identifying appropriate test conditions, test conditions, transducers for inclusion in the capsule, appropriate post-irradiation examinations, and out-of-pile laboratory tests needed to support the irradiation. As documented in this report, the irradiation test builds on prior research and exceeds previous tests in terms of the number of materials tested and accumulated fluence. The test will irradiate the six most promising transducer materials (three piezoelectric and three magnetostrictive) to a total fast fluence of at least $1 \times 10^{21} \mathrm{n} / \mathrm{cm}^{2}$. Suitable piezoelectric and magnetostrictive candidates have been identified based on material properties and previous research. Piezoelectric materials identified for inclusion are aluminum nitride $(\mathrm{AlN})$, bismuth titanate niobate $\left(\mathrm{Bi}_{3} \mathrm{TiNbO}_{9}\right)$, and zinc oxide $(\mathrm{ZnO})$. Magnetostrictive materials proposed for inclusion are Remendur (or, alternatively, Vacouflux 50), Arnokrome 4 (or Arnokrome 5), and Galfenol. Magnetostrictive transducers also require a biasing magnet to operate. Selected magnetic materials include samarium-cobalt and Alnico. Concerns regarding transducer design, such as electrical connections and transducer to sample coupling, were addressed. A preliminary test capsule design was developed that is capable of accommodating all test specimens as well as extensive instrumentation for monitoring temperature and neutron and gamma flux in real time.

- Signal Processing Enhancement - The second task of this project addresses the need for an enhanced signal processing capability for future in-pile ultrasonic measurements. Progress on this task was limited by the accelerated schedule for Task 1 . However, an extensive description of general ultrasonic signal processing methods was developed, along with some specific information about the parameters to eventually be measured in-pile. Methods for incorporating various signal processing techniques into a common platform have also been identified. 
In summary, two issues related to the future deployment of ultrasonic sensors in irradiation tests are being addressed by the current project. As documented in this report, FY 12 funding has allowed the project to meet all planned accomplishments for developing this unique new, compact, multipurpose sensor for irradiation testing programs. 


\section{CONTENTS}

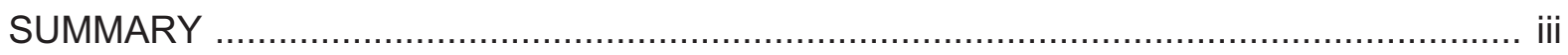

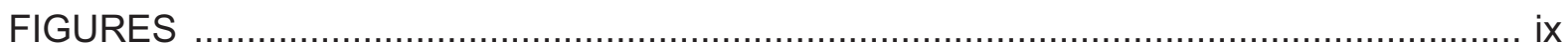

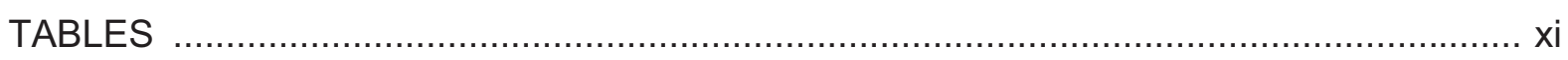

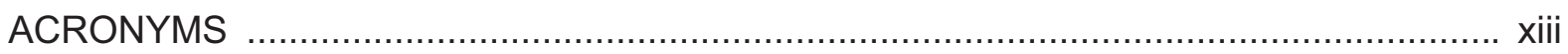

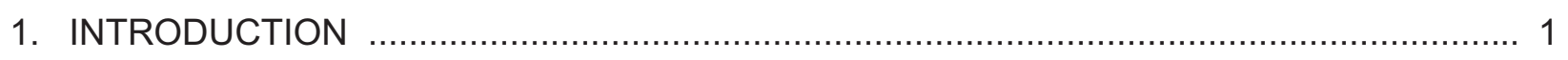

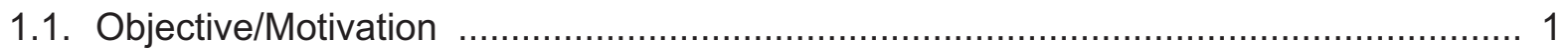

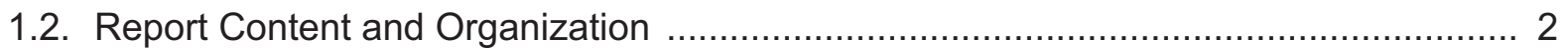

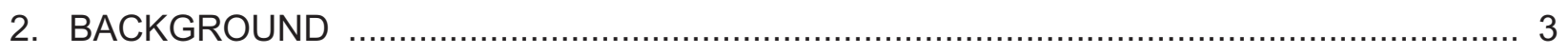

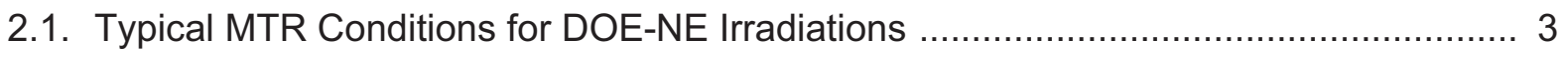

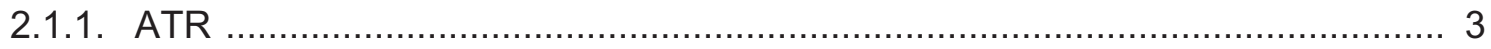

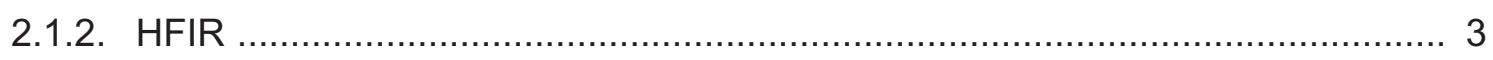

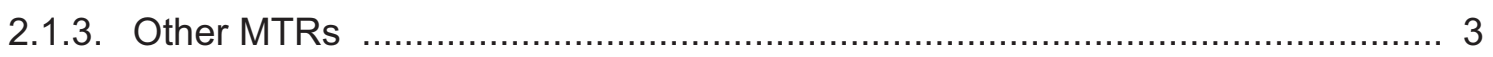

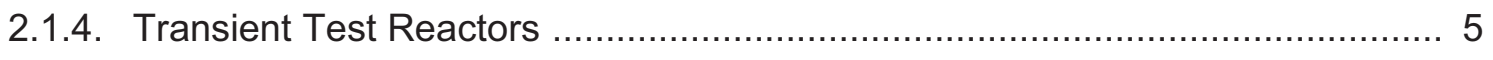

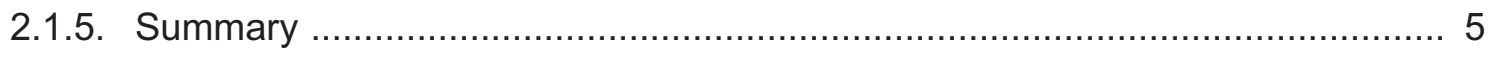

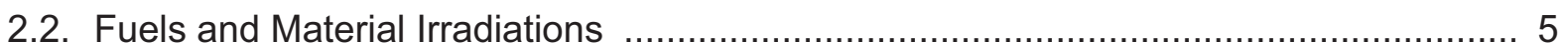

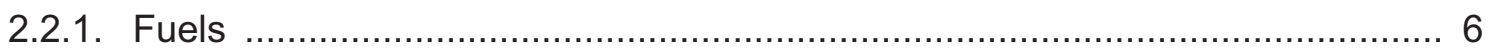

2.2.1.1. Ceramic Fuel for LWR and SFR Operation ............................. 6

2.2.1.2. Metal Fuel for SFR Operation ................................................. 9

2.2.1.3. Particle Fuel for HTGR Operation ........................................ 11

2.2.1.4. Phenomena of Interest ................................................... 12

2.2.1.5. Desired Measurement Parameters and Accuracies ..................... 15

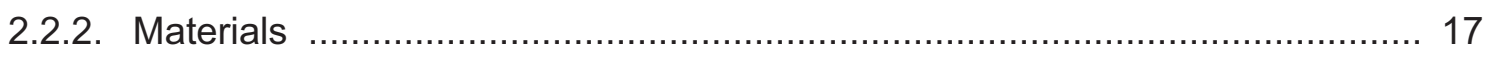

2.2.2.1. High Temperature Alloys ................................................... 17

2.2.2.2. Vessel Steel and Internal Structures ....................................... 19

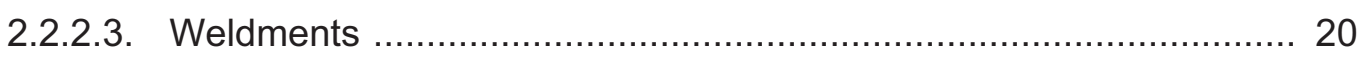

2.2.2.4. Graphite ....................................................................... 21

2.2.2.5. Desired Measurement Parameters and Accuracies ...................... 22

2.3. Instrumentation Development Required for DOE-NE Irradiations .......................... 24

3. TASK 1: ULTRASONIC TRANSDUCER IRRADIATION TEST ............................... 27

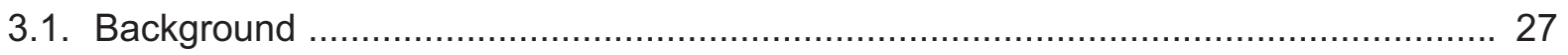

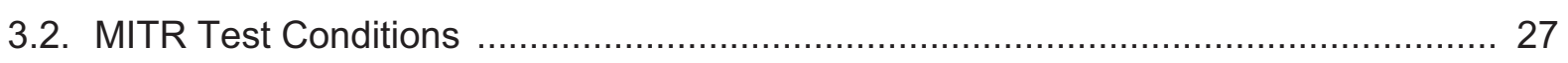

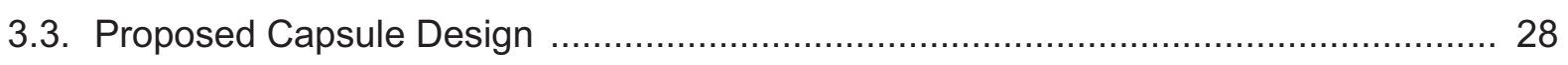

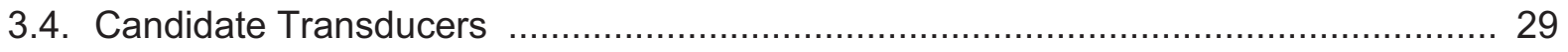

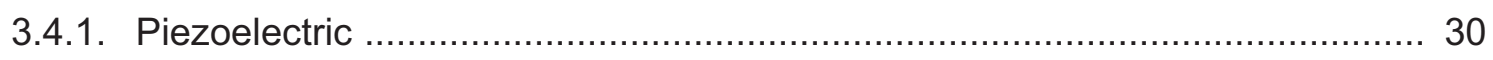

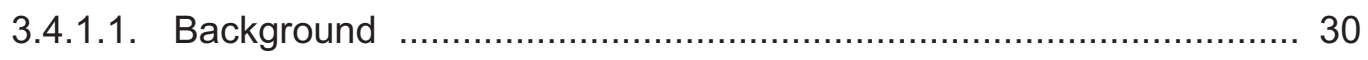

3.4.1.2. Desirable Attributes ...................................................... 30 
3.4.1.3. Candidate Materials and Selection Process ............................. 33

3.4.1.4. Material Selection ........................................................... 34

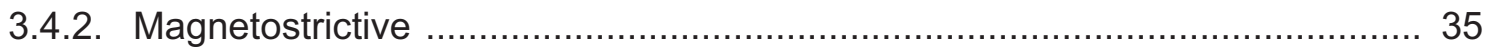

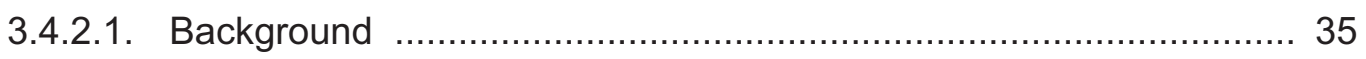

3.4.2.2. Magnetostrictive Material Candidates ....................................... 35

3.4.2.3. Transducer Design Considerations ......................................... 36

3.4.2.4. Magnetostrictive Material Selection ...................................... 36

3.4.2.5. Magnet Material Selection ...................................................... 39

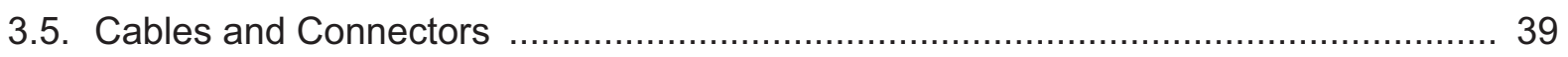

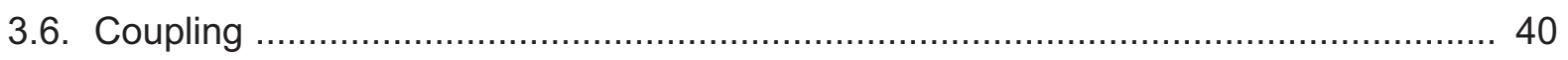

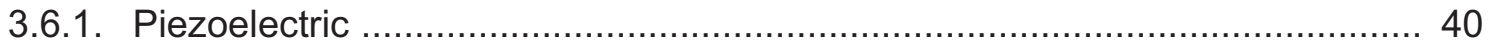

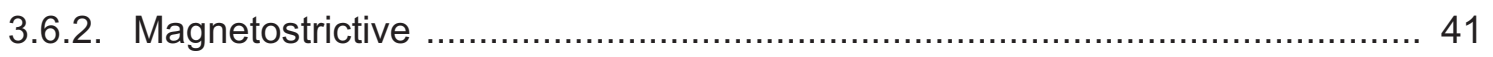

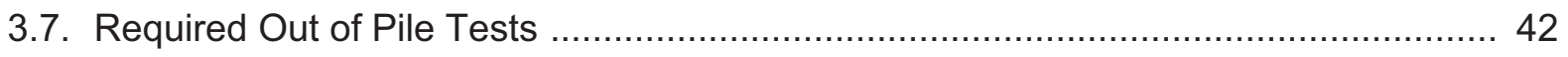

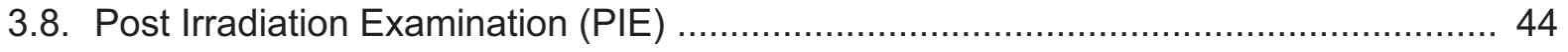

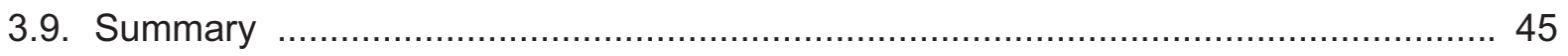

4. TASK 2: ULTRASONICS SIGNAL PROCESSING SOFTWARE ................................ 47

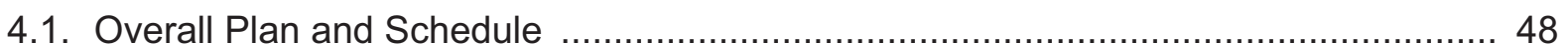

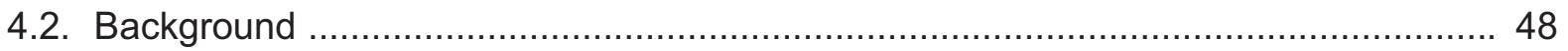

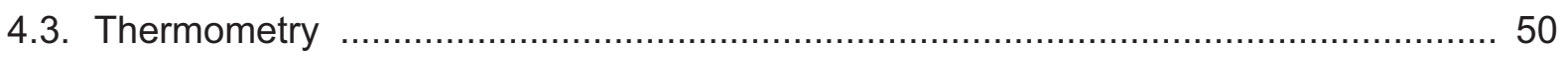

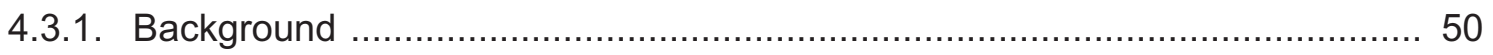

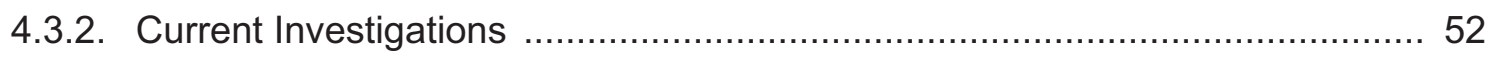

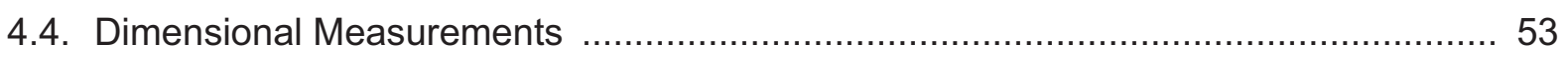

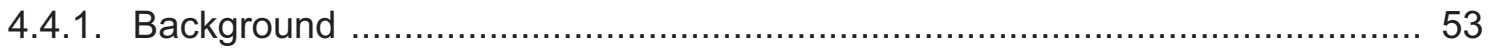

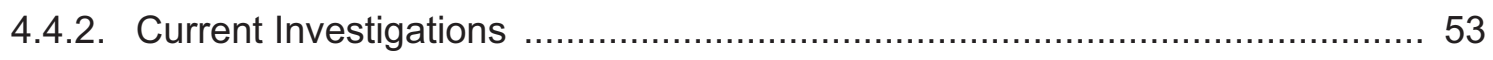

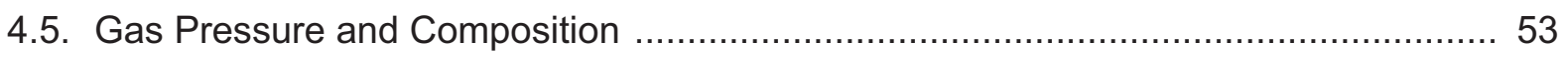

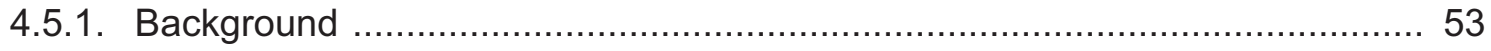

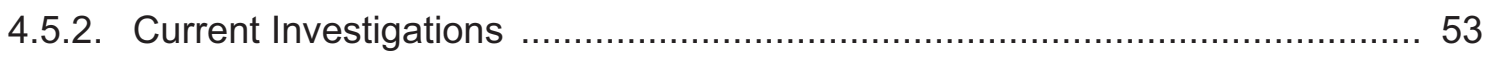

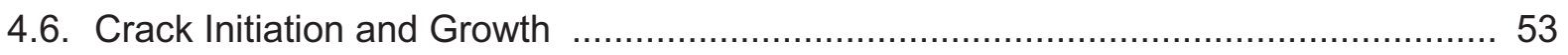

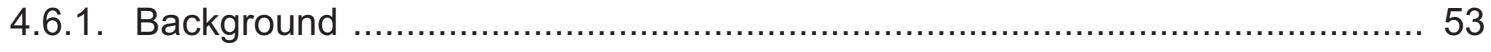

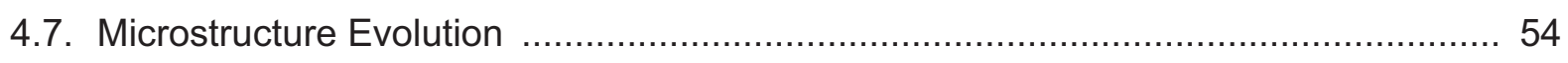

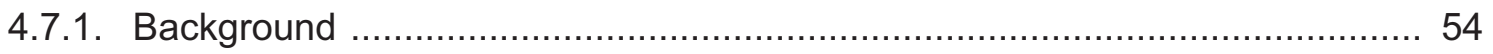

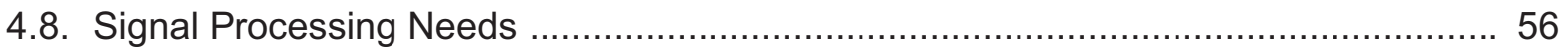

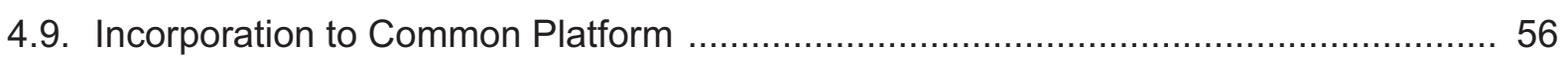

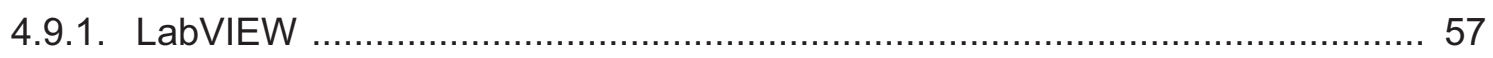

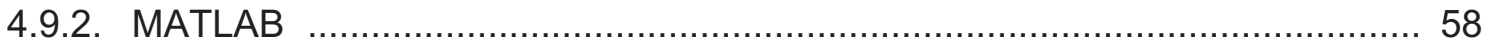

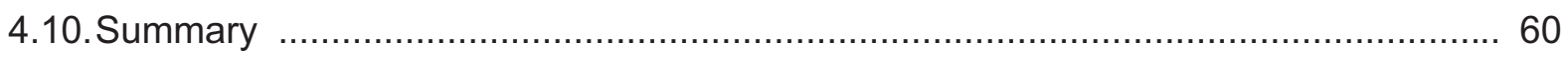

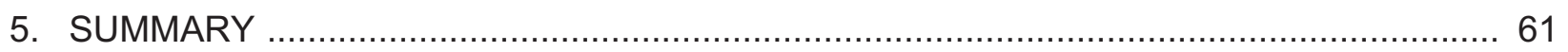

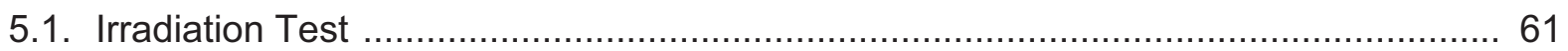

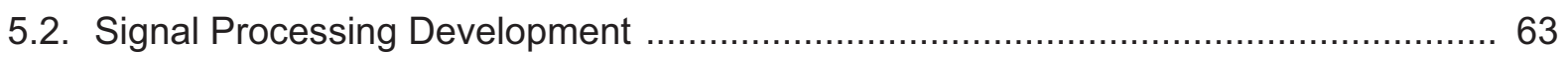

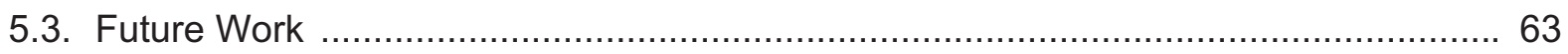




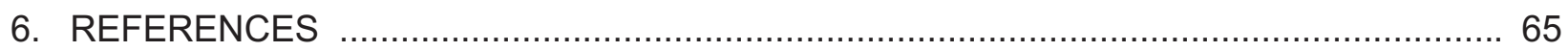

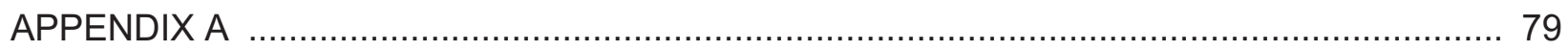

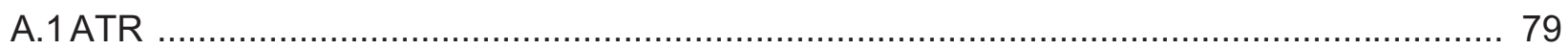

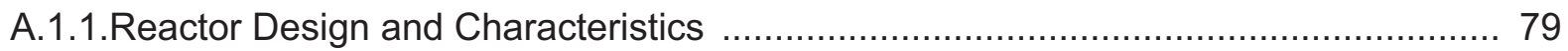

A.1.2.Test Configurations and Conditions ............................................................... 80

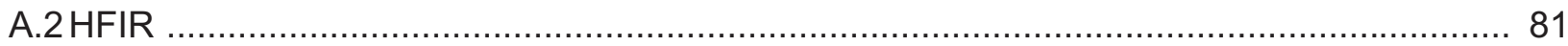

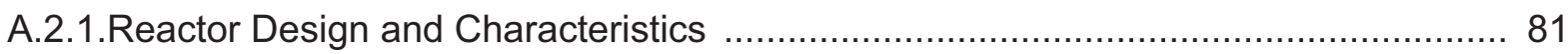

A.2.2.Test Configurations and Conditions …........................................................... 82

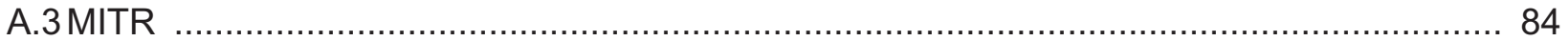


NEET In-Pile Ultrasonic Sensor Enablement-FY 2012 Status Report

September 2012 


\section{FIGURES}

2-1. Schematic of FCRD LWR-2 fuel rodlet and capsule assembly for ATR irradiation. ${ }^{8}$................... 7

2-2. Top view of FCRD LWR-2 test assembly for ATR irradiation. ................................................ 8

2-3. Typical oxide fuel drop-in capsule configuration. ..................................................................... 9

2-4. Typical metallic fuel drop-in capsule configuration. ............................................................. 10

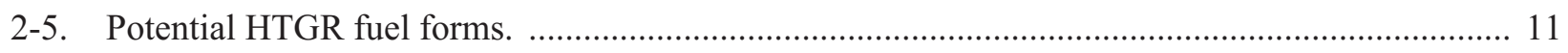

2-6. Typical AGR irradiation test configures (a) gas monitoring system and (b) cross section illustrating fuel compact and sensor placement (each stack contains six capsules). .................... 12

2-7. Examples of constituent redistribution in metallic fast reactor fuels. .......................................... 13

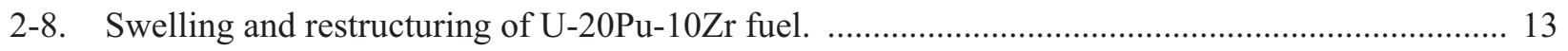

2-9. Fission gas release for fast reactor metallic fuel compositions (U-Uranium, Pu-Plutonium,

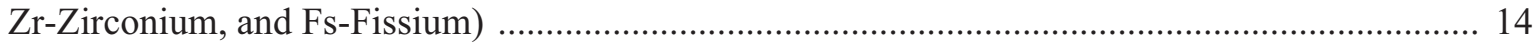

2-10. Examples of catastrophic fuel failure (left) and fuel restructuring (right). ................................ 15

2-11. Schematic of AGC-1 test train and photographs of test train during assembly. .......................... 22

3-1. Conceptual sketch of graphite sample holder. ............................................................................. 29

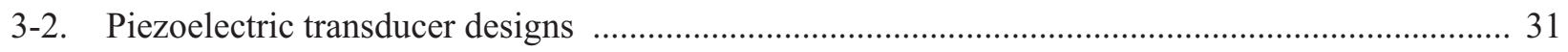

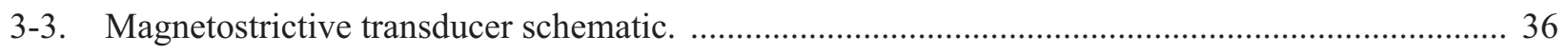

3-4. High-temperature ultrasonic sensor developed at ANL (left) and HEDL (right). ...................... 41

3-5. Schematics of the HEDL single ultrasonic transducer developed for under-sodium viewing applications (left), ${ }^{39}$ the transducer design for irradiation testing of AlN (right). ${ }^{38}$.................... 42

4-1. Generic schematic of signal processing flow in NDE systems. ................................................ 47

4-2. A typical time-of-flight based ultrasonic thermometry system. ….......................................... 51

4-3. Signal processing method used in ultrasonic thermometry testing at INL. ............................... 52

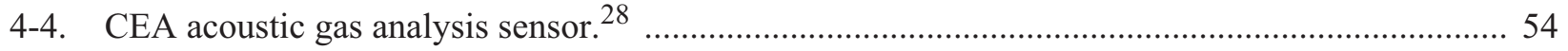

4-5. Examples of two different data types using imagingGUI. ..................................................... 59

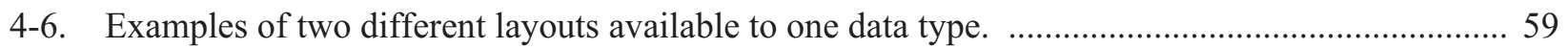

4-7. Examples of different user-generated Filters and Functions available with different data

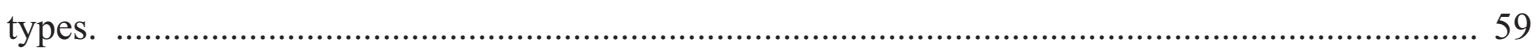

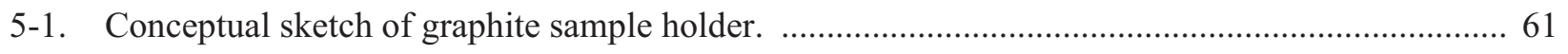

A- ATR core cross section showing irradiation locations............................................... 79

A-2 Schematic diagrams illustrating ATR irradiation locations. ......................................... 80

A-3 Schematic of HFIR reactor core and beryllium reflector. .............................................81

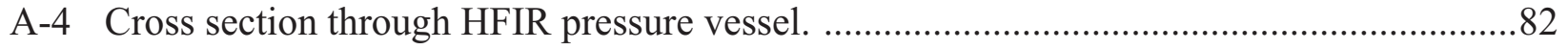

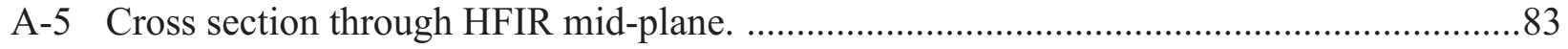

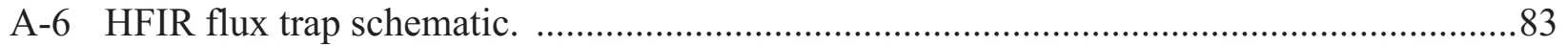

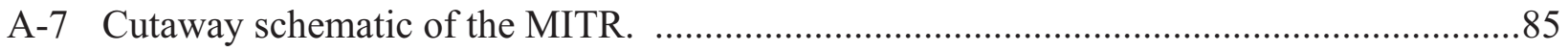


NEET In-Pile Ultrasonic Sensor Enablement-FY 2012 Status Report

September 2012 


\section{TABLES}

2-1. Comparison of design parameters in selected operating test reactors. ${ }^{3}$........................................ 4

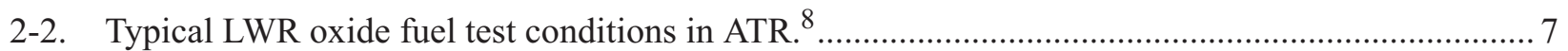

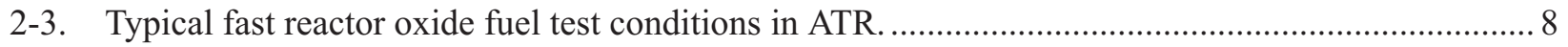

2-4. Typical fast reactor metallic fuel test conditions in ATR. ........................................................... 10

2-5. Summary of desired parameters for detection during fuel irradiation tests. .................................. 16

2-6. Summary of desired parameters for detection during materials irradiation tests.'.......................... 23

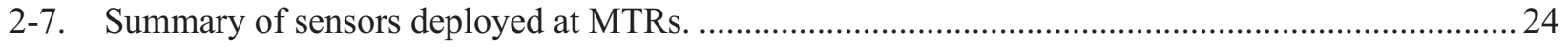

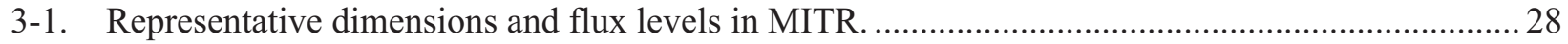

3-2. Characteristics of "hard" and "soft" ceramic materials. ............................................................... 31

3-3. Characteristics of High-Q and Low-Q piezoelectric materials.................................................... 32

3-4. Characteristics of candidate piezoelectric materials. .................................................................... 33

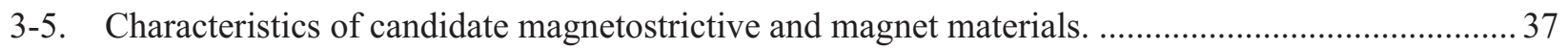

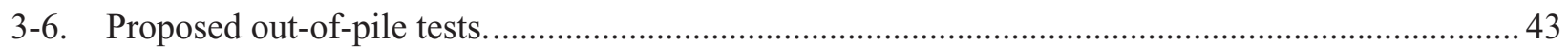

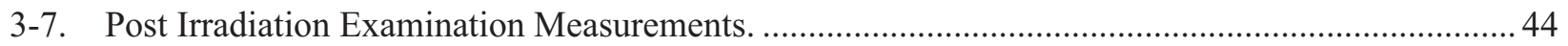

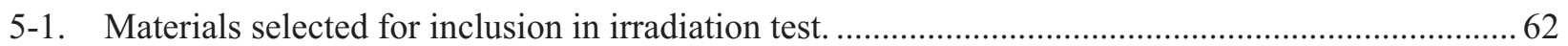

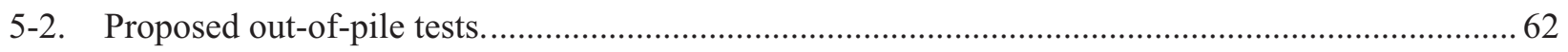

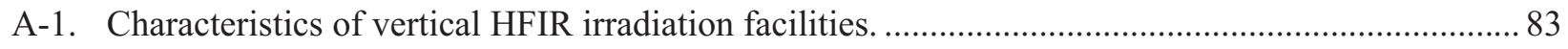


NEET In-Pile Ultrasonic Sensor Enablement-FY 2012 Status Report

September 2012 


\section{ACRONYMS}

ACRR Annular Core Research Reactor

AGC Advanced Graphite Capsule

ANL Argonne National Laboratory

ARC Advanced Reactor Concepts

ASI Advanced Sensors and Instrumentation

ASME American Society of Mechanical Engineers

ATR Advanced Test Reactor

BNC Baynet Neill-Concelman

BWR Boiling Water Reactor

CANDU CANada Deuterium Uranium

CEA Commissariat à l'Énergie Atomique et aux Energies Alternatives

CRBR Clinch River Breeder Reactor

CRUD Cladding Oxide

DCDP Direct Current Potential Drop

DOE Department of Energy

DOE-NE Office of Nuclear Energy in the Department of Energy

ENDF Evaluated Nuclear Data Files

FCCI Fuel-Cladding Chemical Interaction

FCMI Fuel-Cladding Mechanical Interaction

FCRD Fuel Cycle Research and Development

FSV Fort St. Vrain

GCR Gas Cooled Reactor

HAZ Heat Affected Zone

HBWR Halden Boiling Water Reactor

HEDL Hanford Engineering Development Laboratory

HFIR High-Flux Isotope Reactor

HSIS Hydraulic Shuttle Irradiation System

HTIR-TC High Temperature Irradiation Resistant ThermoCouple

HTTL High Temperature Test Laboratory

ID Inner Diameter

IFE/HRP Institute for Energy Technology at the Halden Reactor Project

IHX Intermediate Heat Exchanger

INL Idaho National Laboratory

JAEA Japan Atomic Energy

JHR Jules Horowitz Reactor

KAERI Korea Atomic Energy Research Institute

LHGR Linear Heat Generation Rate

LVDT Linear Variable Differential Transformer

LWR Light Water Reactor 
LWRS Light Water Reactor Sustainability

MFC Materials and Fuels Complex

MIT Massachusetts Institute of Technology

MITR Massachusetts Institute of Technology Nuclear Research Reactor

MOX Mixed OXide

MTR Material Test Reactor

NEET Nuclear Energy Enabling Technologies

NDE Nondestructive Evaluation

NDT Nondestructive Testing

NGNP Next Generation Nuclear Plant

NRC Nuclear Regulatory Commission

NSRR Nuclear Safety Research Reactor

NSUF National Scientific User Facility

ODS Oxide Dispersion Strengthened

OECD Organization for Economic Cooperation and Development

ORNL Oak Ridge National Laboratory

PIE Post-Irradiation Examination

PNNL Pacific Northwest National Laboratory

PWR Pressurized Water Reactor

PZT Lead Zirconium Titanate

RB* Large Removable Beryllium Facility

SAW Surface Acoustic Wave

SEM Scanning Electron Microscope

SFR Sodium Fast Reactor

SNL Sandia National Laboratories

SNR Signal to Noise Ratio

UT Ultrasonic Thermometer

TA-V Technical Area V

TREAT Transient REActor Test

TRISO Tri-structural Isotropic

USV Under Sodium Viewing

VVER Vodo-Vodyanoi Energetichesky Reactor

VXF Vertical Experiment Facility 


\section{INTRODUCTION}

Ultrasonic technologies offer the potential to measure a range of parameters, including geometry changes, temperature, crack initiation and growth, gas pressure and composition, and microstructural changes, under harsh irradiation test conditions. Many Department of Energy-Office of Nuclear Energy (DOE-NE) programs (e.g., Light Water Reactor Sustainability (LWRS), Fuel Cycle Research and Development (FCRD), Advanced Test Reactor National Scientific User Facility (ATR NSUF), Small Modular Reactors (SMRs), Next Generation Nuclear Plant (NGNP), etc.) would benefit from the use of ultrasonic technologies to provide enhanced sensors for in-pile instrumentation during irradiation testing. For example, FCRD efforts are evaluating the ability of single, small diameter ultrasonic thermometers (UTs) to provide a temperature profile in candidate metallic and oxide fuel, an ultrasonic technique to detect morphology changes (such as crack initiation and growth), and acoustic techniques to evaluate fission gas composition and pressure. Ultrasonics techniques are also being explored within the Advanced Reactor Concepts (ARC) initiative.

This project addresses technology deployment issues that are common to various types of ultrasonic measurements. For example, it is recognized that accuracies may be considerably enhanced, and the potential exists for significant reductions in irradiation capsule size, if ultrasonic transducers can be deployed in-pile. It is currently anticipated that some of the applications under investigation require high frequency piezoelectric transducers. Another technology deployment issue common to many ultrasonic measurement techniques is the need for enhanced signal processing software. Research to address each of these needs will be completed in the Ultrasonics Transducer Irradiation and Software Enhancements project.

\subsection{Objective/Motivation}

Several DOE-NE programs, such as the FCRD, ${ }^{1}$ ARC, $, 2,3$ LWRS, ${ }^{4}$ and NGNP ${ }^{5-11}$ programs, are investigating new fuels and materials for advanced and existing reactors. A key objective of such programs is to understand the performance of these fuels and materials when irradiated. The Nuclear Energy Enabling Technology (NEET) Advanced Sensors and Instrumentation (ASI) in-pile instrumentation development activities are focused upon addressing cross-cutting needs for DOE-NE irradiation testing by providing higher fidelity, real-time data, with increased accuracy and resolution from smaller, compact sensors that are less intrusive. ${ }^{12}$ The NEET ASI has funded the Ultrasonics Transducer Irradiation and Software Enhancements project because it will enable the use of ultrasonics-based sensors for irradiation testing.

The objective for Task 1 of this project is to evaluate the performance of ultrasonic transducer materials in high flux/high temperature irradiation environments. Building upon recent results from ultrasonic sensor investigations, an in-depth assessment of prior piezoelectric and magnetostrictive transducer irradiations was used to finalize a list of candidate materials for irradiation evaluation. In addition, a design for an instrumented-lead irradiation test capsule and a test plan for evaluating ultrasonic transducer materials will be developed. This test will include an irradiation evaluation of the most promising candidate piezoelectric and magnetostrictive transducer materials. To maximize the benefit of this irradiation test, appropriate individuals from various DOE-NE programs, such as ARC, LWRS, SMRs, FCRD, NGNP and ATR NSUF efforts, have been contacted. In addition, recent results from piezoelectric irradiation studies in foreign research reactors were also considered. This test will be an instrumented lead test, such that real time signals are received from the transducers. Such a test will enable an accurate measure of the performance and possible degradation of candidate transducer materials under irradiation. This test will also provide fundamental data on piezoelectric and magnetostrictive material performance in irradiation environments, which can be directly compared. Prior tests either tested to few samples, or samples that were too dissimilar, for such a comparison. This additional information may enable further application of ultrasonic technologies in the future.

The objective for Task 2 is to enhance software used to support various types of ultrasonic sensors. Researchers will contact ultrasonics experts and researchers from DOE-NE programs, to define require- 
ments for software to support various ultrasonic sensors. Ultrasonic instrumentation is a well developed technology widely used in non-nuclear applications; however, several improvements are required for successful implementation in irradiation tests. The harsh testing conditions that ultrasonic sensors must survive are likely to reduce signal to noise ratio, complicating identification of signal features. Therefore, a primary goal of Task 2 work will be the development of methods to improve signal to noise ratio. Ultrasonic sensors utilize several different signal characteristics (i.e. delay time, resonant frequency, attenuation, etc.) for monitoring the many parameters previously identified. Enhanced software, specific for in-pile ultrasonics applications, will ultimately be developed in Task 2 that is capable of acquiring and processing signals specific to parameters of interest to DOE-NE programs.

\subsection{Report Content and Organization}

Section 2 describes representative irradiation reactors in which new sensor technologies may be deployed, as well as representative fuel and materials and irradiation test conditions that are of interest to DOE-NE programs. Physical parameters that must be detected during irradiation tests are also listed with desired accuracies. Section 3 summarizes efforts made by this project to support the transducer material irradiation test, including a description of the irradiation test conditions, a discussion of the materials to be included in the test, and a description of the proposed test capsule. Section 4 lists requirements for enhanced signal processing capabilities needed for future development of in-pile ultrasound based sensor systems.

Section 5 summarizes key information in this document, and Section 6 lists references cited in this document. Additional details about three materials and test reactors (MTRs) of special interest to this project are found in Appendix A. 


\section{BACKGROUND}

To ensure that NEET in-pile instrumentation research is relevant, sensor enhancements must be able to survive the irradiation conditions of interest to DOE-NE programs. It is also important that the enhanced sensors be able to measure thermal and structural properties and irradiation test parameters with the desired accuracy and resolution required by these DOE-NE programs. This section summarizes information obtained from the various DOE-NE programs that is being used to guide NEET ultrasonic sensor investigations.

This section describes representative fuel and materials often tested and irradiation test conditions that are currently of interest to DOE-NE programs. Key phenomena of interest in fuel and materials performance evaluations are identified for which additional data are needed. Physical parameters that must be detected during irradiation tests are also listed with desired accuracies (specified by various DOE-NE programs).

\subsection{Typical MTR Conditions for DOE-NE Irradiations}

Most DOE-NE irradiations are performed in the Advanced Test Reactor (ATR) located at the Idaho National Laboratory (INL) and the High Flux Irradiation Reactor (HFIR) located at Oak Ridge National Laboratory (ORNL). Key design parameters and characteristics for each of these facilities are highlighted in this section. Additional details about each these reactors, including descriptions of irradiation locations; may be found in Appendix A.

\subsubsection{ATR}

The ATR is a unique facility for scientific investigation of nuclear fuel and materials. ${ }^{1,13}$ Designed to allow simulation of long neutron radiation exposures in a short time period, the ATR has a maximum power rating of $250 \mathrm{MW}_{\text {th }}$ with a maximum unperturbed thermal neutron flux of $1 \times 10^{15} \mathrm{n} / \mathrm{cm}^{2}-\mathrm{s}$ and a maximum fast neutron flux of $5 \times 10^{14} \mathrm{n} / \mathrm{cm}^{2}$-s. The ATR is cooled by pressurized $(2.5 \mathrm{MPa} / 360 \mathrm{psig})$ water that enters the reactor vessel bottom at an average temperature of $52{ }^{\circ} \mathrm{C}\left(126^{\circ} \mathrm{F}\right)$, flows up outside cylindrical tanks that support and contain the core, passes through concentric thermal shields into the open part of the vessel, then flows down through the core to a flow distribution tank below the core. When the reactor is operating at full power, the primary coolant exits the vessel at $71{ }^{\circ} \mathrm{C}\left(160^{\circ} \mathrm{F}\right)$.

\subsubsection{HFIR}

The HFIR is a beryllium-reflected, pressurized, light-water-cooled and moderated flux-trap-type reactor. The core, which consists of aluminum-clad involute-fuel plates, currently utilizes highly enriched ${ }^{235} \mathrm{U}$ fuel, with a design power level of $100 \mathrm{MW}_{\text {th }}$ with a maximum thermal flux of $2 \times 10^{15}$ and a maximum fast flux of $1 \times 10^{15}$. The HFIR was originally designed (in the 1960s) to primarily support the overall program to produce transuranic isotopes for use in the U.S. heavy-element research program. Today, the reactor is a highly versatile machine, producing medical and transuranic isotopes and performing materials test experimental irradiations and neutron-scattering experiments, including the capability to conduct cold-source low-temperature neutron experiments.

\subsubsection{Other MTRs}

Table 2-1 compares operating parameters for selected test and prototype reactors used (or under construction) throughout the world. Information in this table was primarily obtained from the IAEA Nuclear Research Reactor Database, ${ }^{14}$ which contains information from nearly 280 research reactors (operating, shutdown, and proposed). Although these reactors range in power levels from 0 to several hundred $\mathrm{MW}_{\text {th }}$, nearly 200 of them have power levels below $5 \mathrm{MW}_{\mathrm{th}}$. Most of the reactors listed in Table 2-1 achieved criticality in the 1960s (or earlier) although the Hanaro reactor in South Korea, which went critical in 1995, is an exception. 
Table 2-1. Comparison of design parameters in selected operating test reactors. ${ }^{14}$

\begin{tabular}{|c|c|c|c|c|c|c|c|c|c|c|}
\hline Parameter & $\begin{array}{l}\text { ATR } \\
\text { (USA) }\end{array}$ & $\begin{array}{l}\text { HFIR } \\
\text { (USA) }\end{array}$ & $\begin{array}{l}\text { MIT } \\
\text { (USA) }\end{array}$ & $\begin{array}{c}\text { HBWR } \\
\text { (Norway) }\end{array}$ & $\begin{array}{c}\text { HFR } \\
\text { (Netherlands) }\end{array}$ & $\begin{array}{l}\text { OSIRIS }^{\text {O }} \\
\text { (France) }\end{array}$ & $\begin{array}{c}\text { JHR } \\
\text { (France) }\end{array}$ & $\begin{array}{c}\text { BR2 } \\
\text { (Belgium) }\end{array}$ & $\begin{array}{c}\text { Hanaro } \\
\text { (South Korea) }\end{array}$ & $\begin{array}{c}\text { JMTR } \\
\text { (Japan) }\end{array}$ \\
\hline First Criticality & 1967 & 1965 & 1958 & 1959 & 1961 & 1966 & 2016 & 1961 & 1995 & 1968 \\
\hline $\begin{array}{c}\text { Maximum } \\
\text { thermal power, } \\
\mathrm{MW}_{\text {th }}\end{array}$ & 250 & 100 & 5 & 20 & $60^{b}$ & 70 & 100 & 100 & 30 & 50 \\
\hline $\begin{array}{l}\text { Max. thermal } \\
\text { neutron flux, } \\
\mathrm{n} / \mathrm{cm}^{2}-\mathrm{sec}\end{array}$ & $1 \times 10^{15}$ & $2 \times 10^{15}$ & $7 \times 10^{13}$ & $1 \times 10^{14}$ & $3 \times 10^{14}$ & $3 \times 10^{14}$ & $5 \times 10^{14}$ & $1 \times 10^{15}$ & $5 \times 10^{14}$ & $4 \times 10^{14}$ \\
\hline $\begin{array}{l}\text { Max. fast flux, } \mathrm{n} / \\
\mathrm{cm}^{2}-\mathrm{sec}^{\mathrm{c}}\end{array}$ & $5 \times 10^{14}$ & $1 \times 10^{15}$ & $2 \times 10^{14}$ & $1 \times 10^{14}$ & $5 \times 10^{14}$ & $3 \times 10^{14}$ & $1 \times 10^{15}$ & $7 \times 10^{14}$ & $3 \times 10^{14}$ & $4 \times 10^{14}$ \\
\hline Fuel Material & UAl & UAI & UAl & $\mathrm{UO}_{2}$ & U-Al Alloy & $\mathrm{U}_{3} \mathrm{Si}_{2} \mathrm{Al}$ & $U_{M o^{d}}$ & UAI & $\mathrm{U}_{3} \mathrm{Si}-\mathrm{Al}$ & $\mathrm{USi}_{2} \mathrm{Alx}$ \\
\hline $\begin{array}{l}\text { Fuel rod/plate } \\
\text { length, } \mathrm{m}\end{array}$ & 1.22 & 0.61 & 2.0 & 0.800 & 0.625 & 0.950 & 0.600 & 0.914 & 0.700 & 1.27 \\
\hline Primary coolant & $\mathrm{H}_{2} \mathrm{O}$ & $\mathrm{H}_{2} \mathrm{O}$ & $\mathrm{H}_{2} \mathrm{O}$ & $\mathrm{D}_{2} \mathrm{O}$ & $\mathrm{H}_{2} \mathrm{O}$ & $\mathrm{H}_{2} \mathrm{O}$ & $\mathrm{H}_{2} \mathrm{O}$ & $\mathrm{H}_{2} \mathrm{O}$ & $\mathrm{H}_{2} \mathrm{O}$ & $\mathrm{H}_{2} \mathrm{O}$ \\
\hline Test conditions $^{\mathrm{e}}$ & $\begin{array}{l}\text { PWR, } \\
\text { HTGR }\end{array}$ & $\begin{array}{l}\text { PWR, } \\
\text { HTGR }\end{array}$ & $\begin{array}{l}\text { PWR, } \\
\text { BWR, } \\
\text { HTGR }\end{array}$ & $\begin{array}{c}\text { PWR, BWR, } \\
\text { PHWR, VVER, } \\
\text { HTGR }\end{array}$ & $\begin{array}{c}\text { PWR, BWR, } \\
\text { HTGR }\end{array}$ & PWR & $\begin{array}{l}\text { PWR, } \\
\text { HTGR }\end{array}$ & PWR & PWR, PHWR & BWR, \\
\hline
\end{tabular}

a. Scheduled for shutdown in 2015. France currently plans to build a new $100 \mathrm{MW}_{\text {th }}$ materials test reactor, the Jules Horowitz Reactor (JHR). b. Uprate possible in 1984 after new reactor vessel installed.

c. $\mathrm{E}>0.1 \mathrm{MeV}$.

d. The reactor will be started with $\mathrm{U}_{3} \mathrm{Si}_{2}$ fuel, and transitions when it becomes available.

e. PWR- Pressurized Water Reactor; HTGR - High Temperature Gas Cooled Reactor; BWR-Boiling Water Reactor; PHWR - Pressurized Heavy Water Reactor; and VVER - Vodo-Vodyanoi Energetichesky Reactor (Pressurized Water Reactor)

The Jules Horowitz Reactor (JHR), ${ }^{15,16,17}$ which is scheduled to go critical in 2016, is another exception with respect to initial date for achieving criticality. The JHR is being built to replace materials irradiation capabilities of older reactors in Europe as they are retired from service. This $100 \mathrm{MW}_{\text {th }}$ reactor is designed to include static capsules, instrumented capsules, and in-pile loops. To support irradiation programs anticipated for the JHR, CEA is developing four standard types of test trains for experiments in loops at nominal and off-normal Light Water Reactor (LWR) conditions, of capsules at LWR accident conditions, and sodium potassium loops simulating Sodium Fast Reactor (SFR) conditions (with high dpa and low thermal gradients).

It is also worth highlighting the Halden Boiling Water Reactor (HBWR). ${ }^{17}$ Although this reactor is older and its maximum power level $\left(20 \mathrm{MW}_{\text {th }}\right)$ is over an order of magnitude smaller than the ATR, its testing flexibility and the expertise of its staff for instrumenting its tests make this facility unique. For decades, organizations within the international community (including the US Nuclear Regulatory Commission, vendors such as General Electric and AREVA, and the US naval reactor program) have utilized this facility for in-pile irradiation needs. Approximately 40\% of HBWR testing is devoted to Organization for Economic Cooperation and Development (OECD) programs with the remainder sponsored by bilateral agreements between Norway and customers from other countries. ${ }^{17}$ Most of these bilateral agreements allow the HBWR to perform tests for utility customers to address issues related to fuel thermal performance, fuel pellet/clad interactions, fuel fission gas release, reactor vessel embrittlement, structural materials degradation (e.g., corrosion, creep, etc.). As noted in Table 2-1, this reactor has developed loops for simulating BWR, PWR, CANDU, and VVER conditions.

In reviewing Table 2-1, it is clear that the ATR and HFIR offer higher flux levels than most other MTRs. Although the high flux levels present in these MTRs are advantageous for accumulation of high fluence, there are questions related the applicability of their energy spectra for assessing sample performance in fast reactors and the effect of localized heating associated with the higher gamma fields present in such MTRs. The effects of some of these differences can be quantified using enhanced in-pile instrumentation to obtain precise measurements of the flux as a function of energy level and of temperature increases associated with gamma heating. Several DOE-NE efforts, such as the ATR NSUF and the FCRD programs, are 
sponsoring sensor development efforts to make ATR and HFIR more competitive by adding additional in-pile measurement capabilities required for US research programs. This NEET ultrasonics cross-cutting effort, if successful, may offer US MTRs additional in-pile instrumentation capabilities by enabling ultrasonics sensors that offer unprecedented measurement accuracy and resolution.

\subsubsection{Transient Test Reactors}

Transient testing of nuclear fuels has typically been conducted at various stages of the fuel development cycle, depending upon the particular issues that require experimental data for resolution. Fundamental fuel transient behavior characteristics, if determined early, can help guide fuel design considerations. These data are important to provide technical justification to a licensing authority that the transient behavior of the newly designed nuclear fuel system is sufficiently understood and predicted by integral, accident analysis codes.

In the US, there are two transient test reactors: the TREAT (Transient REActor Test) facility, which is located at the Materials and Fuels Complex (MFC) of the INL and the ACRR (Annular Core Research Reactor), which is located at Technical Area V (TA-V) at the Sandia National Laboratory (SNL). In addition, transient test reactors, such as CABRI in Cadarache, France and the Nuclear Safety Research Reactor (NSRR) in Japan, are options for transient testing of fuel and cladding materials. As documented in References 1 and 18, the designs of these facilities differ with respect to the size of fuel that they can accommodate and the speed and magnitude of transients that can be conducted.

Currently, DOE-NE programs are not performing transient testing. However, if such tests are performed, ultrasonics sensors can offer some unique capabilities with respect to measurements at high temperatures, high flux, and fast response time. In subsequent years, as DOE-NE programs for developing fuels and materials begin to consider transient testing, on-going ultrasonics sensor development efforts will expand to accommodate transient reactor test conditions.

\subsubsection{Summary}

As described in this section, there are several irradiation options available to support DOE-NE programs. Currently, most DOE-NE irradiations are performed in the ATR and HFIR. As noted above, there are questions related to the applicability of their energy spectra to assess sample performance in fast reactors and the effect of localized heating associated with the higher gamma fields present in such MTRs. The effects of some of these differences can be quantified using enhanced in-pile instrumentation to obtain precise measurements of the flux as a function of energy level and of temperature increases associated with gamma heating. Several DOE-NE efforts, such as the ATR NSUF and the FCRD programs, are sponsoring sensor development efforts to make ATR and HFIR more competitive by adding additional in-pile measurement capabilities required for US research programs. This NEET ultrasonics cross-cutting effort, if successful, may offer US MTRs additional in-pile instrumentation capabilities by enabling ultrasonics sensors that offer unprecedented measurement accuracy and resolution at high temperatures.

\subsection{Fuels and Material Irradiations}

Several DOE-NE programs, such as the FCRD $,{ }^{1} \mathrm{ARC},{ }^{2,3 \mathrm{a}} \mathrm{LWRS},{ }^{4}$ and $\mathrm{NGNP}{ }^{5-8}$ programs, are investigating new fuels and materials for advanced and existing reactors. A key objective of such programs is to understand the performance of these fuels and materials when irradiated. The NEET ASI in-pile instrumentation development activities are focused upon addressing cross-cutting needs for DOE-NE irradiation testing by providing smaller, compact sensors that can provide higher fidelity, real-time data, with

a. The ARC program is limiting current research to evaluating advanced structural materials and relies on other DOE-NE programs for fuel development. 
increased accuracy and resolution. ${ }^{9}$ The NEET ASI has funded the Ultrasonics Transducer Irradiation and Software Enhancements project because it will enable the use of ultrasonics-based sensors for irradiation testing. To ensure that NEET in-pile instrumentation research is relevant, enhanced sensors must be able to survive the irradiation conditions of interest to DOE-NE programs. It is also important that the enhanced sensors be able to measure thermal and structural properties and irradiation test parameters with the desired accuracy and resolution required by these DOE-NE programs. This section summarizes information obtained from the various DOE-NE programs that is being used to guide our NEET ultrasonic sensor investigations.

\subsubsection{Fuels}

DOE-NE efforts to develop and evaluate the performance of new fuels and cladding materials are conducted in the FCRD, LWRS, and NGNP programs. As will be discussed in this section, fuel rods may be fabricated from ceramic or metallic materials. Particle fuel consists of ceramic materials encased in carbide coatings. This section describe typical irradiation conditions and test configurations that are used by these DOE-NE programs.

\subsubsection{Ceramic Fuel for LWR and SFR Operation}

Ceramic fuels (including oxide, nitride, and carbide, for example) are of interest for both thermal and fast reactor applications.

\section{LWR Fuels Investigated}

Oxide fuels, which are employed in the U.S. commercial LWR industry, typically contain $\mathrm{UO}_{2}$ with enrichments up to $5 \%$. Some reactors have used mixed oxide fuel, containing $\mathrm{UO}_{2}$ and $\mathrm{PuO}_{2}$; and several DOE-NE programs are investigating advanced oxide fuel compositions (containing $\mathrm{UO}_{2}, \mathrm{PuO}_{2}$, and $\mathrm{ThO}_{2}$ ), and cladding materials. For example, the LWRS Advanced LWR Nuclear Fuel Development Pathway is focused on demonstrating the viability of silicon carbide ceramic matrix composite (SiC CMC) fuel cladding as an option to improve fuel performance. Initial tests on a prototype of an all-ceramic system are being performed at HFIR. These tests use unfueled samples (prototype rodlets made with SiC-based cladding) in static capsules and demonstrate basic $\mathrm{SiC}$ performance. The rodlets use a thin zirconium liner bonded with a ceramic matrix composite $\mathrm{SiC}$ outer tube with end caps welded to the zirconium liner. Further tests are being planned for the ATR. These tests will include fuel to evaluate the SiC fuel cladding response to steady-state and operationally transient conditions. Tests will also be completed to evaluate severe transient and accident performance and to benchmark computational nuclear fuel models.

\section{Typical LWR Irradiation Test Design}

Typical operating conditions for oxide fuels in LWRs, which are representative of ATR test conditions for LWR tests for the FCRD program and expected to be typical of conditions that will be specified for LWRS 
fuels tests, are listed in Table 2-2. An example FCRD irradiation capsule configuration used previously in ATR to irradiate LWR MOX fuel is shown in Figures 2-1 and 2-2.

Table 2-2. Typical LWR oxide fuel test conditions in ATR. ${ }^{1}$

\begin{tabular}{|l|c|}
\hline \multicolumn{1}{|c|}{ Parameter } & Typical Value \\
\hline Linear Heat Generation Rate (LHGR) & $200-330 \mathrm{~W} / \mathrm{cm}$ \\
Fuel Centerline Peak Temperature & $1400{ }^{\circ} \mathrm{C}$ \\
Capsule Assembly Peak Pressure & $5.5 \mathrm{MPa}$ \\
Flux (thermal) & $10^{14} \mathrm{n}_{\mathrm{th}} / \mathrm{cm}^{2}-\mathrm{s}$ \\
\hline
\end{tabular}

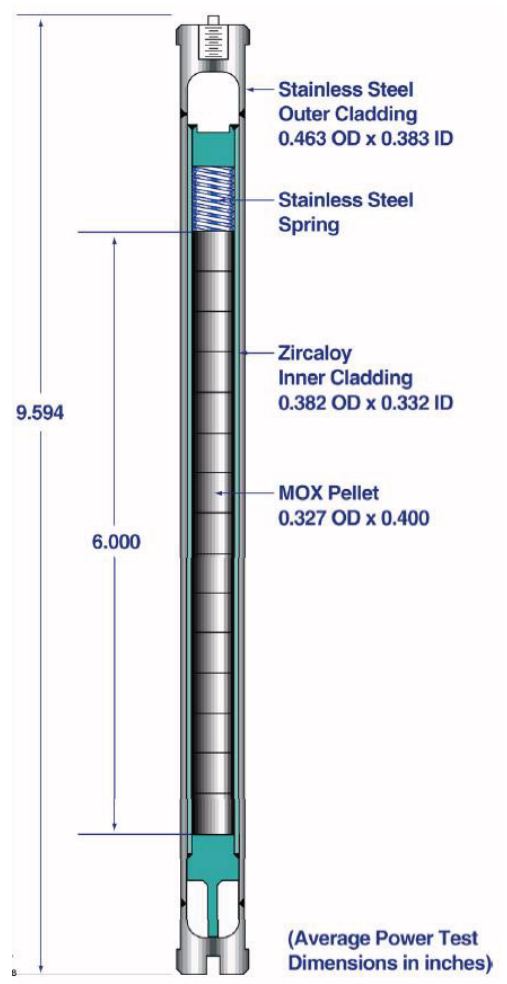

Figure 2-1.Schematic of FCRD LWR-2 fuel rodlet and capsule assembly for ATR irradiation. ${ }^{1}$

\section{SFR Fuels Investigated}

Ceramic fuels for fast reactor applications are also under consideration within the ARC and FCRD programs. In the FCRD program, such fuels are of interest because they could be used to transmute transuranic elements from used nuclear fuel from LWRs. Hence fuel compositions under investigation contain $\mathrm{UO}_{2}$ and $\mathrm{PuO}_{2}$ with small amounts of actinides, such as $\mathrm{Np}$ and Am. Nitride fuels containing uranium, plutonium, and zirconium nitride with small amounts of actinides are also under investigation. The ARC program has not yet finalized fuels designs for irradiation testing. However, FCRD irradiations use ceramic fuel dimensions based on those used in the Experimental Breeder Reactor II (EBR-II) program. The current reference fast reactor ceramic fuel cladding is HT-9 with 5.84- $\mathrm{mm}$ outer diameter (OD) and $4.93 \mathrm{~mm}$ inner diameter (ID). The FCRD program is also investigating new cladding materials [e.g., improved alloys, Oxide Dispersion Strengthened (ODS), etc.] and cladding coatings or liners to prevent interaction between fuel and cladding materials. 


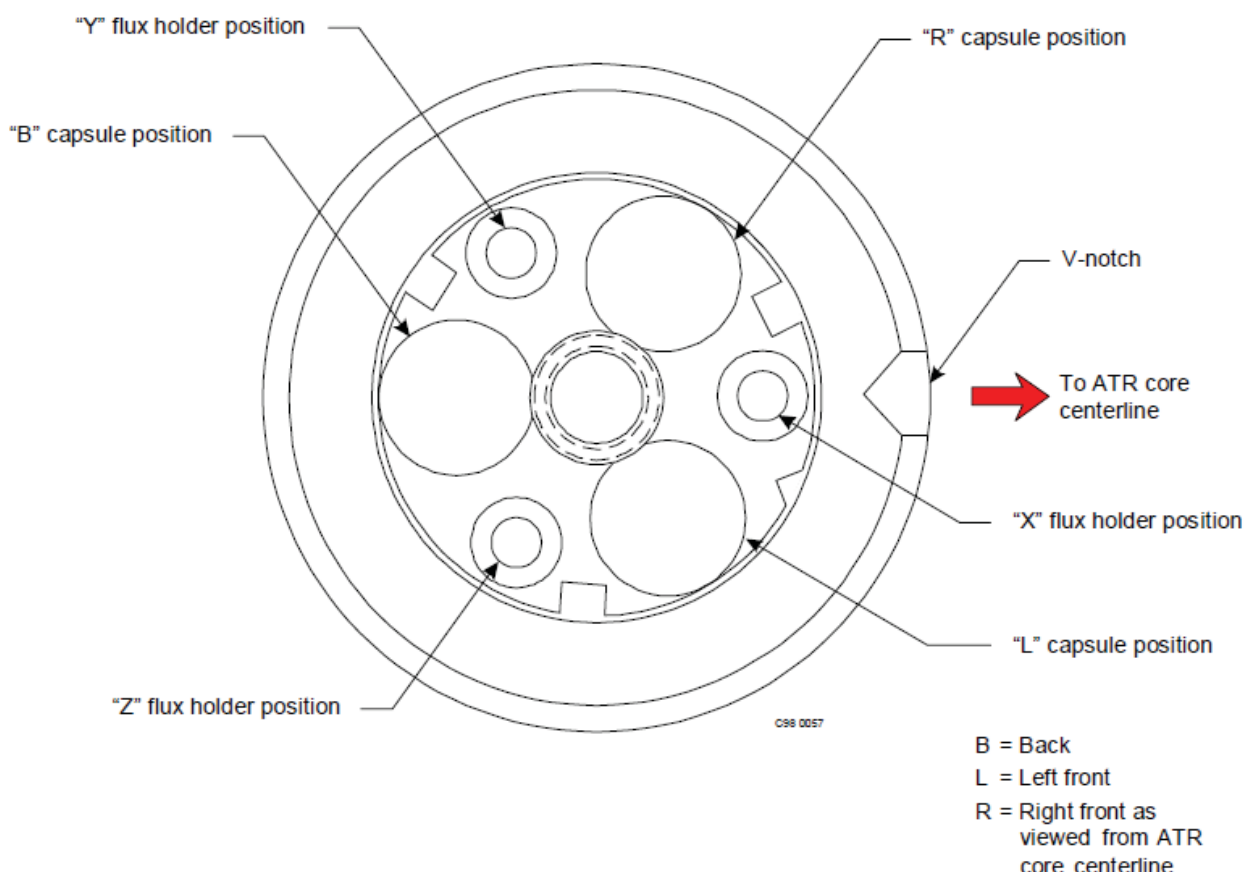

Figure 2-2.Top view of FCRD LWR-2 test assembly for ATR irradiation.

\section{Typical SFR Irradiation Test Design}

The FCRD program is currently conducting irradiation experiments in the ATR and the HFIR (and designing additional tests for future irradiations). Fuel test parameters are based on those used in previous fast reactors. The basic ATR drop-in capsule design with oxide fuel is shown in Figure 2-3. Typical fast reactor oxide fuel ATR test conditions are listed in Table 2-3.

Table 2-3. Typical fast reactor oxide fuel test conditions in ATR.

\begin{tabular}{|l|c|}
\hline \multicolumn{1}{|c|}{ Parameter } & Typical Value \\
\hline Linear Heat Generation Rate (LHGR) & $350 \mathrm{~W} / \mathrm{cm}$ \\
Peak Cladding Inner Temperature & $550-650{ }^{\circ} \mathrm{C}$ \\
Fuel Centerline Temperature & $2600{ }^{\circ} \mathrm{C}$ \\
Fuel Pin Plenum Pressure & $8.6 \mathrm{MPa}$ \\
Fast Flux & $\sim 10^{14} \mathrm{n}_{\text {fast }} / \mathrm{cm}^{2}$-s \\
\hline
\end{tabular}

The oxide fuel column is typically $4.85 \mathrm{~mm}$ OD and $38.1 \mathrm{~mm}$ long and may consist of multiple pellets. Additional insulator pellets (e.g., $\mathrm{dUO}_{2}$ or $\mathrm{HfO}_{2}$ ) may be placed above and below the fuel column. The fuel pellets are designed to have a sufficient length-to-diameter ratio to prevent tumbling during fuel loading into the rodlet. The fuel column is held down by a spring to prevent fuel pellet movement during shipping and handling. During fabrication, the miniature fuel rodlet is sealed in a helium environment at a pressure slightly less than atmospheric. For ATR irradiations, the sealed fuel rodlet is encapsulated in an outer capsule (316 SS, $8.99 \mathrm{~mm}$ OD, $5.94 \mathrm{~mm} \mathrm{ID)} \mathrm{with} \mathrm{a} \mathrm{helium} \mathrm{backfill} \mathrm{at} \mathrm{a} \mathrm{pressure} \mathrm{slightly} \mathrm{less} \mathrm{than}$ atmospheric. The gas gap between the rodlet OD and the capsule ID provides enough thermal resistance to achieve desired fuel cladding temperatures (hence, desired fuel temperatures). A typical drop-in capsule experiment can include up to 5 capsules (each with one rodlet) stacked vertically in an ATR irradiation 


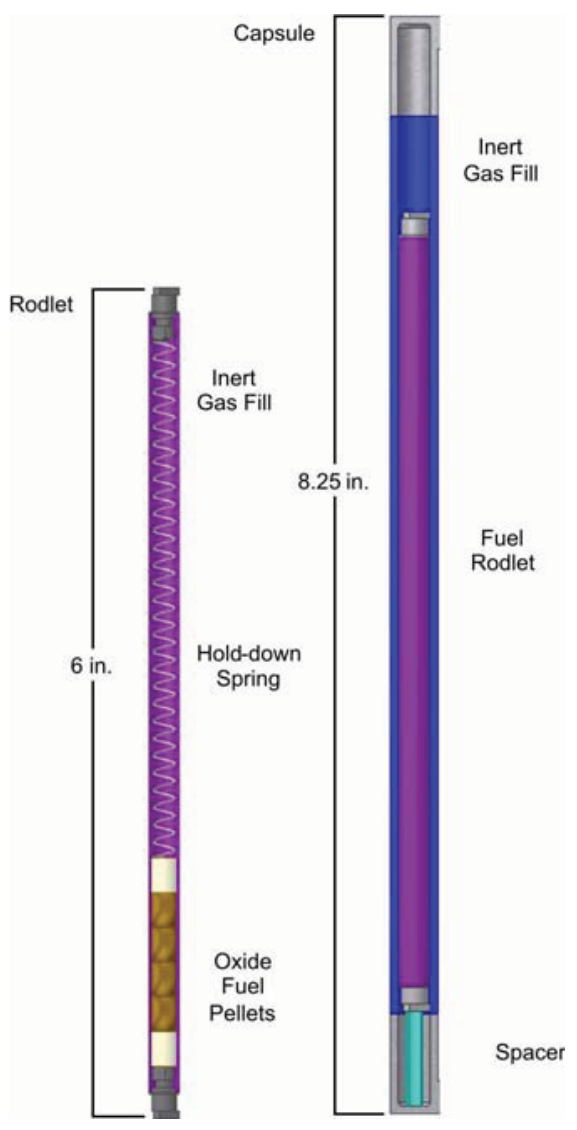

Figure 2-3.Typical oxide fuel drop-in capsule configuration.

position (Outboard A positions in Figure A-1 of the Appendix). The current vision for an instrumented lead experiment involves the same basic fuel rodlet and capsule design with the same radial dimensions.

\subsubsection{Metal Fuel for SFR Operation}

Metallic fuels, which are of primary interest for use in fast reactors, are being studied by the ARC and FCRD programs.

\section{SFR Fuels Investigated}

The FCRD fast reactor metallic fuel dimensions and compositions are based on those used in the EBR-II program, with evolutions that accommodate transuranic species, the potential carryover of lanthanide species during reprocessing, and improved fuel form stability.

Fast reactor metallic fuel primarily consists of uranium, plutonium, and zirconium. However, the FCRD program has included small (e.g., less than 10\%) amounts of actinide materials, such as americium, neptunium, lanthanum, cerium, praseodymium, and neodymium, The current reference fast reactor metallic fuel cladding is HT-9 with $5.84 \mathrm{~mm}$ OD and $4.93 \mathrm{~mm}$ ID. Investigations into new claddings include advanced cladding materials (e.g., improved alloys, ODS) and cladding coatings or liners to prevent interaction between fuel and cladding materials. 


\section{Typical Irradiation Test Design}

The FCRD program is currently conducting (and/or planning) irradiation experiments in ATR and HFIR. The basic ATR drop-in capsule design is shown in Figure 2-4.Typical ATR test conditions for fast reactor metallic fuels are listed in Table 2-4.

Table 2-4. Typical fast reactor metallic fuel test conditions in ATR.

\begin{tabular}{|l|c|}
\hline \multicolumn{1}{|c|}{ Parameter } & Typical Value \\
\hline Linear Heat Generation Rate (LHGR) & $350 \mathrm{~W} / \mathrm{cm}$ \\
Peak Cladding Inner Temperature & $550-650{ }^{\circ} \mathrm{C}$ \\
Fuel Centerline Temperature & $900-1100{ }^{\circ} \mathrm{C}$ \\
Fuel Pin Plenum Pressure & $8.6 \mathrm{MPa}$ \\
Fast Flux $(>1 \mathrm{MeV})$ & $\sim 3-5 \times 10^{14} \mathrm{n}_{\mathrm{fast}} / \mathrm{cm}^{2}-\mathrm{s}$ \\
\hline
\end{tabular}

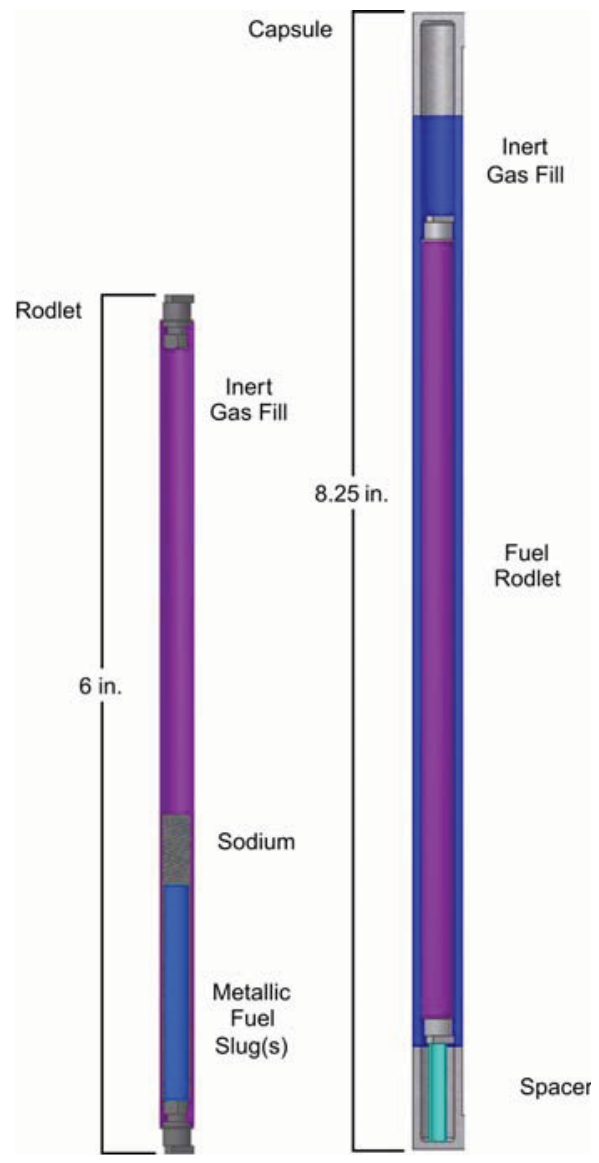

Figure 2-4.Typical metallic fuel drop-in capsule configuration.

The metallic fuel column is typically $4.27 \mathrm{~mm}$ OD and $38.1 \mathrm{~mm}$ long and may consist of multiple pieces. The fuel column is surrounded by molten sodium which forms a bond between the fuel OD and the cladding ID, ensuring good thermal conductivity (and low fuel centerline temperatures). Initially, approximately 0.25 to 0.75 of molten sodium covers the top of the fuel. As the fuel swells and expands during irradiation, the molten sodium expands in these gaps, increasing the overall height of the sodium in the 
capsule. During fabrication, the miniature fuel rodlet is sealed in a helium environment at a pressure slightly less than atmospheric. For ATR irradiations, the sealed fuel rodlet is encapsulated in an outer capsule (316 SS, $8.99 \mathrm{~mm}$ OD, $5.94 \mathrm{~mm}$ ID) with a helium backfill at a pressure slightly less than atmospheric. The gas gap between the rodlet OD and the capsule ID provides enough thermal resistance to achieve desired fuel cladding temperatures (hence, desired fuel temperatures). A typical drop-in capsule experiment can include up to 5 capsules (each with one rodlet) stacked vertically in an ATR irradiation position (the Outboard A positions shown in Figure A-1 of the Appendix). The current vision for an instrumented lead experiment involves the same basic fuel rodlet and capsule design with the same radial dimensions.

\subsubsection{Particle Fuel for HTGR Operation}

Fuel and material irradiation activities within the NGNP program are designed provide data on fuel performance under irradiation to support fuel process development, support qualification of a fuel design and fabrication process for normal operating conditions, and support development and validation of fuel performance and fission product transport models and codes.

\section{Description}

Some vendors within the NGNP program have expressed preferences for the prismatic reactor design, while others have supported the pebble bed design. Hence, the NGNP fuel program focuses on qualifying the tri-isotropic (TRISO)-coated particle fuel that is formed by surrounding the uranium kernel (the active part of the particle) with layers of carbon (C) and silicon carbide (SiC). The fuel material within the particles differs in each design, with the particles containing uranium dioxide for pebble fuel and uranium oxycarbide for prismatic fuel. As shown in Figure 2-5, the fuel particles in a pebble bed reactor are distributed in a spherical graphite matrix - the so-called "pebble" that circulates through the core of the reactor continuously. In the prismatic reactor, the particles are distributed in cylindrical rods or "compacts" that are stacked in cylindrical holes within prismatic graphite blocks.

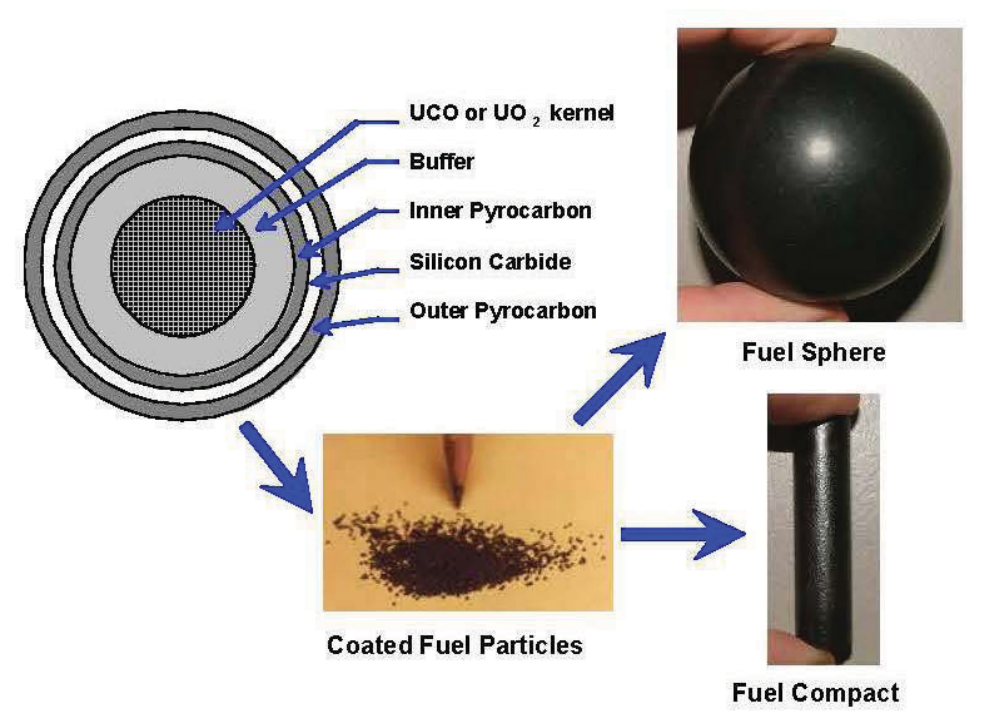

Figure 2-5.Potential HTGR fuel forms. 


\section{Typical Irradiation Test Design}

As documented in References 5 through 7, eight irradiations are planned within the NGNP fuel development and qualification program to demonstrate that manufacturing of the fuel particles leads to a repeatable process that yields coatings that retain fission products. In addition, irradiations and post-irradiation safety tests are performed to quantify fuel performance for normal operating and accident conditions, providing insights about fission product transport and source terms from gas reactor fuel particles. As illustrated from schematics of the AGR-1 and AGR-2 tests, typical irradiations focus on obtaining data that can be used to validate fuel performance as a function of temperature and burnup. A specialized irradiation test capsule has been developed for these irradiation tests that allow measurements of flux, temperature, gas release, and coolant chemistry. This specialized test capsule represents an advancement with respect to gas reactor irradiation, especially in tests where there is the potential for fission product transport and fuel failures may occur at elevated temperatures.

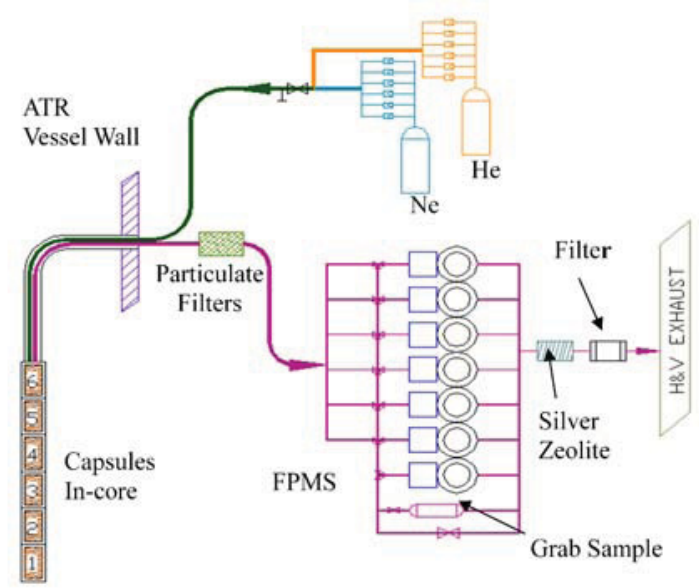

(a)

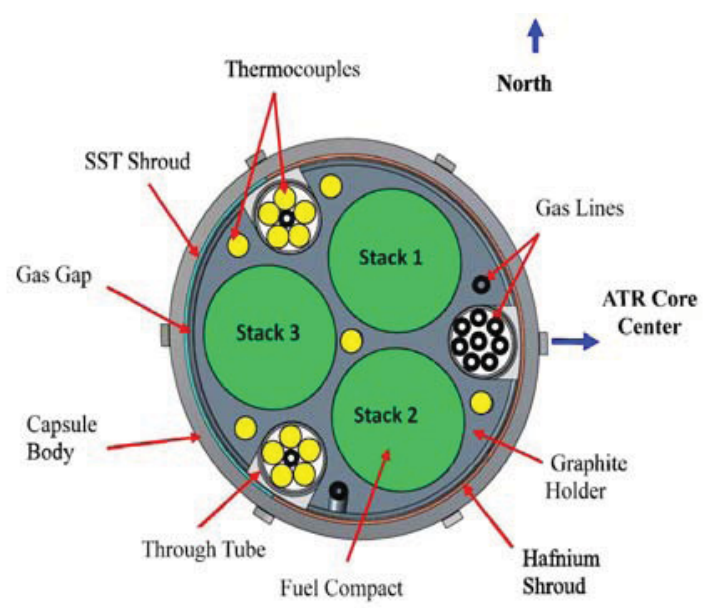

(b)

Figure 2-6.Typical AGR irradiation test configures (a) gas monitoring system and (b) cross section illustrating fuel compact and sensor placement (each stack contains six capsules).

\subsubsection{Phenomena of Interest}

\section{LWR and SFR}

Irradiation experiments for LWR and SFR fuels are designed to determine behavior within the fuel and between fuel and cladding materials. During irradiation, the fuel and cladding are subjected to temperature and flux gradients, and fission products and transmutation products are generated from interactions with neutrons.

Microstructural changes may occur due to temperature gradients, as some fuel constituents may migrate in the presence of a temperature gradient. Microstructural changes also occur as the fuel composition changes and the fuel matrix accommodates fission products (solid and gaseous) and changing stoichiometry (especially in ceramic fuels).

Constituent redistribution is an important process because changes in concentration within the fuel pin can lead to changes in phase and to low-melting temperature eutectic formation. Examples of constituent redis- 
tribution in metallic fast reactor fuels, along with their corresponding element maps, are shown in Figure 2-7.

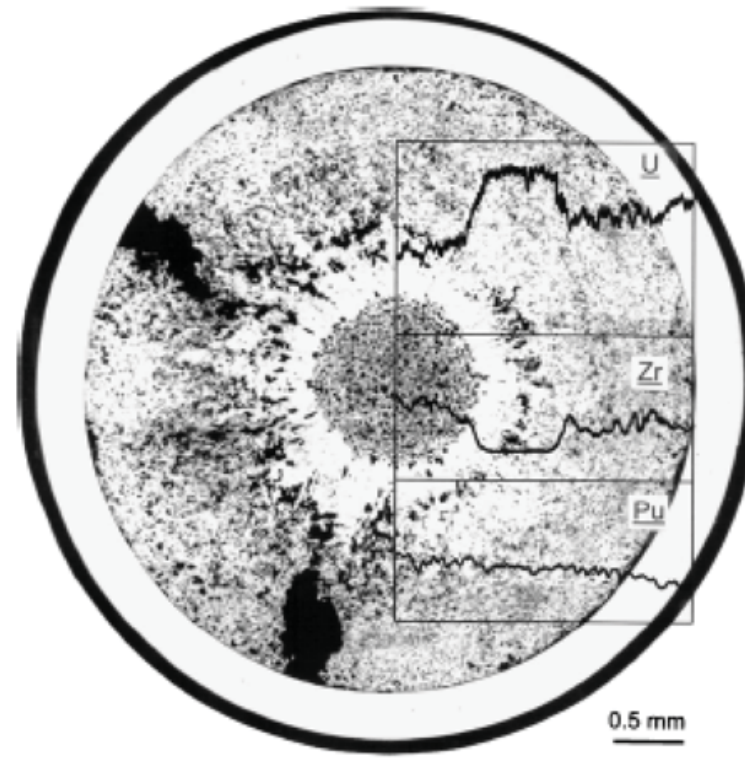

$\mathrm{U}-\mathrm{Pu}-\mathrm{Zr}$

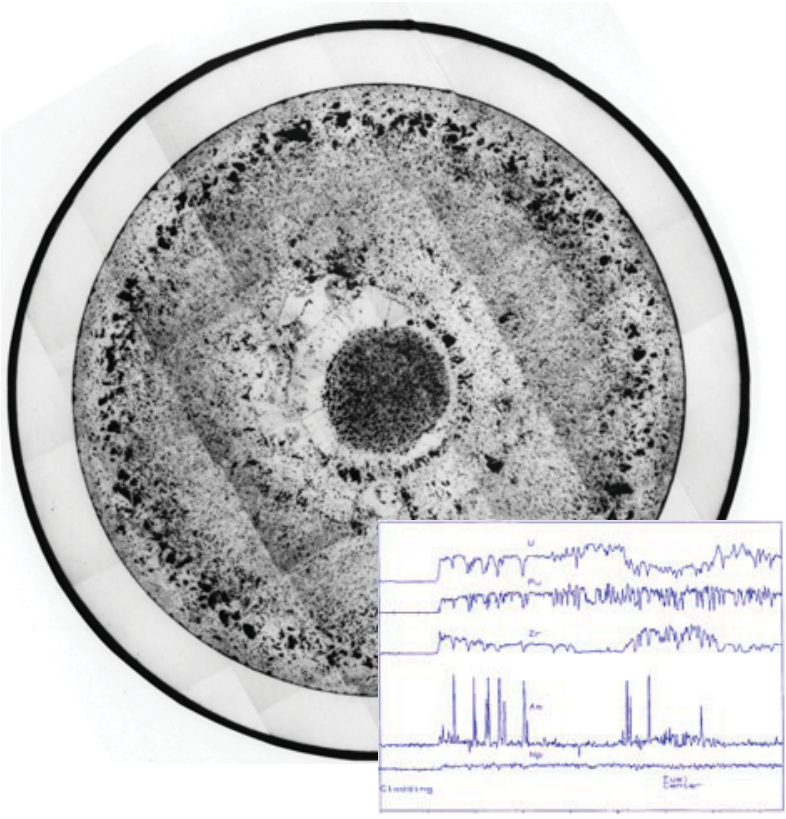

U-Pu-Am-Np-Zr

Figure 2-7.Examples of constituent redistribution in metallic fast reactor fuels.

Fission product generation (including solid and gaseous fission products) leads to fuel swelling. The amount of swelling for any particular fuel form and composition is important to know because the initial fuel and cladding sizes must be designed to accommodate swelling without producing unacceptable mechanical interaction between fuel and cladding. Figure 2-8 shows examples of metallic fuel swelling

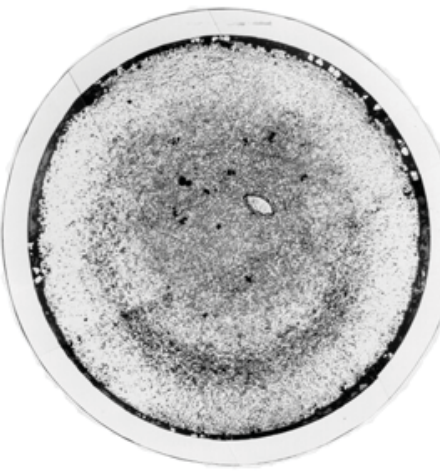

$\mathrm{X} 423$ at $0.9 \%$ burnup

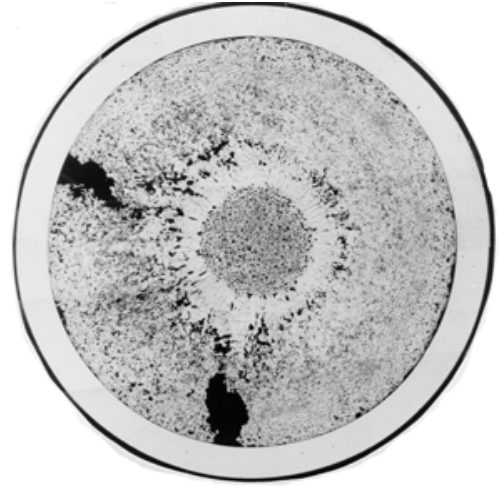

X419 at 3\% burnup

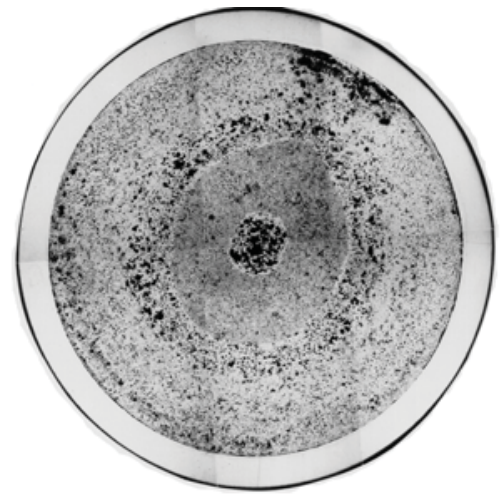

$\mathrm{X} 420 \mathrm{~B}$ at $17 \%$ burnup

Figure 2-8.Swelling and restructuring of $\mathrm{U}-20 \mathrm{Pu}-10 \mathrm{Zr}$ fuel.

and restructuring and indicates that swelling and restructuring occur early in irradiation. Short-term irradiations of MOX fuel and minor actinide-containing MOX fuel conducted by Japan Atomic Energy Agency (JAEA) show that restructuring and redistribution begins within the first 24 hours of irradiation and can even be seen as early as 10 minutes. ${ }^{10}$ 
Initially, fuel may be either fully dense or fabricated with some initial porosity. During irradiation, fuel porosity increases due to restructuring, irradiation damage, and the accumulation of fission products, at some point the porosity becomes interconnected, and gases produced during fission can escape from the fuel matrix, leading to fission gas release. This released gas increases pressure in the fuel rod plenum. It is important to track fission gas release to determine how fuel composition (especially the transuranics) affects total fission gas release and release rates. An example of fission gas release for a few metallic fuel compositions is shown in Figure 2-9.

Thermal and mechanical forces and changing composition may lead to cracking and other microstructural changes during irradiation. Physical changes in the fuel may change thermal transport and diffusion pathways, leading to increased fission product or fission gas release or thermal anomalies.

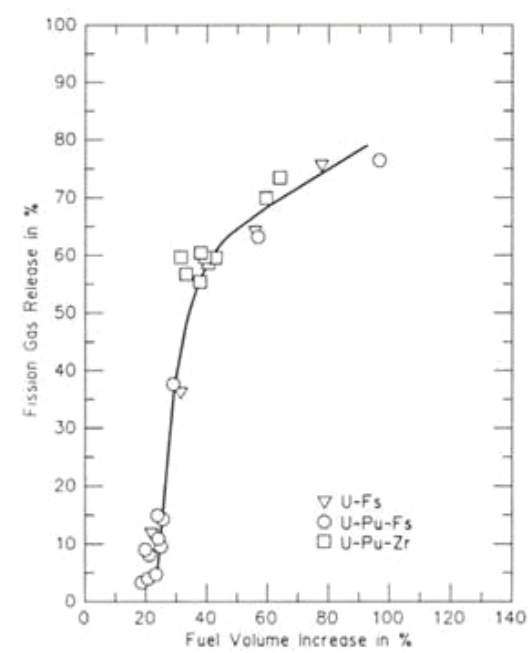

Figure 2-9.Fission gas release for fast reactor metallic fuel compositions (U-Uranium, Pu-Plutonium, Zr-Zirconium, and Fs-Fissium)

In addition to fuel swelling, the cladding may experience creep during irradiation. Eventually, the fuel and cladding usually come into contact. Fuel constituents, especially some fission products or reprocessing carryover, may interact with the cladding, reducing the effective strength of the cladding. Understanding and predicting fuel-cladding interaction is important to determine ultimate fuel rod lifetimes. Examples of fuel-cladding interaction with catastrophic failure and general fuel restructuring are shown in Figure 2-10. Important metallic fuel performance phenomena include:

- irradiation growth;

- fuel swelling and fuel-cladding mechanical interaction (FCMI);

- gas release;

- fuel constituent redistribution;

- fuel-cladding chemical interaction (FCCI).

Important oxide fuel performance phenomena include:

- fuel swelling and fuel-cladding mechanical interaction (FCMI);

- fuel restructuring;

- gas release; 

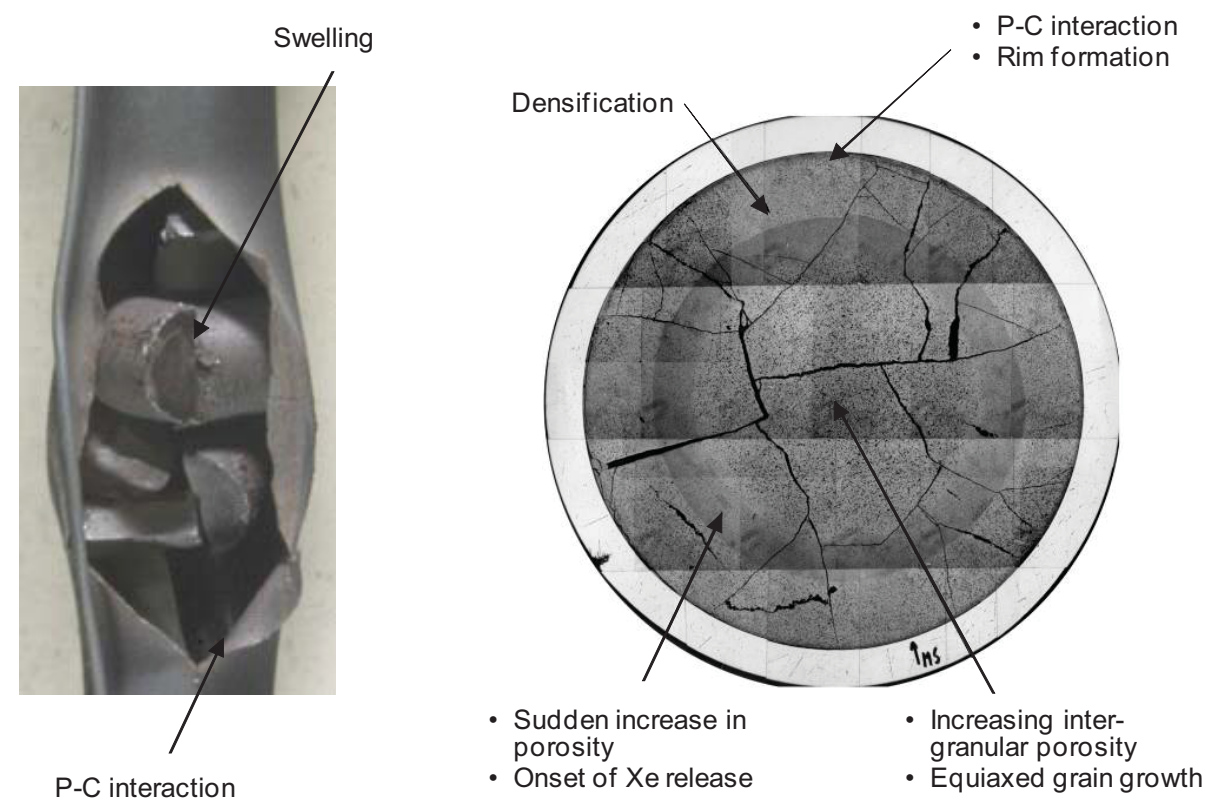

Figure 2-10.Examples of catastrophic fuel failure (left) and fuel restructuring (right).

- fuel-cladding chemical interaction (FCCI);

- fuel cladding oxide (CRUD) formation

- fuel-coolant compatibility.

\section{HTGR}

As noted in Section 2.2.1.3, a specialized ATR test capsule has been developed by the NGNP program that allows fission gas releases to be monitored 'near real time' along with temperature, flux, and coolant chemistry. As noted within References 5 through 7, fuel development and qualification activities will provide data on TRISO-coated fuel performance under normal and accident conditions. The primary objectives include providing data, as necessary, to support fuel-process development, qualify a fuel design and fabrication process for normal operation conditions, support development and validation of fuel performance and fission-product transport models and codes, and provide irradiated fuel and materials as necessary for Post Irradiation Examinations (PIEs) and safety testing.

Data obtained during the irradiations provide insights related to fission gas release from various sources (e.g., contamination, initially damaged coatings, and fuel particle failures) and information related to fission product transport through various particle coatings. In addition, PIE are planned to gain insights related to the endstate of various fission product species and the integrity of various coatings. Combined, this information will be used to quantify the source term from gas reactor fuel particles.

\subsubsection{Desired Measurement Parameters and Accuracies}

In-situ instrumentation is desired to provide real-time data on fuel performance phenomena. Without wireless transmission capabilities, drop-in or static capsule experiments only allow data to be obtained at the endpoint of an experiment. In-situ instrumentation in irradiation tests can provide data showing the evolu- 
tion of particular phenomena over time. Selected parameters of interest for fuel modeling, with accuracies currently requested by DOE-NE programs, are listed in Table 2-5. ${ }^{11,12,19}$

Table 2-5. Summary of desired parameters for detection during fuel irradiation tests. ${ }^{\mathrm{a}}$

\begin{tabular}{|c|c|c|c|}
\hline \multirow{2}{*}{ Parameter } & \multirow{2}{*}{ Representative Peak Value } & \multicolumn{2}{|r|}{ Desired } \\
\hline & & Accuracy & Spatial Resolution \\
\hline \multirow[t]{4}{*}{ fuel temperature } & Ceramic LWR - $1400^{\circ} \mathrm{C}$ & \multirow[t]{4}{*}{$2 \%$} & \multirow{4}{*}{$\begin{array}{l}1-2 \mathrm{~cm} \text { (axially); } \\
0.5 \mathrm{~cm} \text { (radially) }\end{array}$} \\
\hline & Ceramic SFR- $2600^{\circ} \mathrm{C}$ & & \\
\hline & Metallic SFR $-1100^{\circ} \mathrm{C}$ & & \\
\hline & TRISO HTGR $-1250^{\circ} \mathrm{C}$ & & \\
\hline \multirow[t]{4}{*}{ cladding temperature } & Ceramic LWR - $<400{ }^{\circ} \mathrm{C}$ & \multirow[t]{3}{*}{$2 \%$} & \multirow[t]{3}{*}{$1-2 \mathrm{~cm}$ (axially) } \\
\hline & Ceramic SFR $-650^{\circ} \mathrm{C}$ & & \\
\hline & Metallic SFR - $650^{\circ} \mathrm{C}$ & & \\
\hline & TRISO GCFR & NA & NA \\
\hline \multirow[t]{4}{*}{ pressure in fuel rod plenum } & Ceramic LWR - 5.5 MPa & \multirow[t]{4}{*}{$5 \%$} & \multirow[t]{4}{*}{$\mathrm{NA}^{\mathrm{b}}$} \\
\hline & Ceramic SFR-8.6 MPa & & \\
\hline & Metallic SFR - 8.6 MPa & & \\
\hline & HTGR-NA & & \\
\hline $\begin{array}{l}\text { LWR, SFR, and HTGR fission gas } \\
\text { release (amount and composition) }\end{array}$ & $0-100 \%$ of inventory & $10 \%$ & NA \\
\hline \multirow{3}{*}{$\begin{array}{l}\text { LWR and SFR fuel and cladding } \\
\text { dimensions (includes fuel / cladding } \\
\text { gap size); HTGR-NA }\end{array}$} & Initial Length, $1 \mathrm{~cm}$ & $1 \%$ & NA \\
\hline & Outer diameter/Strain, $0.5 \mathrm{~cm} / 5-10 \%$ & $0.1 \%$ & NA \\
\hline & Fuel-Cladding Gap (0-0.1 mm) & $0.1 \%$ & NA \\
\hline \multirow{3}{*}{$\begin{array}{l}\text { LWR, SFR, and HTGR fuel } \\
\text { morphology/microstructure/ } \\
\text { cracking/ constituent redistribution }\end{array}$} & Grain size, $10 \mu \mathrm{m}$ & $5 \%$ & $1-10 \mu \mathrm{m}$ \\
\hline & Swelling/Porosity, 5-20\% & $2 \%$ & \\
\hline & Crack formation and growth & $2 \%$ & $10-100 \mu \mathrm{m}$ \\
\hline \multirow[t]{2}{*}{ fuel thermal properties } & $\begin{array}{c}\text { Thermal conductivity } \\
\text { Ceramic: }<8 \mathrm{~W} / \mathrm{mK} ; \text { Metallic: }<50 \mathrm{~W} / \mathrm{mK} \text {; } \\
\text { TRISO pebble/compact: } 4-12 \mathrm{~W} / \mathrm{mK}\end{array}$ & $4 \%$ & $<1 \mathrm{~cm}$ (radially) \\
\hline & $\begin{array}{l}\text { Density (inferred from changes in length, diameter, } \\
\text { porosity, etc.) } \\
\text { Ceramic: }<11 \mathrm{~g} / \mathrm{cm}^{3} \text {; Metallic: }<50 \mathrm{~g} / \mathrm{cm}^{3} \\
\text { TRISO pebble } / \text { compact: } 2.25 \mathrm{~g} / \mathrm{cm}^{3 \mathrm{c}}\end{array}$ & $2 \%$ & NA \\
\hline \multirow{2}{*}{$\begin{array}{l}\text { maximum neutron flux for } \\
\text { estimating fluence and fuel burnup } \\
\text { for fuel irradiations }\end{array}$} & Thermal neutron flux $-\sim 1-5 \times 10^{14} \mathrm{n} / \mathrm{cm}^{2}-\mathrm{s}$ & $1-10 \%$ & $5 \mathrm{~cm}$ (axially) \\
\hline & Fast neutron flux $(\mathrm{E}>1 \mathrm{MeV})-\sim 1-5 \times 10^{14} \mathrm{n} / \mathrm{cm}^{2}-\mathrm{s}$ & $15 \%$ & $5 \mathrm{~cm}$ (axially) \\
\hline
\end{tabular}

a. Representative peak values, accuracy, and resolution are based on engineering judgement by cognizant program experts.

b. NA-Not Applicable.

c. Value dependent upon particle packing fraction and matrix.

Although all of the listed parameters are of interest for modeling fuel behavior, the FCRD program has placed the highest priority on sensors that can provide insights related to fuel morphology because such insights are needed to clarify changes in other parameters, such as thermal conductivity, density, etc. NGNP irradiations are focused on demonstrating the integrity of the HTGR fuel particle coatings to resist failure during normal operating and accident conditions. Hence, this program places the highest emphasis on detecting any fission product gasses released from the fuel and correlating it to the fuel burnup and temperatures occurring during irradiation testing. 


\subsubsection{Materials}

As noted within Ref. 4, there are many different types of materials within an LWR; over 25 different metal alloys can be found within the primary and secondary systems, not to mention the concrete containment vessel, instrumentation and control, and other support facilities. Over its forty-year lifetime, LWR internal structures may expect to see fluences up to $\sim 10^{22} \mathrm{n} / \mathrm{cm}^{2}$ in a BWR and $\sim 10^{23} \mathrm{n} / \mathrm{cm}^{2}$ in a PWR (E > 1 $\mathrm{MeV}$ ), corresponding to $\sim 7 \mathrm{dpa}$ and $70 \mathrm{dpa}$, respectively. The neutron irradiation field can produce large property and dimensional changes in materials. Such changes occur primarily via five radiation damage processes: radiation-induced hardening and embrittlement, phase instabilities from radiation-induced or -enhanced segregation and precipitation, irradiation creep due to unbalanced absorption of interstitials versus vacancies at dislocations, volumetric swelling from cavity formation, and high temperature helium embrittlement due to formation of helium-filled cavities on grain boundaries. Extending the service life of a reactor will increase neutron fluence and susceptibility to radiation damage (although new damage mechanisms are possible). Likewise, material performance becomes more complex when one considers the additional conditions proposed within DOE-NE programs for NGNP and SFR.

This section discusses types of irradiations currently conducted, planned or anticipated to occur in the near term in support of DOE-NE programs investigating irradiation effects on materials degradation. As noted within this section, DOE-NE programs are focused on degradation that may occur in high temperature alloys, vessel and internal materials, weldments, and graphite. The LWRS and NGNP programs are the only programs currently conducting materials irradiations. Other programs, such as the ARC program that relies on SFR technologies, have identified the need for and/or are planning materials irradiation tests. It should also be noted that many irradiation effects investigations are currently conducted out-of-pile using post irradiation examination (PIE) techniques. However, it is anticipated that the need to validate new computational tools for simulating material performance during irradiation will require higher fidelity data with increased accuracy and resolution. Such requirements demand that irradiations be performed in instrumented tests where data can be obtained real-time in the environment that exists during the irradiation (e.g., at representative temperatures, pressures, and fluxes).

\subsubsection{High Temperature Alloys}

\section{$L W R$}

In collaboration with EPRI, the LWRS program includes a task to explore and develop new alloys with enhanced radiation resistance. At this time, this effort is limited to participating in expert panel groups to develop a comprehensive R\&D plan for these advanced alloys. Future work will include alloy development, alloy optimization, fabrication of new alloys, and evaluation of their performance under LWR-relevant conditions (e.g., mechanical testing, corrosion testing, and irradiation performance among others) and, ultimately, validation of these new alloys.

\section{GCR}

The high outlet temperature of an HTGR, above $750^{\circ} \mathrm{C}$ depending on the application need, requires the development and qualification of high-performance metallic alloys to transfer heat from the reactor to the process application in an Intermediate Heat Exchanger (IHX). Because these alloys will contain the high-pressure helium used to cool the reactor, stringent requirements are imposed to ensure that this piping and the equipment through which the helium flows will maintain its integrity. Design of the pressure boundary and the materials used in these applications must meet the requirements of the nuclear section of the American Society of Mechanical Engineers (ASME) Code. Currently, high temperature alloys and 
associated ASME codes for reactor applications are approved only up to $760^{\circ} \mathrm{C}$. Thus, the goal of high temperature materials NGNP R\&D is to obtain the performance data required to support the development of these high temperature components and associated design codes over the broader range of envisioned outlet temperatures for HTGRs to support co-generation of steam and electricity at lower temperatures $\left(750-800^{\circ} \mathrm{C}\right)$ and hydrogen production and hot gas delivery at higher temperatures $\left(850-950^{\circ} \mathrm{C}\right)$ for a variety of end user applications.

The objective of the current NGNP high-temperature materials R\&D program is to establish the relevant thermochemical performance data to support the development of the high-temperature components operating between 750 to $900^{\circ} \mathrm{C}$. Creep, creep-fatigue, aging, and environmental degradation testing are planned using candidate high-temperature nickel-based alloys, such as Inconel 617 and Incoloy $800 \mathrm{H}$. Constitutive models are also needed to describe the behavior of the alloy in tensile loading at elevated temperatures. Thick and thin sections of base material, weldments, and other joints, such as diffusion bonding, will be evaluated given the different design options under consideration for the IHX. Depending on the outlet temperature, additional high-temperature data may be needed to support relevant ASME code cases for the material.

\section{SFR}

Advanced materials are a critical element in the development of economically competitive sodium reactor technologies in the ARC program. ${ }^{3}$ Nuclear structural component design in the U.S. must comply with the ASME Boiler and Pressure Vessel Code Section III (Rules for Construction of Nuclear Facility Components). So far, only five materials are qualified for use in elevated-temperature nuclear structural components, including Type 304 SS, Type 316 SS, 2.25Cr-1Mo steels, mod.9Cr-1Mo steel, and Alloy 800H. Currently, the ARC SFR program is interested in (i) ferritic/martensitic steels: Grade 91 steel, Grade 92 steel (and its advanced variants, plus advanced thermo-mechanical treatment), and (ii) austenitic alloys: NF-708, HT-UPS, and advanced HT-UPS. ${ }^{23}$

For code-qualified materials, a number of safety-related issues remain in the areas of weldments, environmental effects, data extrapolation to 60 years, inelastic analysis, notch weakening, thermal striping, etc. For new advanced alloys with improved strength properties and creep resistance, the available data are far more limited than what is needed for nuclear reactor applications. Improved high temperature design methods are also required for these new alloys because time-dependent material issues are more pronounced in terms of phase stability, phase transformation, grain boundary segregation, dissolution of strengthening phases, recovery and recrystallization. For both code-qualified alloys and new advanced alloys, it is important to identify the most critical and least resolved design and materials issues for ARC systems, and develop strategies that incorporate the key practical issues such as sodium compatibility, irradiation effects, creep, creep-fatigue, welding/joining, and fabrication/manufacturing to addresses both material needs and the need for high temperature design methods.

Reference 3 provides a comprehensive review of available data and lists data required for qualifying reference and new advanced alloys for ARC SFR operation. As noted in this reference, there is an extensive database and wide industrial experience with conventional austenitic stainless steels and ferritic steels. However, additional data are required to qualify these materials for the conditions associated with 60 years or longer in a SFR. Of primary concern are the needs to assess the environmental effects of sodium, thermal aging, and neutron irradiation. Likewise, the irradiation database for Grade 91 steel must be expanded to qualify this material for the temperatures, corrosion damage, creep damage, and weldments required for proposed ARC SFR designs. Advanced alloy development involves modification of existing (with and without Code qualification) alloys through minor compositional changes and thermo-mechanical treatments for improved high temperature performance. The conventional processes available for alloy 
development are slow, taking decades to bring a new alloy to commercial market. Although the use of computational tools in a science-based approach for alloy improvement offers an opportunity to accelerate the alloy development process, high fidelity data are needed to validate the use of such codes. The use of enhanced instrumentation that could provide real-time data for advanced alloy qualification could expedite their qualification.

\subsubsection{Vessel Steel and Internal Structures}

Components serving in a nuclear reactor vessel must withstand a very harsh environment including extended times at temperature, neutron irradiation, stress, and/or corrosive media. Extending reactor service to beyond 60 years and increasing the power of existing reactors will increase the demands on materials and components.

\section{$L W R$}

The LWRS program has several activities underway to investigate the effects of irradiation on materials. Currently, evaluations are conducted out-of-pile as PIE of samples irradiated in MTRs or commercial nuclear power plants (NPPs) with no real-time instrumentation (e.g., a "cook and look" approach). ${ }^{4}$

Several activities focus on testing to understand the effects of composition, irradiation history, and environment on stress-corrosion cracking of austenitic steels in high-temperature water environments. Irradiation-assisted stress-corrosion cracking (IASCC) has been observed in both BWRs and PWRs, although higher irradiation doses are required for the onset of IASCC in PWRs. The effects of increased exposure to irradiation, stress, and/or coolant can substantially increase susceptibility to stress-corrosion cracking of austenitic steels (304 and 316 stainless steel) in high-temperature water environments. ${ }^{20}$ Despite 30 years of experience, the underlying mechanisms of IASCC are unknown. In the LWRS program, an effort is underway to evaluate, using post-irradiation techniques, the response and mechanisms of IASCC in austenitic stainless steels with single variable experiments. For these evaluations, a group of high-value irradiated specimens has been acquired from international research programs.

The LWRS program is also investigating high fluence effects on RPV materials. ${ }^{22}$ There are only sparse data available on long term thermal aging effects. Available data indicate no significant effects of aging; however, the exposure temperature was only $260^{\circ} \mathrm{C}$, which is well below the average of about $288^{\circ} \mathrm{C}$ for U.S. PWRs and even further below the typical RPV temperature of about $300^{\circ} \mathrm{C}$ for $\mathrm{B} \& \mathrm{~W}$ reactors. There are other international thermal aging studies on similar steels showing increasing effects of thermal aging with temperature and dependent on the specific material, with chemical composition (e.g., copper) and heat treatment being two other important variables. Activities include post-irradiation evaluations of sample irradiated in MTRs to obtain high fluence data and evaluations of samples from decommissioned commercial reactors, such as the Palisades, Zion, and Ginna reactors, to address concerns about the use of high flux MTR samples being nonprototypical of materials within lower flux operating NPPs. Examination results will be used to support development of a computation tool that can predict transition temperature shifts (TTS) and embrittlement in RPV steels.

The LWRS program is also evaluating irradiation-induced swelling and phase transformation effects in high-fluence core internals using PIE methods on specimens that were irradiated at the Fast Flux Test Facility or the Experimental Breeder Reactor II. Research tasks are designed to provide detailed microstructural analysis of swelling and phase transformation in samples and components (both model alloys and service materials), including transmission electron microscopy and volumetric measurements. Tasks are also underway to evaluate the effects of sample composition and sample irradiation environment. Examination results are used to develop and validate phenomenological models. 


\section{GCR}

Although it has not been identified as a primary focus of the current NGNP program, initial designs considered higher core outlet temperatures (up to $1000^{\circ} \mathrm{C}$ ). Reference 22 reviews existing data on candidate NGNP RPV vessel materials and identifies additional data required for ASME code qualification at higher temperatures.

\section{SFR}

As noted above in Section 2.2.2.1, advanced alloys for the vessel and internal structures are a critical element in the development of sodium reactor technologies in the ARC SFR Program. ${ }^{22}$ Enhanced materials performance not only improves safety margins and provides design flexibility, but also is essential for the economics of future advanced sodium reactors.

\subsubsection{Weldments}

\section{SFR}

The ARC SFR program is also considering the survivability of weldments of advanced alloys. ${ }^{3}$ It is well recognized that lack of validated weldment design criteria is a significant issue for advanced reactors. Weldments are often the critical locations in the design of high temperature components, due to their lower strength and metallurgical variations. Weldment safety evaluation was one of the nine areas of concerns that were identified by the Nuclear Regulatory Commission (NRC) in the license review of the Clinch River Breeder Reactor (CRBR) project. Weldment cracking was regarded as the foremost-unresolved structural integrity issue, particularly in components that are subjected to repeated thermal transient loadings. The factors identified by the NRC that needed additional consideration included: ${ }^{21}$

- Crack initiation in the heat affected zone (HAZ) of the weldment exposed to cyclic sodium temperatures at the inside surface

- Effects of material property variations in the weld on creep-fatigue and creep-rupture damage

- Effects of time rate, cyclic rate, and hold-time effects on propagation of long shallow cracks in the HAZ of the weldment

- Enhanced creep in the remaining uncracked wall thickness caused by residual stresses and thermal cycling

- Stability of the remaining uncracked wall ligament for operation in the creep regime

A confirmatory program between the NRC and the CRBR project was established to address these issues, and to quantify the safety margins of weldments in service at elevated temperatures. The basic elements of the program were:

- Evaluate potential for premature crack initiation at weldments due to thermal fatigue, residual stresses, and damage caused by the welding process.

- Confirm adequacy of creep-rupture and creep-fatigue damage evaluation procedures at weldments.

- Assess growth behavior of cracks in the HAZ of weldments.

- Evaluate consequences of enhanced creep in uncracked ligaments.

- Assess stability of uncracked ligaments for creep conditions.

- Define effects of long-term elevated temperature service on crack initiation.

- Evaluate effects of loading sequence on creep-fatigue behavior. 
Although PIE was used to obtain the above data, future evaluations could benefit from the use of enhanced in-pile instrumentation.

\subsubsection{Graphite}

\section{NGNP}

In HTGRs, graphite physically contains the fuel and comprises the majority of the core volume. It also forms the inner and outer reflector (non-fueled) regions of the core. Graphite has been used effectively in the past as a structural and moderator material in both research and commercial HTGRs, establishing graphite as a viable structural material for high-temperature reactor cores.

However, while the general characteristics necessary for fabricating available graphite are understood, the specific performance of currently available nuclear-grade graphite at the anticipated operating conditions is unknown. Previously-used nuclear-grade graphite, such as H327 and H451 used in the Fort St. Vrain (FSV) reactor, required an extensive development program that covered both fabrication processes and actual performance data to determine if they were suitable for reactor applications. Unfortunately, historical nuclear grades are no longer produced, and the raw feedstock material (e.g., petroleum and pitch coke) used to fabricate the graphite is no longer available from the sources historically used. Thus, the new graphite grades and associated fabrication processes must be qualified. The NGNP project approach developed for qualifying graphite addresses needs identified by gas reactor vendors, NRC, and ASME. ${ }^{6,7}$ The approach also factors in international experience, particularly in the U.K. where the current incomplete understanding of in-pile graphite behavior in British gas-cooled reactors is causing the British utility to gather such data to respond to regulatory inquiries about the safety of those reactors in light of unexplained cracks found in graphite during reactor operation.

There is no irradiation experience with these new graphite types, so there is currently no way to quantitatively predict how they will actually perform within a reactor environment. While the graphite will be structurally stable for some period of time, the lifetime (as a function of dose and temperature) is not known for available grades of graphite. This is a critical safety issue in that the stability of the graphite must be understood to determine the structural safety of the internal core. Therefore, the new graphite grades need to be characterized to demonstrate that they exhibit acceptable non-irradiated and irradiated thermo-mechanical and thermo-physical performance.

The program consists of statistical characterization of unirradiated graphite material properties to establish the lot-to-lot, billet-to-billet and within billet variability of the material. Irradiations are planned at specified temperatures and doses within the design service condition envelope anticipated for NGNP. Extensive post-irradiation examinations are planned to establish the change in relevant material properties (e.g., thermal diffusivity, specific heat capacity, and thermal coefficient of expansion, density, etc.) as a function of temperature and neutron dose. Of particular interest is the irradiation induced creep of graphite, which is critical to determining the lifetime of the graphite under irradiation. Data obtained from PIE of irradiated samples will be used to establish constitutive relations for use in a detailed predictive thermo-mechanical finite element model. These data will also support development of ASTM standards and design rules.

The historic thermo-mechanical and thermo-physical irradiation performance database of graphite focused largely on moderate doses ( 5 to 7 displacements per atom [dpa]) and modest temperatures $\left(400\right.$ to $\left.850^{\circ} \mathrm{C}\right)$, which is typical of the design service conditions of older HTGRs operating in the US and Germany. There are much less data at the higher temperatures and doses anticipated for higher temperature designs. For prismatic designs, peak graphite temperatures could be as high as 1,000 to $1,250^{\circ} \mathrm{C}$, and the expected peak graphite doses in the reflectors could be 5 to 6 dpa with operation service lifetimes of about 6 to 10 years. 
A series of eight irradiations are planned within the NGNP project to establish the thermo-mechanical and thermo-physical response of the major grades of graphite as a function of temperature and radiation dose (see Figure 2-11). Advanced Graphite Capsule (AGC)-1 through AGC-6 will be conducted at ATR to establish the behavior of graphite in the temperature/dose envelope for NGNP. HTV-1 and HTV-2 will be conducted in HFIR to establish graphite behavior under accelerated temperature and damage conditions so that AGC-6 can be designed properly, accounting for shrinkage/swelling and creep anticipated at high temperatures and high doses. These irradiations will contain specimens of sufficient size, number, and type to support statistical assessments necessary to capture the inherent variability in graphite; to support traditional ASTM requirements for sample analysis; and to more completely characterize the physical, thermal, and mechanical properties of the irradiated graphite. The first graphite capsule test train, AGC-1, is shown in Figure 2-11. This capsule can accommodate over 400 samples. Loads are applied to the samples during testing so that PIE can be used to measure creep rates at various temperatures, ranging from 600 to $1,200^{\circ} \mathrm{C}$.

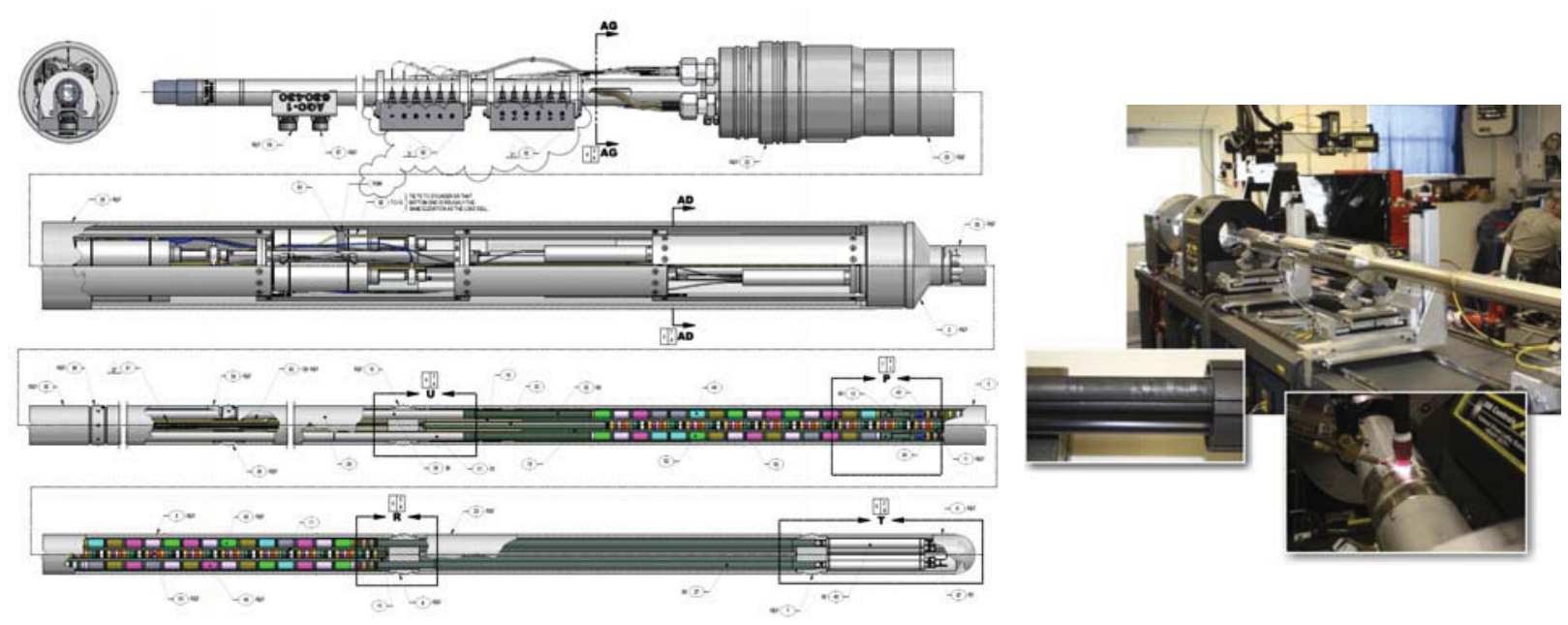

Figure 2-11.Schematic of AGC-1 test train and photographs of test train during assembly.

The technology needs to satisfy requirements for the pebble bed are more substantial. While lower peak graphite temperatures of 1,000 to $1,100^{\circ} \mathrm{C}$ are expected, much higher doses are anticipated (20-25 dpa) because of the vendor's desire to ensure that the reflector lasts the lifetime of the reactor. Thus, new graphite grades need to be appropriately fabricated and characterized to demonstrate acceptable performance within a more demanding environment for pebble bed applications.

Extensive post-irradiation characterizations are planned to establish the change in relevant material properties as a function of temperature and neutron dose. A complete properties database for these new grades of graphite is required to describe the graphite's physical, mechanical, and oxidation properties. Of particular interest is the graphite's irradiation-induced creep, which is critical to determining the lifetime of the graphite under irradiation. From these data sets, constitutive relations will be established for use in a detailed predictive thermo-mechanical finite element model. These data are needed to support the ongoing development of the risk-derived ASME graphite design code.

\subsubsection{Desired Measurement Parameters and Accuracies}

As noted in this section, most materials irradiations are currently relying on PIE to characterize material properties after an irradiation is completed. Enhanced in-pile instrumentation offers the potential for 
increased accuracy higher fidelity data since measurements are obtained at the conditions of interest. Selected parameters of interest for materials performance modeling, with currently-requested accuracies, are listed in Table 2-6.

Table 2-6. Summary of desired parameters for detection during materials irradiation tests. ${ }^{\text {a,b }}$

\begin{tabular}{|c|c|c|c|}
\hline \multirow[b]{2}{*}{ Parameter } & \multirow[b]{2}{*}{ Representative Peak Values } & \multicolumn{2}{|c|}{ Desired } \\
\hline & & Accuracy & $\begin{array}{c}\text { Spatial } \\
\text { Resolution }\end{array}$ \\
\hline \multirow[t]{4}{*}{ Material temperature distribution } & LWRS Fuel Cladding- $>1200^{\circ} \mathrm{C}$ & \multirow[t]{3}{*}{$2 \%$} & \multirow{3}{*}{$\begin{array}{l}1-2 \mathrm{~cm} \text { (axially); } \\
0.5 \mathrm{~cm} \text { (radially) }\end{array}$} \\
\hline & LWRS Vessel and Internal Materials- $500^{\circ} \mathrm{C}$ & & \\
\hline & HTGR and LWRS high temperature alloys- $950^{\circ} \mathrm{C}$ & & \\
\hline & HTGR Graphite - 600 to $1200{ }^{\circ} \mathrm{C}$ & $\begin{array}{l} \pm 50^{\circ} \mathrm{C} \text { (axially) } \\
\pm 40^{\circ} \mathrm{C} \text { (radially) }\end{array}$ & $\mathrm{NA}^{\mathrm{c}}$ \\
\hline \multirow[t]{2}{*}{$\begin{array}{l}\text { Material dimensional changes due to } \\
\text { swelling; }\end{array}$} & $\begin{array}{l}\text { Initial Specimen Length, } \\
\text { HTGR Graphite }-2.54 \mathrm{~cm}\end{array}$ & $1 \%$ & NA \\
\hline & $\begin{array}{l}\text { Outer diameter/Strain, } \\
\text { LWR vessel and internal materials }-0.5 \mathrm{~cm} / 5-10 \%\end{array}$ & $0.1 \%$ & NA \\
\hline \multirow{3}{*}{$\begin{array}{l}\text { Material morphology/ } \\
\text { microstructure/cracking/ constituent } \\
\text { redistribution }\end{array}$} & $\begin{array}{c}\text { Grain size, } \\
\text { LWR vessel and internal materials }>10 \mu \mathrm{m}\end{array}$ & $5 \%$ & $1-10 \mu \mathrm{m}$ \\
\hline & $\begin{array}{c}\text { Swelling/Porosity, } \\
\text { LWR vessel and internal materials 5-20\% }\end{array}$ & $2 \%$ & $10-100 \mu \mathrm{m}$ \\
\hline & $\begin{array}{c}\text { Crack formation and growth } \\
\text { LWR vessel and internal materials }>10 \mu \mathrm{m}\end{array}$ & $2 \%$ & $10-100 \mu \mathrm{m}$ \\
\hline \multirow[t]{4}{*}{ Material thermal properties } & $\begin{array}{l}\text { Thermal conductivity } \\
\text { HTGR Graphite - }\end{array}$ & $4 \%$ & $<1 \mathrm{~cm}$ (radially) \\
\hline & $\begin{array}{c}\text { Thermal conductivity } \\
\text { LWR vessel and internal materials } \sim 50 \mathrm{~W} / \mathrm{m}-\mathrm{K}\end{array}$ & $5-20 \%$ & $<1 \mathrm{~cm}$ \\
\hline & $\begin{array}{l}\text { Thermal coefficient of expansion; } \\
\text { HTGR Graphite - 5\% }\end{array}$ & $2 \%$ & NA \\
\hline & $\begin{array}{c}\text { Density (estimated from changes in length, diameter, } \\
\text { porosity, etc.) } \\
\text { HTGR Graphite }-0.5 \%\end{array}$ & $0.2 \%$ & NA \\
\hline \multirow[t]{5}{*}{$\begin{array}{c}\text { Material mechanical/electrical } \\
\text { properties }\end{array}$} & $\begin{array}{c}\text { Irradiation creep } \\
\text { HTGR Graphite - 3-4\% }\end{array}$ & NA & NA \\
\hline & $\begin{array}{c}\text { Young's modulus } \\
\text { HTGR Graphite - 3-4\% }\end{array}$ & NA & NA \\
\hline & $\begin{array}{c}\text { Electrical resistivity } \\
\text { HTGR Graphite - 3-4\% }\end{array}$ & NA & NA \\
\hline & $\begin{array}{c}\text { Poisson's ratio } \\
\text { HTGR Graphite - 3-4\% }\end{array}$ & NA & NA \\
\hline & $\begin{array}{c}\text { Fracture toughness, shear strength } \\
\text { HTGR Graphite - 3-4\% }\end{array}$ & NA & NA \\
\hline \multirow{2}{*}{$\begin{array}{l}\text { Material irradiation neutron flux for } \\
\text { estimating fluence }\end{array}$} & Thermal neutron flux $-\sim 1-5 \times 10^{14} \mathrm{n} / \mathrm{cm}^{2}-\mathrm{s}$ & $1-10 \%$ & $5 \mathrm{~cm}$ (axially) \\
\hline & Fast neutron flux $(\mathrm{E}>1 \mathrm{MeV})-\sim 1-5 \times 10^{14} \mathrm{n} / \mathrm{cm}^{2}-\mathrm{s}$ & $15 \%$ & $5 \mathrm{~cm}$ (axially) \\
\hline
\end{tabular}

a. Representative peak values, accuracy, and resolution are based on engineering judgement and are preliminary.

b. Only LWRS and NGNP irradiation information available for a limited number of parameters at this time.

c. NA-Not Available.

At this time, the NGNP and LWRS project irradiation test requirements are more detailed than other DOE-NE programs. However, both projects rely heavily on PIE rather than real-time data obtained during irradiation testing. Efforts underway by the NEET, ATR NSUF, and FCRD programs are designed to develop and deploy in-pile sensors that can provide the required data during irradiation testing and assess the accuracy of data obtained with PIE to reflect conditions that occur during the irradiation. 


\subsection{Instrumentation Development Required for DOE-NE Irradiations}

As indicated in Section 2.2, it is anticipated that irradiation testing of fuels or materials will be performed as part of all the DOE-NE programs reviewed in this document. As discussed in Reference 24, sensors that are currently available at other MTRs (see Table 2-7) can be used to obtain many of the desired parameters with the accuracies specified in Tables 2-5 and 2-6. However, many of the sensors used at other MTRs need enhancements before they can be successfully deployed in the higher flux, harsher test conditions typical of ATR and HFIR tests. The FCRD and ATR NSUF programs ${ }^{24}$ are funding efforts to enhance these sensors such that they can withstand anticipated ATR and HFIR test conditions required by DOE-NE programs. As each enhancement activity is completed, new sensors are available to measure parameters, such as temperature, thermal conductivity, and creep elongation. However, in general, the resolution available with such sensors is limited due to the limited size of the irradiation test and the desire to minimize the impact of the sensor on test results. It should also be noted that existing and near-term sensor technology development efforts will not provide any capability for detecting changes in fuel microstructure or constituent migration.

Table 2-7. Summary of sensors deployed at MTRs.

\begin{tabular}{|c|c|c|c|}
\hline Parameter & Sensor & Operating Conditions & Accuracy \\
\hline \multirow[t]{6}{*}{ Temperature } & Melt Wires & $100-1200{ }^{\circ} \mathrm{C}$ & $\begin{array}{c}2-3^{\circ} \mathrm{C} \text {, but limited by number of } \\
\text { wires with different melting } \\
\text { points included in test. }\end{array}$ \\
\hline & SiC monitors & $100-800^{\circ} \mathrm{C}$ & $2 \%$ \\
\hline & Thermocouples $(\mathrm{N}, \mathrm{K})$ & $100-1000{ }^{\circ} \mathrm{C}$ & $2 \%$ \\
\hline & $\begin{array}{c}\text { Thermocouples } \\
\text { (High Temperature Irradiation } \\
\text { Resistant Thermocouples } \\
\text { (HTIR-TCs) }\end{array}$ & $100-1800{ }^{\circ} \mathrm{C}$ & $2 \%$ \\
\hline & $\begin{array}{c}\text { Thermocouples - Type C, D, R, } \\
\text { and S }\end{array}$ & $100-2000^{\circ} \mathrm{C}$ & $\begin{array}{c}2 \% \text { or worse, decalibrate due to } \\
\text { transmutation }\end{array}$ \\
\hline & Ultrasonic Thermometers $^{\mathrm{a}}$ & $1300-3000{ }^{\circ} \mathrm{C}$ & $2 \%$ \\
\hline \multirow[t]{2}{*}{ Thermal Conductivity } & Multiple Thermocouple & $\begin{array}{l}100-2000{ }^{\circ} \mathrm{C} \text {, depending on } \\
\text { thermocouple type }\end{array}$ & $2-8 \%$ \\
\hline & Hot Wire Needle Probe & $\begin{array}{c}100-2000^{\circ} \mathrm{C} \text {, depending on } \\
\text { materials selected }\end{array}$ & $2 \%$ \\
\hline \multirow[t]{2}{*}{$\begin{array}{l}\text { Density / Geometry } \\
\text { Changes }\end{array}$} & $\begin{array}{c}\text { Length - Linear Variable } \\
\text { Differential Transformers } \\
\text { (LVDTs) }\end{array}$ & up to $500{ }^{\circ} \mathrm{C}^{\mathrm{b}}$ & $1-10 \mu \mathrm{m}$ \\
\hline & Diameter - Diameter Gauge & up to $500^{\circ} \mathrm{C}^{\mathrm{b}}$ & $1-10 \mu \mathrm{m}$ \\
\hline Crack Initiation /Growth & $\begin{array}{l}\text { Crack Length - Direct Current } \\
\text { Potential Drop (DCPD) Method }\end{array}$ & $350{ }^{\circ} \mathrm{C} / 2250 \mathrm{psia}$ & $\sim 20 \%$ \\
\hline Young's Modulus & Loaded Creep Specimen & up to $500{ }^{\circ} \mathrm{C}^{\mathrm{b}}$ & $\sim 10 \%$ \\
\hline \multirow[t]{2}{*}{ Fission Gas/Pressure } & Sampling & Numerous isotopes & Unknown \\
\hline & Pressure gauge & $\begin{array}{c}15 \text { bar (220 psi) to } 70 \text { bar (1020 } \\
\text { psi) }\end{array}$ & $\begin{array}{c} \pm 0.2 \text { bar (2.9 psi) to } \pm 0.5 \text { bar ( } 7.3 \\
\text { psi) }\end{array}$ \\
\hline \multirow[t]{3}{*}{ Flux - Thermal } & Flux wires / Foils & Material dependent & $\sim 10 \%$ \\
\hline & SPNDs & Dependent on emitter & $\sim 1-10 \%{ }^{\mathrm{c}}$ \\
\hline & Fission Chambers & Dependent on fissile deposit & $\sim 1-10 \%{ }^{\mathrm{c}}$ \\
\hline \multirow[t]{2}{*}{ Fast } & Flux wires / Foils & Material dependent & $\sim 1-10 \%$ \\
\hline & Fission Chambers & Dependent on fissile deposit & $\sim 1-10 \%$ \\
\hline
\end{tabular}

a. Prior in-pile use typically limited to short duration, fuel damage tests.

b. Some loss of accuracy at $350{ }^{\circ} \mathrm{C}$ due to Curie temperature effects, unless developmental LVDTs are deployed.

c. Accuracy decreases with use. 
Within the FCRD program, a workshop was held in November 2010 to identify candidate advanced technologies that could provide additional parameters with enhanced resolution and accuracy that are not currently measured during fuel irradiations. ${ }^{1}$ During the workshop, international experts from industry, academia, and research organizations discussed possible criteria and agreed to rank candidate technologies using the following five items:

- Potential to detect parameters with desired accuracy. A noted objective of the FCRD effort is to develop instrumentation capable of unprecedented accuracy and resolution for obtaining the data needed to characterize three-dimensional changes in fuel microstructure during irradiation testing. Many of the candidate technologies offer the potential for improved detection of the 'higher priority' parameters (e.g., thermal properties, cracking, porosity, etc.) identified by fuel modeling experts. However, experts agreed that there were limited sensor technologies offering the potential to directly detect changes in fuel microstructure during irradiation testing, which is the highest priority in the FCRD program.

- Potential to detect desired parameters in prototypic conditions (environment, temperature, etc.). Although experts recognized that some tests could be performed in non-prototypic conditions (e.g., metallic fuel surrounded by inert gas), it was agreed that such tests must be carefully planned to demonstrate their applicability. Hence, sensors that have the potential to provide data in prototypic conditions were ranked more highly.

- Versatility. Reference 1 identifies several parameters desired by fuel modeling experts. However, the size of irradiation tests limits the number of sensors that can be installed in a single test. Hence, experts viewed a single probe that can be used to detect a parameter at multiple locations more favorably. Likewise, from a funding perspective, a single technology that can provide data for detecting multiple parameters was ranked more highly because it offers the FCRD effort more opportunities.

- Ease of Installation. Instrumented test rigs are complicated. The ease with which a sensor can be installed is another important consideration. Clearly, sensors are more desirable (and ranked more highly) if they can be installed without concerns about bends, breakage, special connectors, or a line of sight.

- Technology Readiness (demonstrated in-pile experience to obtained desired accuracy under desired conditions). Funding resources for the FCRD instrumentation development effort are limited. Technologies are less desirable if they require large investments to overcome large technology hurdles prior to deployment. Although experts deemed that all of the technologies described would require some investment to assess their viability for in-pile testing, experts favored technologies that could be deployed with less investment.

Results indicate that experts favored more mature technologies. Specifically, experts emphasized that existing research demonstrates that ultrasonic technologies offered the potential for some quick successes. For example, prior use of ultrasonic thermometers suggest that a single probe could be used to obtain a temperature profile with accuracies and resolutions not possible with existing technologies.

Experts also favored technologies that could obtain the desired data under prototypic conditions and if they offered the potential to detect most, if not all, of the parameters requested by fuel modeling experts. For example, ultrasonic sensors were ranked higher because of their potential to detect desired parameters in metallic fuel surrounded by sodium and in oxide fuel surrounded by helium for the range of temperatures of interest.

Experts also ranked technologies more highly if they offered the potential for 'diverse' parameter detection. For example, initial research investments in ultrasonic technologies could lead to methods that could 
ultimately be used to detect a wide range of parameters (e.g., physical and environmental parameters). Based on results from this workshop, efforts to develop one ultrasonic sensor, an ultrasonic thermometer, was initiated by the FCRD program.

Nevertheless, several key obstacles were identified by the experts at this workshop that must be overcome prior to wide-range deployment of ultrasonics-based instrumentation for irradiation testing. Specifically, it was observed that additional irradiation testing was needed to assess the survivability of ultrasonics transducers and that enhancements were needed with respect to signal processing software to improve the accuracy and ease of use for in-pile applications of ultrasonics technologies. The NEET tasks described in this report document initial results to address these needs. 


\section{TASK 1: ULTRASONIC TRANSDUCER IRRADIATION TEST}

Task 1 of this project supports efforts to develop a test capsule design and define irradiation conditions for evaluating most promising candidate piezoelectric and magnetostrictive transducer materials and designs. From the onset of this effort, an instrumented lead test was proposed, such that real time signals are received from the transducers being tested. Collecting real time signals will enable an accurate measure of the performance and possible degradation of candidate transducer and sensor materials under irradiation. In addition, laboratory testing will be completed to verify that transducer materials will survive anticipated thermal conditions.

During the first year of this project, it was announced that a PSU proposal, which was developed in conjunction with this NEET effort, for an ultrasonic transducer irradiation had been selected by the ATR NSUF for irradiation in the Massachusetts Institute of Technology Nuclear Research Reactor (MITR). Hence, this task is currently focused on supporting this irradiation. This section documents the status of this effort. Specifically, some background on the need for this test is first discussed. Then, a brief overview of the irradiation conditions is provided. Next, the current status of the proposed capsule design and selected test materials are summarized. In addition, proposed PIE to support this test are identified. Finally, the proposed laboratory tests that would be performed prior to and during the irradiation to provide insights about data obtained from this irradiation are provided.

\subsection{Background}

There is a need to improve the ability to characterize and track the evolution of nuclear fuel properties, especially in MTRs. Ultrasonic measurements have a long and successful history of use for materials characterization, including detection and characterization of degradation and damage. ${ }^{25}$ PIEs have successfully shown that fuel microstructural parameters, such as porosity and grain size, can be correlated to ultrasonic velocity. ${ }^{26}$ According to Villard, ${ }^{27}$ frequency requirements for such measurements are restricted to greater than $10 \mathrm{MHz}$. However, lower frequencies can be used for some applications, such as ultrasonic thermometry, where frequency requirements may be $100-150 \mathrm{kHz}$ or lower. ${ }^{28}$

The development of ultrasonic tools to perform a variety of in-pile measurements requires a fundamental understanding of the behavior of ultrasonic transducer materials in high-radiation environments. While a number of irradiation studies of ultrasonic transducers have been described in the literature, a one-to-one comparison of these studies is difficult, as the materials and irradiation test conditions often differ. In addition, the tests to date are generally at lower flux/fluences than what might be seen in US MTRs (see Section 2). As a result, a series of experiments to baseline the performance of ultrasonic transducer materials (in terms of change in sensitivity as a function of temperature and irradiation) are necessary to support the irradiation test.

Results of this irradiation test will enable development of ultrasonic sensors for in-pile measurements, including fuel and material morphology changes, fission gas composition and pressure measurements, fuel and material geometry changes, and temperature. Results from these tests will provide a method for selecting optimum ultrasonic transducer materials for different in-pile measurements and guide the development of signal processing tools to enhance the measurement to demonstrate the intended in-pile measurements.

\subsection{MITR Test Conditions}

As noted above, the ultrasonics transducer irradiation will be performed in the MITR. Relevant MITR design information is summarized here to provide perspective about the design of the ultrasonics transducer capsule and test conditions developed by this project. Additional MITR information may be found in Appendix A. 
The MITR is a tank-type research reactor. ${ }^{29}$ It is currently licensed for 5 MW and is being relicensed for 6 MW operation. The identified irradiation position and flux condition at the MITR are summarized in Table $3-1$.

Table 3-1. Representative dimensions and flux levels in MITR.

\begin{tabular}{|c|}
\hline MITR In-Core Experimental Facility \\
\hline $\begin{array}{c}\text { Irradiation tube for sample capsule irradiation or isotope production (instrumented or } \\
\text { unistrumented.) }\end{array}$ \\
\hline Coolant loops that replicate conditions in both pressurized and boiling reactors. \\
\hline Facilities for testing mechanical properties of samples in a light water reactor environment. \\
\hline $\begin{array}{c}\text { High temperature irradiation facility for materials irradiations in inert gas }(\mathrm{He} / \mathrm{Ne} \text { mix) at HTGR } \\
\text { temperatures. }\end{array}$ \\
Size: \\
Space for 3 capsules \\
Max in-core volume $\sim 46$ mm ID x $610 \mathrm{~mm}$ long \\
Neutron Flux (n/cm $\left.{ }^{2}-\mathrm{s}\right):$ \\
Thermal: $\sim 3 \times 10^{13}$ \\
Fast: up to $1 \times 10^{14}(\mathrm{E}>0.1 \mathrm{MeV})$ \\
\hline
\end{tabular}

The ATR-NSUF/PSU test capsule will have a $46 \mathrm{~mm}$ diameter and $610 \mathrm{~mm}$ length. Temperature control will be afforded by a helium/neon gas gap with adjustable gas composition. The proposed test temperature will be approximately $300{ }^{\circ} \mathrm{C}$. It is proposed that the test exceed fast neutron fluences of prior piezoelectric transducer irradiations (e.g., $>1 \times 10^{21} \mathrm{n} / \mathrm{cm}^{2}$ ). In order to observe rapid changes at relatively low fluences, it is proposed to start the test with the reactor coming to power slowly. Hence, it is anticipated that the capsule will be irradiated for at least 310 days. Additional details related to the proposed test conditions and capsule design are found in Section 3.6.

\subsection{Proposed Capsule Design}

As noted in Section 3.2, the expected test conditions are as follows:

- Temperature: $300{ }^{\circ} \mathrm{C}-350{ }^{\circ} \mathrm{C}$,

- Fast Flux (>1 MeV): $4 \times 10^{13} \mathrm{n} / \mathrm{cm}^{2} * \mathrm{sec}$,

- Gas Environment: Helium (possibly including a small amount of neon for temperature control)

- $\quad$ Testing Period: 310 Effective Full Power Days requiring approximately 540 calendar days (18 months) to accomplish.

The MITR configuration restricts the test capsule to a cylinder $46 \mathrm{~mm}$ in diameter and $610 \mathrm{~mm}$ in length. The currently proposed capsule design uses structural graphite as a holder material. Graphite is an ideal material as it has low density (for reduced gamma heating), it is thermally conductive (to produce a uniform predictable temperature), low neutron activation, and has a high melting temperature. The graphite will hold the test specimens in place while also efficiently conducting heat generated during the test to the coolant. Based on estimated space requirements for each transducer, it is proposed to include six piezoelectric samples and three magnetostrictive samples. Each sample would be encapsulated separately (this will allow samples with cobalt to be easily separated from the other samples, such that all non-cobalt bearing samples may undergo PIE). It may be advantageous to place transducers at each end of the waveguides used for monitoring signals, as this effectively doubles the number of samples included in the test. Recom- 
mended instrumentation for this test should be included to allow accurate monitoring of temperature, gamma heating, and both fast and thermal neutron flux. It is advised to include at least two sensors of each type, both to increase the accuracy of the measurements and for redundancy in the case that some instruments may be damaged during the test. A conceptual drawing of the proposed test capsule is shown in Figure 3-1.
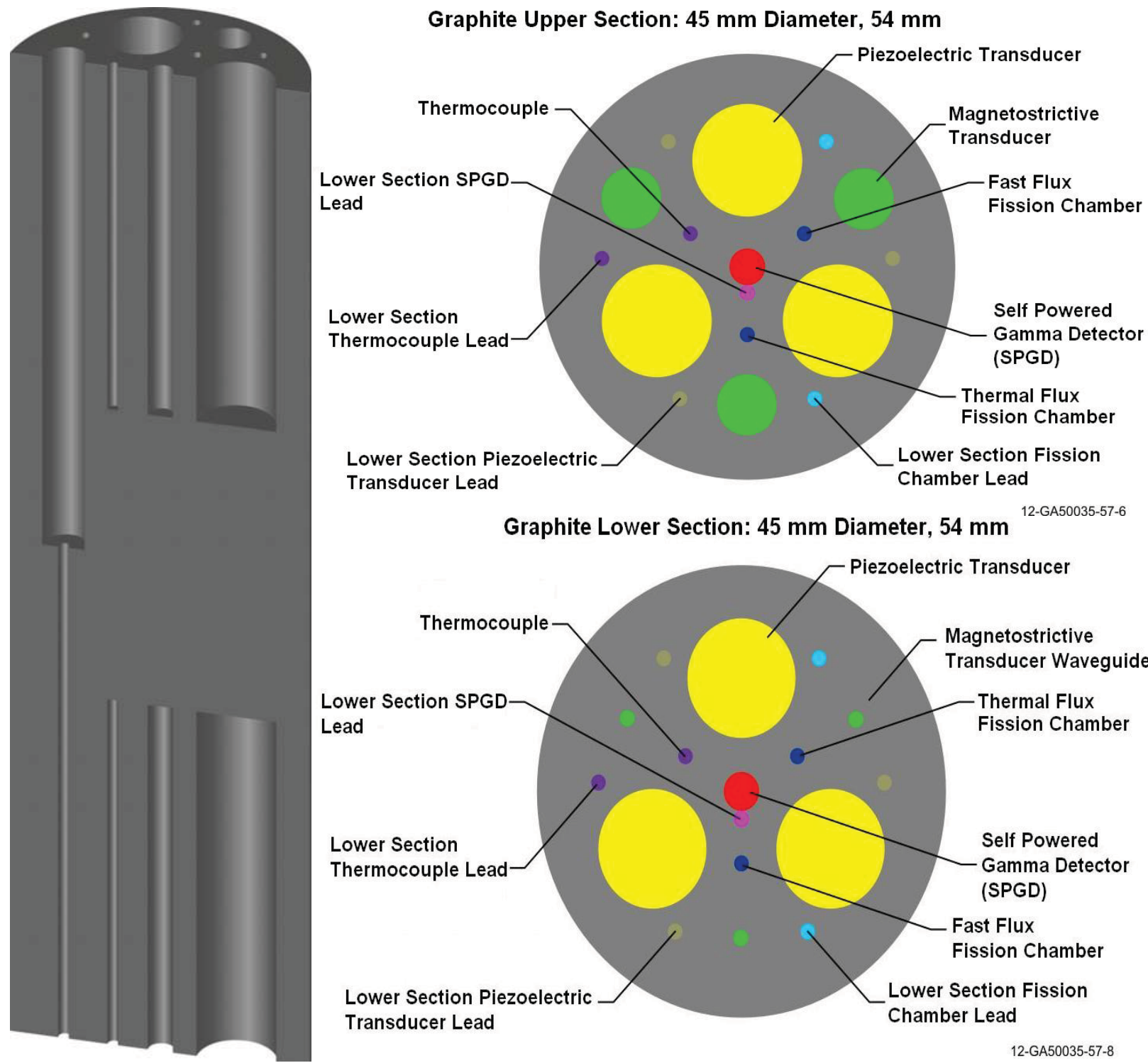

12-GA50035-57-8

Figure 3-1. Conceptual sketch of graphite sample holder.

\subsection{Candidate Transducers}

To generate and receive ultrasonic pulses and signals, the two most commonly used methods are either piezoelectric or magnetostrictive materials. Ultrasonic measurements using piezoelectric transducers have been demonstrated over a wide frequency range from $\mathrm{kHz}$ and up to $\mathrm{GHz}$; however, most non-destructive examination (NDE), materials characterization, and process monitoring are performed in the range from 1-20 MHz, making piezoelectric transduction ideal. The current capabilities of magnetostrictive transduc- 
ers are typically limited to operation at frequencies up to the order of $100 \mathrm{kHz}$, though recent research suggests that higher frequencies may be possible for small transducers. However, mechanical coupling as well as enhanced guided wave mode generation makes magnetostrictive transduction ideal for low frequency measurements, such as ultrasonic thermometry. ${ }^{30}$ Therefore, radiation tolerant sensors which utilize piezoelectric or magnetostrictive materials are being considered as candidates for instrumentation and US MTR testing.

Prior studies have shown that typical piezoelectric and magnetostrictive materials used in transducers degrade when subjected to high temperature and radiation. ${ }^{31-36}$ Candidate magnetostrictive and piezoelectric materials must, therefore, be carefully selected; and transducer assemblies must be carefully designed. As discussed below, only limited radiation effects data are available to guide this process.

Additional studies and tests are needed to select the optimum transducer materials for various in-pile ultrasonic sensors. The MITR irradiation test and associated laboratory supported by this project will provide important information for selecting appropriate transducers for ultrasonic sensors.

The remainder of this subsection identifies what transducer materials are proposed for inclusion in this irradiation test and the justification for including them.

\subsubsection{Piezoelectric}

\subsubsection{Background}

The active component of an ultrasonic imaging system is the piezoelectric element, which serves as both the acoustic pulse generator (transmitter) and detector (receiver). It usually consists of a single crystal or piezoelectric ceramic that will contract/expand and create a propagating compression or shear wave when pulsed by an electric field. This wave is coupled through a faceplate and into the transmitting medium, for example, water or molten metals. To minimize beam diameter and enhance detection resolution, the faceplate may incorporate a concave focusing lens. An acoustically attenuative damping material is coupled behind the crystal to attenuate back-propagating waves, to damp the piezoelectric element, and to improve its time response and bandwidth.

The piezoelectric transducers proposed for this test were selected based on research by Parks and Tittmann $^{37}$ and from early ultrasonic sensors developed at the Hanford Engineering Development Laboratory (HEDL) ${ }^{38}$ for under-sodium viewing which shared many similar constraints with respect to thermal and neutron radiation tolerance. Schematics of the transducers used by HEDL and Parks and Tittmann ${ }^{37}$ are shown in Figure 3-2 a) and b) respectively, and the preliminary transducer design for ATR insertion is shown in Figure 3-2 c). Both transducers rely on spring loading pressure for coupling the piezoelectric element to the faceplate or test piece. Electrical contact with the piezoelectric element is also achieved through application of pressure. A backing layer behind the piezoelectric sensor provides damping and prevents excessive "ringing" of the transducer. In the design of Parks and Tittmann, ${ }^{37}$ the backing layer material is carbon/carbon composite, whereas some other designs incorporate a stainless steel "sponge".

\subsubsection{Desirable Attributes}

There are a variety of piezoelectric materials, both crystalline and ceramic, that can be used to produce the sound energy radiated by ultrasonic transducers. Some piezoelectric elements that can operate in hostile environments, specifically those encountered in fast liquid-metal cooled reactors, have been under investigation. ${ }^{39,40}$ The properties of most relevance to in-pile measurements include maximum operating temperature, sensitivity, and resistance to radiation damage. Adding different dopants to a ceramic formulation creates either metal (cation) vacancies or oxygen (anion) in the crystal structure and generates so-called "soft" and "hard" ceramics, respectively. It has been noted that "hard" piezoelectric materials are the most 
(A)

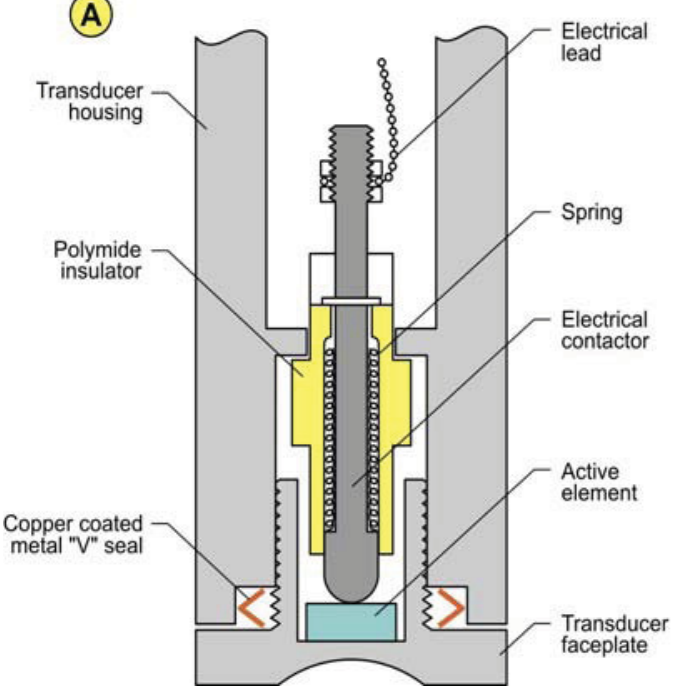

(B)

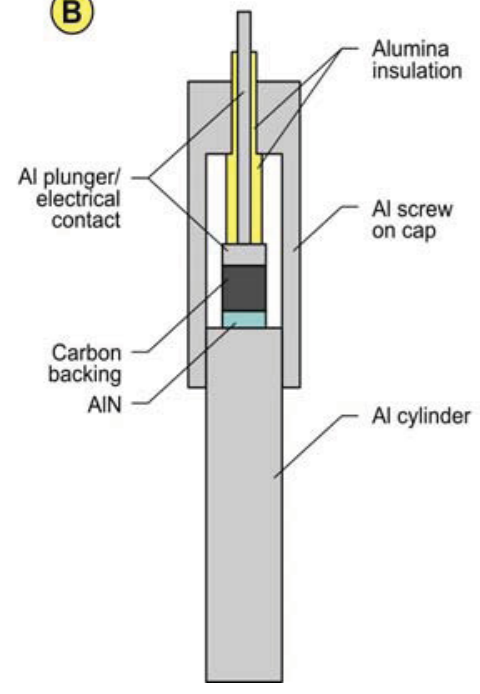

(C)

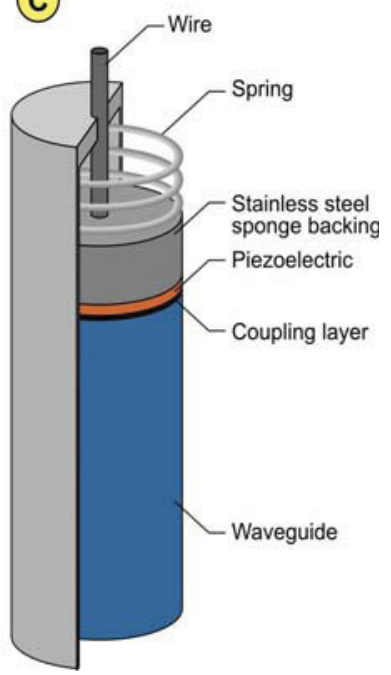

Figure 3-2. Piezoelectric transducer designs

radiation resistant. 41 "Hard" ceramics have characteristics generally opposite those of "soft" ceramics, including higher Curie temperatures, small piezoelectric charge constants, large electromechanical coupling factors, and large mechanical quality factors. Generally "hard" ceramics are more stable and compatible with high mechanical loads and high voltages but cannot produce the same large displacements as "soft" ceramics. Consequently, "hard" ceramics are used better in power applications, rather than in sensing applications. Thus, when choosing a ceramic for a particular application, it can be useful to look beyond general categorization, and carefully compare specific characteristics. The characteristics comparison between "soft" and "hard" is listed in Table 3-2.

Table 3-2. Characteristics of "hard" and "soft" ceramic materials.

\begin{tabular}{|c|c|c|}
\hline Characteristic & "Soft" Ceramic & "Hard" Ceramic \\
\hline Piezoelectric Constants & Larger & Smaller \\
\hline Permittivity & Higher & Lower \\
\hline Dielectric Constants & Larger & Smaller \\
\hline Dielectric Losses & Higher & Lower \\
\hline Curie Temperature & Lower & Higher \\
\hline Electromechanical Coupling Factors & Larger & Smaller \\
\hline Electrical Resistance & Very High & Lower \\
\hline Mechanical Quality Factors & Low & High \\
\hline Coercive Field & Low & High \\
\hline Linearity & Poor & Good \\
\hline Polarization/Depolarization & Easier & More Difficult \\
\hline Radiation Resistance & Lower & Higher \\
\hline
\end{tabular}


In addition, the selected piezoelectric materials should not contain any atomic species with large neutron absorption cross sections, if transmutation of these species will cause performance degradation. For example, although Lithium Niobate $\left(\mathrm{LiNbO}_{3}\right)$ is commonly used at high temperatures, it is not considered an ideal candidate material due to the exceptionally large absorption cross section of ${ }^{6} \mathrm{Li}(\mathrm{n}, \alpha)^{3} \mathrm{H}$, which was shown to render this material nearly amorphous and have a dramatic reduction in the piezoelectric response. ${ }^{35}$ In general, the effects of radiation on ceramics are different from that for metals and are less well understood. ${ }^{42}$ Moreover, typical studies on radiation tolerance of ceramic materials focus on mechanical, thermal, optical and/or dielectric properties; and the radiation effects on piezoelectric material have received inordinately little attention, particularly given their potential impact on a range of measurement applications. The existence of ionic and covalent bonding is a primary cause of the increased complexity in the radiation response of ceramics.

There have been impressive steps towards a quantitative theoretical prediction of radiation tolerance in ceramic materials. Specifically, models have been developed to predict the materials resistance to amorphization, which is of primary concern, as opposed to point defects and defect aggregates. Hobbs, et. al. ${ }^{42}$ have shown a strong correlation between the topology of the crystal structure and radiation tolerance. However, these methods must be used with caution. For example, it is quite possible that a material like $\mathrm{LiNbO}_{3}$ could be considered resistant to amorphization due to the ionic character of the chemical bond which favors long range order. However, the large absorption cross-section of ${ }^{6} \mathrm{Li}$, the associated high-energy products and corresponding chemical changes render the material intolerant to thermal neutron radiation.

While selecting piezoelectric material, it is also important to consider its Q-factor. Higher Q-factor causes longer ring down time and narrow frequency range. Therefore, materials with high Q-factor are better transmitters. Table 3-3 shows the relationship between transducer performance and Q-factor. Be aware, however, that a high Q-factor material can be prepared to exhibit some characteristics approaching those of a low Q-factor material, or vice versa. Thus, when choosing a ceramic for a particular application, it can be useful to look beyond general categorization, and carefully compare specific characteristics.

Table 3-3. Characteristics of High-Q and Low-Q piezoelectric materials.

\begin{tabular}{|c|c|}
\hline High-Q & Low-Q \\
\hline Longer ring-down time & Shorter ring-down time \\
\hline Narrow frequency range & Wide frequency range \\
\hline Better transmitters & Better receivers \\
\hline Used in CW Doppler and therapy & Used in pulse-echo imaging \\
\hline
\end{tabular}

The properties of most relevance to in-pile measurements include maximum operating temperature, sensitivity, and resistance to radiation damage, with the choice of materials resulting in a trade-off between these properties. For the range of possible materials, some of these properties have been determined and are readily accessible. For instance, $\mathrm{T}_{\mathrm{c}}$ (from which maximum operating temperature can be inferred), and electromechanical coupling coefficient are known for many piezoelectric materials. On the other hand, less commonly used and novel piezoelectric materials, such as Aluminum Nitride (AlN), are not yet well characterized. Data related to the radiation resistance of nearly all materials are incomplete; and data have seldom been reported under the same conditions, making comparisons hard or even impossible. 


\subsubsection{Candidate Materials and Selection Process}

A summary of commercially available high-temperature transducer materials and their electrical/ mechanical properties appears in Table 3-4. Several materials in Table 3-4, such as $\mathrm{AlN}, \mathrm{ZnO}$, and $\mathrm{Bi}_{3} \mathrm{TiNbO}_{9}$, do not have large transmutation reaction cross-sections and are reported as radiation tolerant. However, these materials have high Q-factor as Quartz and are widely used as thin-film type microsensor, such as surface acoustic wave (SAW) and membranes, for high temperature sensing applications. Other materials listed in Table 3-4, such as PZT-5A, K-15, and K-81, with moderate operating temperature and lower Q-factor have been used for NDE and sensing applications in molten metals. Lead zirconate titanate (PZT) has been shown to demonstrate excellent damage resistance both to neutrons ${ }^{43}$ and gamma radiation. ${ }^{44}$ Recently Kazys ${ }^{45}$ has reported on the development of high-temperature, radiation-resistant transducers of bismuth titanate for use in the lead-bismuth cooled MYRRHA accelerator-driven non-critical fission core reactor. The ultrasonic transducers pursued for metal cooled fast reactor applications are of either the sintered ceramic type (e.g., PZT) or single crystal (e.g., lithium niobate) ${ }^{46,47}$ operating in compression mode. Maximum operating temperature is generally restricted to one half the transition temperature.

Table 3-4. Characteristics of candidate piezoelectric materials.

\begin{tabular}{|c|c|c|c|c|c|c|c|c|}
\hline Material & $\begin{array}{c}\text { Transition } \\
\text { Temperature, } \\
{ }^{\circ} \mathrm{C}\end{array}$ & $\begin{array}{l}\text { Transition } \\
\text { Type }\end{array}$ & Q Factor & $\begin{array}{c}d_{33} \\
(m / V)^{*} 10^{-12}\end{array}$ & $\begin{array}{c}g_{33} \\
(\mathrm{Vm} / \mathrm{N})^{*} 10^{3}\end{array}$ & $\begin{array}{c}\text { Acoustic } \\
\text { Impedance, } \\
\mathrm{gm} / \mathrm{cm}^{2}-\mathrm{s}\end{array}$ & $\begin{array}{c}\text { Problematic } \\
\text { Atomic Species } \\
\text { (ENDF) }\end{array}$ & $\begin{array}{c}\text { Radiation } \\
\text { Tolerant }\end{array}$ \\
\hline Quartz & 550 & $\begin{array}{c}\text { Curie } \\
\text { Temperature }\end{array}$ & 10,000 & 2 & 50 & 15 & & \\
\hline $\begin{array}{c}\text { Y-Cut } \mathrm{LiNbO}_{3} \\
\text { (Lithium Niobate) }\end{array}$ & $1050-1210^{48}$ & $\begin{array}{c}\text { Curie } \\
\text { Temperature }\end{array}$ & 100 & 6 & 23 & 32 & Li-6 & no ${ }^{35}$ \\
\hline $\begin{array}{c}\text { PZT-5A (Lead } \\
\text { Zirconate Titanate) }\end{array}$ & 365 & $\begin{array}{c}\text { Curie } \\
\text { Temperature }\end{array}$ & 75 & 375 & 25 & 29 & & \\
\hline $\begin{array}{l}\text { K-15 (Bismuth } \\
\text { Titanate) }\end{array}$ & 600 & $\begin{array}{c}\text { Curie } \\
\text { Temperature }\end{array}$ & 100 & 18 & 10 & $\leq 29$ & & \\
\hline $\begin{array}{c}\text { K-81 (Lead } \\
\text { Meta-niobate) }\end{array}$ & 400 & $\begin{array}{c}\text { Curie } \\
\text { Temperature }\end{array}$ & 15 & 85 & 32 & 20 & & \\
\hline Z-Cut Tourmaline & 1800 & $\begin{array}{c}\text { Curie } \\
\text { Temperature }\end{array}$ & & 1.8 & & & & \\
\hline $\begin{array}{l}\text { AlN (Aluminum } \\
\text { Nitride) }\end{array}$ & $2200^{49}$ & Melt & 5000 & $0.2^{50}$ & & & & yes 51 \\
\hline $\begin{array}{l}\mathrm{GaPO}_{4} \text { (Gallium } \\
\text { Orthophosphate) }\end{array}$ & $970^{52}$ & $\alpha-\beta$ & $\sim 10,000$ & $0.16^{52}$ & & & & no $^{51}$ \\
\hline $\begin{array}{c}\mathrm{Bi}_{3} \mathrm{TiNbO}_{9} \\
\text { (Bismuth Titanate } \\
\text { Niobate) }\end{array}$ & $909^{52}$ & $\begin{array}{c}\text { Curie } \\
\text { Temperature }\end{array}$ & & & & & & yes 53 \\
\hline$\left[\mathrm{RECa}_{4} \mathrm{O}\left(\mathrm{BO}_{3}\right)_{3}\right]^{52}$ & 1500 & Melt & & $0.06-0.31$ & & & B-10 & \\
\hline $\mathrm{ZnO}$ (Zinc Oxide) & $>1500$ & & & $9.93^{54}$ & 0.4 & 15.88 & & yes 51 \\
\hline $\begin{array}{c}\mathrm{La}_{3} \mathrm{Ga}_{5} \mathrm{SiO}_{14} 55 \\
(\mathrm{LGS})\end{array}$ & 1470 & melt & & & & & & no 51 \\
\hline
\end{tabular}




\subsubsection{Material Selection}

Due to volume limitations in the proposed tests, the number of piezoelectric transducer materials that can be included in this test is limited. This section describes the logic used to prioritize candidate piezoelectric transducer materials for inclusion in the MITR irradiation.

\section{Aluminum Nitride (AlN)}

Aluminum nitride is a relatively new material, as far as bulk single crystals are concerned. In fact, the work of Parks and Tittmann ${ }^{37}$ with this material is the first of its sort. In the past, thin film AlN has been shown to be unaffected by gamma irradiation up to $18.7 \mathrm{MGy}{ }^{45}$ and temperatures of $1000{ }^{\circ} \mathrm{C} .{ }^{56,57}$ Moreover, this material has been explicitly cited in numerous independent studies as a highly radiation tolerant ceramic. ${ }^{51}$

Further, tests of bulk single crystal AIN in a TRIGA nuclear reactor core showed this material to be completely unaffected by a fast and thermal neutron fluence of $1.85 \times 10^{18} \mathrm{n} / \mathrm{cm}^{2}$ and $5.8 \times 10^{18} \mathrm{n} / \mathrm{cm}^{2}$ respectively and a gamma dose of $26.8 \mathrm{MGy} .{ }^{37}$ This work along with that of Yano ${ }^{58}$ and Ito $^{59}$ have indicated that the ${ }^{14} \mathrm{~N}(\mathrm{n}, \mathrm{p}){ }^{14} \mathrm{C}$ is not of concern, and $\mathrm{AlN}$ is an excellent candidate material.

\section{Bismuth Titanate Niobate $\left(\mathrm{Bi}_{3} \mathrm{TiNbO}_{9}\right)$}

The literature review has revealed bismuth titanate niobate to be the most promising material tested to date. ${ }^{53}$ However, this material lost roughly $60 \%$ of its one way piezoelectric response at a fast neutron fluence of $10^{20} \mathrm{n} / \mathrm{cm}^{2}$; and as such, it is not appropriate. The decrease in the signal response is in agreement with the statements provided in Reference 51, which indicates that disordered Ti-O-Ti bridges of highly covalent character form in titanates when subjected to ballistic radiation effects. Regardless, given that this material has shown the greatest promise to date, it has been selected as a baseline in this irradiation test.

\section{Rare Earth Oxy-Borates $\left(\mathrm{ReCa}_{4} \mathrm{O}\left(\mathrm{BO}_{3}\right)_{3}\right)$}

This material class has the added appeal of having only one solid phase, a property shared with AlN and Langasite. However, the boron is problematic due to its large thermal neutron cross section. Hence, this material has been eliminated as a candidate.

\section{Zinc Oxide (ZnO)}

Zinc oxide is found in the Wurzite structure, as is AlN, and has been cited as a highly radiation tolerant material. ${ }^{51}$ The evaluated nuclear data files (ENDF) do not show any detrimental nuclear cross sections, and this material possesses a high transition temperature and moderate piezoelectric coupling. If $\mathrm{ZnO}$ can be proven effective as a high temperature piezoelectric transducer, $\mathrm{ZnO}$ should be included in the proposed test.

\section{Langasite $\left(\mathrm{La}_{2} \mathrm{Ga}_{5} \mathrm{SiO}_{14}\right)$}

Langasite, as a silicate, is not likely to be radiation tolerant. ${ }^{51}$ Moreover, the longitudinal mode is not commonly utilized with this material, and it appears better suited for SAW applications.

\section{Lithium Niobate ( $\left.\mathrm{LiNbO}_{3}\right)$}

This ferroelectric material is ubiquitous in the realm of high temperature piezoelectric materials, due to its early discovery and high coupling. The coupling coefficient weighs in at 0.49 for $k_{t}$ of the $36^{\circ}$ rotated Y-cut crystal. There has been much interest concerning the high temperature limitations below the Curie temperature. It has been said that the ionic conductivity limits the operable range to the range of $450{ }^{\circ} \mathrm{C}$ to $550{ }^{\circ} \mathrm{C} .{ }^{31}$ However, commercial accelerometers based on $\mathrm{LiNbO}_{3}$ have been rated for continuous operation up to $650{ }^{\circ} \mathrm{C} .{ }^{60} \mathrm{LiNbO}_{3}$ at $1000{ }^{\circ} \mathrm{C}$ has been used in laboratory tests as an ultrasonic transducer. ${ }^{61}$ 
The primary concern regarding $\mathrm{LiNbO}_{3}$ in a reactor core appears to be the ${ }^{6} \mathrm{Li}(\mathrm{n}, \alpha)^{3} \mathrm{H}$ reaction with thermal neutrons. This is allegedly overcome by way of isotope tailoring, ${ }^{31}$ but the data are unavailable. Therefore, $\mathrm{LiNbO}_{3}$ is eliminated from consideration.

\section{Gallium Phosphate $\left(\mathrm{GaPO}_{4}\right)$}

This material has been shown to degrade in a gamma radiation field by Kazys. ${ }^{45}$ Additionally, phosphates have been shown to be readily amorphized at room temperature, and this is attributed to the highly covalent P-O bonding. ${ }^{51}$ Gallium phosphate was eliminated as a candidate material, given its susceptibility to radiolysis and amorphization.

\section{Selected Candidate Materials}

The list of candidate materials has, therefore, been reduced to several, higher priority candidate materials: $\mathrm{AlN}, \mathrm{Bi}_{3} \mathrm{TiNbO}_{9}$, and $\mathrm{ZnO}$. At this time, it is planned to include these piezoelectric materials in this irradiation test.

\subsubsection{Magnetostrictive}

\subsubsection{Background}

The use of magnetostrictive transducers in MTRs has been suggested to measure temperature, ${ }^{62,63}$ liquid level, density, flow, pressure, bubble occurrence and location, and acoustic emissions. ${ }^{64,63}$ Mechanical coupling as well as enhanced guided wave mode generation makes magnetostrictive transduction ideal for low frequency measurements, such as ultrasonic thermometry. ${ }^{30}$ Deployment of these types of sensors has been successful for MTRs for high temperature measurements (up to $2800{ }^{\circ} \mathrm{C}$ ), but limited to short-duration severe fuel damage tests. This clearly overcomes temperature limitations of alternative real-time MTR temperature sensors, such as thermocouples, which can experience electrical shunting at temperatures exceeding $1800{ }^{\circ} \mathrm{C} .{ }^{65}$ Although ultrasonic thermometers with magnetostrictive transducers have been deployed in MTRs; they have not been used in-pile for long duration irradiations. The design of the magnetostrictive transducer selected for inclusion draws from the work of Lynnworth ${ }^{62}$ and Daw. ${ }^{65}$

\subsubsection{Magnetostrictive Material Candidates}

Many magnetostrictive materials are available for the use and fabrication of ultrasonic transducers. The properties of most relevance to in-pile measurements include maximum operating temperature, sensitivity, and resistance to radiation damage. Unlike many of the piezoelectric materials, magnetostrictive materials are primarily metal alloys. Observed effects of radiation on metals differ significantly from observed effects on ceramics. For example, investigations with magnetic Fe-Ni alloys, such as Permalloy, have shown that their magnetic permeability tends to decrease with neutron irradiation. ${ }^{66}$ This is attributed to the immobilization of domains due to point- defects generated by displacement cascades. In effect, this would limit the magnetostrictive capabilities of the material. However, magnetostrictive effects have been reported at fluence of up to $5 \times 10^{19} \mathrm{n} / \mathrm{cm}^{2} .63$

Magnetostrictive materials considered for testing may be generally categorized into three types: pure metals, alloys, and "giant" magnetostrictive materials. The pure metals include the ferromagnetic elements nickel, iron, and cobalt. Alloys typically consist of combinations of the pure magnetostrictive materials with other alloying materials, such as chromium. The "giant" magnetostrictive alloys are newer materials that have significantly improved magnetostrictive response. 


\subsubsection{Transducer Design Considerations}

A general schematic of a proposed magnetostrictive transducer is shown in Figure 3-3. The components of the transducer consist of the magnetostrictive wire, driving coil (with bobbin), biasing magnet (or, alternatively, biasing coil), and damper.

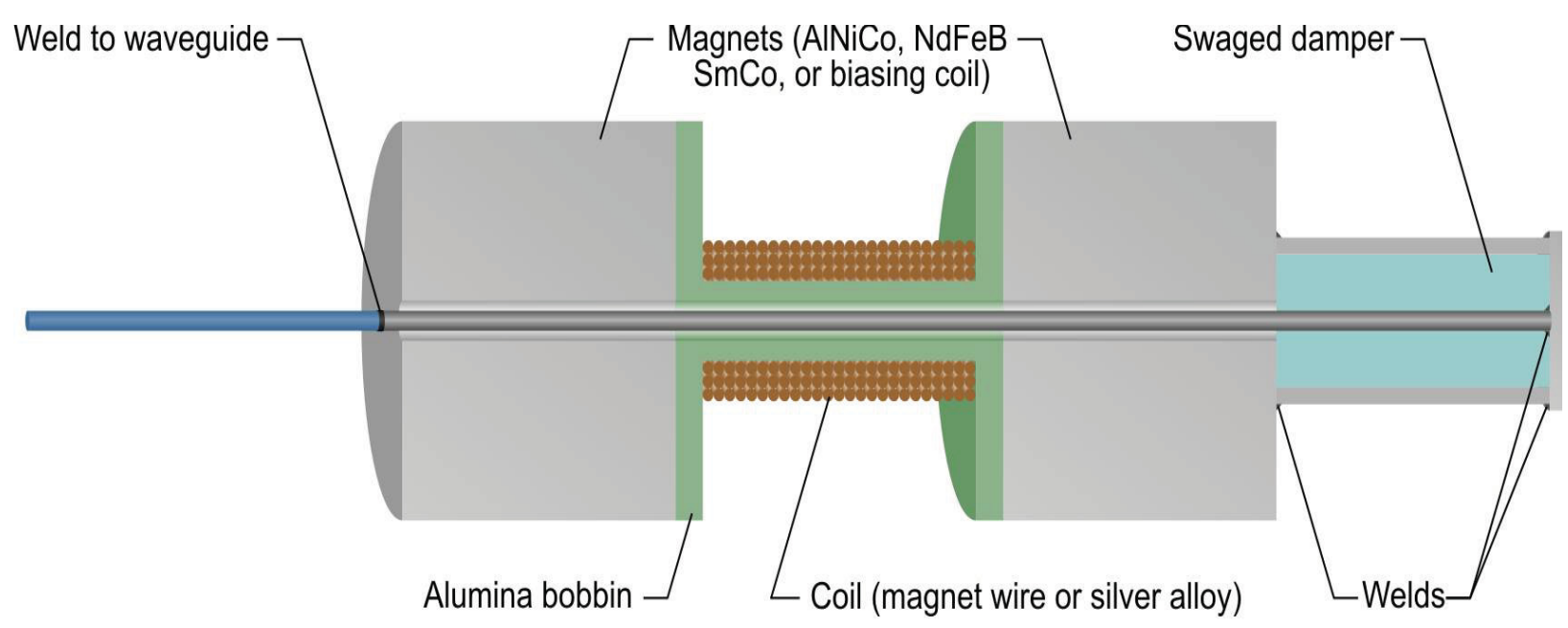

Figure 3-3. Magnetostrictive transducer schematic.

Most materials appropriate for use as biasing magnets contain constituent elements that are not well suited for use in a reactor environment. Typically, this means the presence of cobalt or with high thermal neutron capture cross sections, such as boron, samarium, or neodymium. The primary magnetic materials considered are Alnico (an aluminum-nickel-cobalt alloy), Nd-B-Fe (a neodymium-boron-iron ceramic), and Sm-Co (a samarium-cobalt ceramic). Key properties of these materials are listed in Table 3-5. Alnico provides the weakest magnetic field strength of these options, but it also has the highest Curie temperature. Activation of the cobalt is the primary concern with this material. Prior testing has shown that Alnico magnets can retain their field for at least half the accumulated fluence proposed for this test. Samarium cobalt magnets have high field strength and moderately high Curie temperatures. The concerns with this material are activation of the cobalt and transmutation of the samarium. Prior testing indicates that the nuclear environment does not strongly affect the performance of these magnets. The strongest magnets available are Nd-B-Fe. These magnets are not considered suitable as the Curie temperature is below the proposed test temperature. Another option for generating the biasing magnetic field is the use of a DC biasing coil. This option is not preferred as the coil may increase the volume of the transducer and would necessarily add an additional electrical lead to each magnetostrictive transducer.

Magnetostrictive and magnetic materials considered for this irradiation are summarized in Table 3-5.

Ranking of magnetostrictive materials indicates that materials are highly recommended (1), recommended depending on space considerations (2), or not recommended (3).

\subsubsection{Magnetostrictive Material Selection}

\section{Nickel}

Although nickel is widely used in nuclear applications (i.e. nickel alloys such as Inconel), the low Curie temperature $\left(358^{\circ} \mathrm{C}\right)$ makes it a poor magnetostrictive transducer candidate. 
Table 3-5. Characteristics of candidate magnetostrictive and magnet materials.

\begin{tabular}{|c|c|c|c|c|}
\hline Material & Composition & Key Properties & Comments & Rank \\
\hline Nickel & $100 \% \mathrm{Ni}$ & $\begin{array}{c}\text { 25-50 } \mu \text {-strain max. magnetostriction, CurieCurie } \\
\text { temperature } 358{ }^{\circ} \mathrm{C}\end{array}$ & $\begin{array}{l}\text { Pure metal, easy to acquire/ } \\
\text { manufacture, low } \\
\text { magnetostriction, low Curie } \\
\text { temperature }\end{array}$ & 2 \\
\hline Iron & $100 \% \mathrm{Fe}$ & $\begin{array}{c}\text { 10-20 } \mu \text {-strain max. magnetostriction, Curie } \\
\text { temperature } 770{ }^{\circ} \mathrm{C}\end{array}$ & $\begin{array}{l}\text { Pure metal, easy to acquire/ } \\
\text { manufacture, low } \\
\text { magnetostriction }\end{array}$ & 3 \\
\hline Cobalt & $100 \% \mathrm{Co}$ & $\begin{array}{l}\text { 50-60 } \mu \text {-strain max. magnetostriction, Curie } \\
\text { temperature } 1130{ }^{\circ} \mathrm{C}\end{array}$ & $\begin{array}{l}\text { Pure metal, easy to aquire, low } \\
\text { magnetostriction, cobalt present }\end{array}$ & 3 \\
\hline Remendur & $\begin{array}{l}49 \% \mathrm{Fe}-49 \% \mathrm{Co}- \\
2 \% \mathrm{~V}\end{array}$ & $\begin{array}{c}\text { 70-100 } \mu \text {-strain max. magnetostriction, Curie } \\
\text { temperature } 950^{\circ} \mathrm{C}\end{array}$ & $\begin{array}{l}\text { No longer manufactured, } \\
\text { identical/similar alloys available, } \\
\text { possible activation of cobalt }\end{array}$ & 1 \\
\hline Vacoflux 50 & $\begin{array}{l}49 \% \mathrm{Fe}-49 \% \mathrm{Co}- \\
2 \% \mathrm{~V}\end{array}$ & $\begin{array}{l}70 \mu \text {-strain max. magnetostriction, Curie temperature } \\
\qquad 950{ }^{\circ} \mathrm{C}\end{array}$ & Possible activation of cobalt & $\begin{array}{l}1 \text { (possible } \\
\text { replacement } \\
\text { for Remendur) }\end{array}$ \\
\hline Vacoflux 17 & $\begin{array}{c}81 \% \mathrm{Fe}-17 \% \mathrm{Co}- \\
2 \% \mathrm{Cr}\end{array}$ & $\begin{array}{l}25 \mu \text {-strain max. magnetostriction, Curie temperature } \\
\qquad 920{ }^{\circ} \mathrm{C}\end{array}$ & Possible activation of cobalt & 3 \\
\hline Arnakrome 3 & $\begin{array}{l}60 \% \mathrm{Fe}-30 \% \mathrm{Cr}- \\
10 \% \mathrm{Co}\end{array}$ & $\begin{array}{l}\text { 10-40 } \mu \text {-strain max. magnetostriction, Curie } \\
\text { temperature } 625^{\circ} \mathrm{C}\end{array}$ & Possible activation of cobalt & 2 \\
\hline Arnakrome 4 & $95 \% \mathrm{Fe}-5 \% \mathrm{Cr}$ & $\begin{array}{l}\text { 10-40 } \mu \text {-strain max. magnetostriction, Curie } \\
\text { temperature } 770{ }^{\circ} \mathrm{C}\end{array}$ & Low magnetostriction & $\begin{array}{l}1 \text { (Arnakrome } \\
4 \text { or } 5)\end{array}$ \\
\hline Arnakrome 5 & $92 \% \mathrm{Fe}-8 \% \mathrm{Mn}$ & $\begin{array}{l}\text { 10-40 } \mu \text {-strain max. magnetostriction, Curie } \\
\text { temperature } 770{ }^{\circ} \mathrm{C}\end{array}$ & Low magnetostriction & $\begin{array}{l}1 \text { (Arnakrome } \\
4 \text { or } 5)\end{array}$ \\
\hline Galfenol & $81 \% \mathrm{Fe}-19 \% \mathrm{Ga}$ & $\begin{array}{c}100-400 \mu \text {-strain max. magnetostriction, Curie } \\
\text { temperature } 700{ }^{\circ} \mathrm{C}\end{array}$ & $\begin{array}{l}\text { Relatively new, small amounts of } \\
\text { data, may be difficult to acquire }\end{array}$ & 1 \\
\hline Terfenol-D & $\begin{array}{c}\text { Tb0.3-Dy0.7-Fe } \\
\quad 1.95\end{array}$ & $\begin{array}{c}1000-2000 \mu \text {-strain max. magnetostriction, Curie } \\
\text { temperature } 360^{\circ} \mathrm{C}\end{array}$ & $\begin{array}{l}\text { Very brittle, strong biasing field/ } \\
\text { prestress required, presence of } \\
\text { terbium and dysprosium }\end{array}$ & 3 \\
\hline $\begin{array}{l}\text { Magnet } \\
\text { Type }\end{array}$ & Composition & Key Properties & \multicolumn{2}{|l|}{ Comments } \\
\hline Alnico 5 & $\begin{array}{l}51 \% \mathrm{Fe}-24 \% \mathrm{Co}- \\
14 \% \mathrm{Ni}-8 \% \mathrm{Al}-3 \\
\quad \% \mathrm{Cu}\end{array}$ & $\begin{array}{c}\text { Curie temperature } 860^{\circ} \mathrm{C} \text {, Max. Energy Product } 43.8 \\
\mathrm{~kJ} / \mathrm{m} 3 \text {, Residual Induction } 12800 \text { gauss, Coercive } \\
\text { force } 640 \text { Oersteds. }\end{array}$ & \multicolumn{2}{|c|}{$\begin{array}{l}\text { High Curie temperature, low magnetic strength, } \\
\text { demagnetize over time, cobalt present. }\end{array}$} \\
\hline Alnico 9 & $\begin{array}{l}34 \% \mathrm{Fe}-35 \% \mathrm{Co}- \\
15 \% \mathrm{Ni}-7 \% \mathrm{Al}-4 \\
\% \mathrm{Cu}-5 \% \mathrm{Ti}\end{array}$ & $\begin{array}{c}\text { Curie temperature } 860^{\circ} \mathrm{C} \text {, Max. Energy Product } 71.6 \\
\mathrm{~kJ} / \mathrm{m} 3 \text {, Residual Induction } 10600 \text { gauss, Coercive } \\
\text { force } 1500 \text { Oersteds }\end{array}$ & \multicolumn{2}{|c|}{$\begin{array}{l}\text { High Curie temperature, low magnetic strength, } \\
\text { demagnetize over time, cobalt present. }\end{array}$} \\
\hline $\mathrm{Nd}-\mathrm{B}-\mathrm{Fe}$ & $\begin{array}{l}\mathrm{Nd}_{2} \mathrm{X}_{14} \mathrm{~B}, \mathrm{X}=\mathrm{Fe} \\
\quad \text { or } \mathrm{Co}\end{array}$ & $\begin{array}{l}\text { Curie temperature } 310^{\circ} \mathrm{C} \text {, Max. Energy Product } \\
190-400 \mathrm{~kJ} / \mathrm{m} 3 \text {, Residual Induction } 10000-14100 \\
\text { gauss, Coercive force } 9600-13000 \text { Oersteds }\end{array}$ & \multicolumn{2}{|c|}{$\begin{array}{l}\text { Low Curie temperature, very high magnetic strength, } \\
\text { brittle, presence of neodymium and boron. }\end{array}$} \\
\hline Sm-Co & $\mathrm{SmCo5}$ & $\begin{array}{l}\text { Curie temperature } 750{ }^{\circ} \mathrm{C} \text {, Max. Energy Product } \\
130-180 \mathrm{~kJ} / \mathrm{m} 3 \text {, Residual Induction } 8300-11600 \\
\text { gauss, Coercive force } 7500-10600 \text { Oersteds }\end{array}$ & \multicolumn{2}{|c|}{$\begin{array}{l}\text { High Curie temperature, high magnetic strength, } \\
\text { brittle, presence of samarium and cobalt, higher cost }\end{array}$} \\
\hline $\mathrm{Sm}-\mathrm{Co} /$ & $\mathrm{Sm}_{2} \mathrm{Co}_{17}$ & $\begin{array}{c}\text { Curie temperature } 825^{\circ} \mathrm{C} \text {, Max. Energy Product } \\
190-240 \mathrm{~kJ} / \mathrm{m} 3 \text {, Residual Induction } 10000-11600 \\
\text { gauss, Coercive force } 6000-10600 \text { Oersteds }\end{array}$ & \multicolumn{2}{|c|}{$\begin{array}{l}\text { High Curie temperature, high magnetic strength, } \\
\text { brittle, presence of samarium and cobalt, higher cost }\end{array}$} \\
\hline
\end{tabular}




\section{Iron}

Iron has a suitable Curie temperature; however, its saturation magnetostriction is very low. This makes iron a poor candidate, as the signals produced by this material are likely to be too weak to be of use.

\section{Cobalt}

Cobalt has the highest magnetostriction of any pure metal, and a very high Curie temperature. However, the likely activation of cobalt under irradiation, as well as the availability of cobalt based alloys with greater magnetostriction, makes pure cobalt a poor candidate.

\section{Remendur}

Remendur has the most history of use in nuclear applications of all the magnetostrictive alloys, having been used previously for short duration thermometry applications. Remendur has a high Curie temperature and high magnetostriction. Given this, and its previous use, Remendur is highly recommended for testing, despite the presence of cobalt. Although Remendur is no longer commercially available, several identical alloys are available under different names.

\section{Vacoflux $^{\circledR}$ (Vacuumschmelze) ${ }^{67}$}

Vacoflux 50 is an alloy chemically identical to Remendur, which has been used in European ultrasonic thermometry applications. It is recommended as a possible alternative to Remendur.

Vacoflux 17 is essentially a reduced cobalt variant of Vacoflux 50. As such, it does still contain cobalt and has significantly reduced magnetostriction. Vacoflux 17 is not recommended, as Vacoflux 50/Remendur is the preferable alternative.

\section{Arnokrome $^{T M}$ (Arnold Magnetics) $^{68,69,70}$}

Arnold Magnetics produces several magnetostrictive alloys, Arnokrome 3, Arnokrome 4, and Arnokrome 5. Arnokrome 3 contains cobalt and has much lower magnetostriction than Remendur, and is therefore not of interest in the current study. Arnokrome 4 and 5 have similar magnetostriction to Arnokrome 3, but without the presence of cobalt. Although not as promising as some candidates, it is recommended that either Arnokrome 4 or 5 be included in the irradiation test.

\section{Galfenol $^{71}$}

Galfenol is a relatively new alloy of iron and gallium. Galfenol is a member of the "giant" magnetostrictive alloys and has a very large saturation magnetostriction. It also has an appropriately high Curie temperature. Neither constituent element reacts strongly with neutron radiation. All of these factors appear to make Galfenol the most appealing magnetostrictive material candidate.

\section{Terfenol-D}

Terfenol-D has the highest saturation magnetostriction of any known material and is widely used in the design of actuators. However, Terfenol-D contains both terbium and dysprosium, both of which have high thermal neutron absorption cross sections (particularly dysprosium). Additionally, Terfenol-D has a low Curie temperature of $360^{\circ} \mathrm{C}$, which is very close to the anticipated irradiation temperature of $300-350{ }^{\circ} \mathrm{C}$. Due to these factors, Terfenol-D is not recommended as a candidate material.

\section{Selected Materials}

Assuming three candidates can be accommodated by the test capsule, the top recommended candidates are Remendur (or Vacoflux 50), Arnokrome 4 (or Arnokrome 5), and Galfenol. 


\subsubsection{Magnet Material Selection}

\section{Alnico}

Alnico magnets are considered primarily because they have a very high Curie temperature. The magnetic field strength is not high, compared to ceramic rare-earth magnets, but is sufficiently high for use as a biasing field source. Alnico magnets do have some history of testing in-pile, being tested to approximately half the target fluence of the current study with little loss of performance. ${ }^{72}$ The low coercive force is a concern as this indicates that the magnets lose strength over time.

$\mathrm{Nd}-\mathrm{B}-\mathrm{Fe}$

Neodymium-boron-iron magnets are the strongest commercially available magnets. They are also very resistant to demagnetization. However, their low Curie temperature $\left(310^{\circ} \mathrm{C}\right)$ means that they would be rendered non-magnetic at the expected test temperatures. Previous irradiation testing indicates that Nd-B-Fe magnets are not tolerant to neutron irradiation. Additionally, these magnets contain boron, an element not recommended for inclusion in the irradiation test. ${ }^{73}$

\section{Sm-Co}

Samarium-cobalt magnets have magnetic properties nearly as good as Nd-B-Fe magnets and Curie temperatures nearly as high as Alnico magnets. Although samarium has a high thermal neutron absorption cross section, previous irradiation testing indicates that neutron irradiation has a negligible effect on its magnetic properties. $^{73}$

\section{Selected Materials}

Nd-B-Fe magnets, although the strongest available type, are not appropriate for this test due to low Curie temperature, low radiation resistance, and the presence of boron. Samarium-Cobalt magnets are recommended over Alnico magnets due to higher field strength, increased resistance to demagnetization, and radiation tolerance.

\subsection{Cables and Connectors}

To be used in a high-temperature, high-radiation environment, electric cables and connectors need to be carefully selected to minimize attenuation and to prolong operation life. The size of the cable and connector may also need to be considered if many transducers will be tested at the same time or there is constrained feed-through space.

Two primary cable properties, capacitance and impedance, need to be considered when selecting electric cable of ultrasonic transducer. The cable capacitance $(\mathrm{pF} / \mathrm{m})$ should be as low as possible to minimize attenuation of the transmitting and receiving ultrasonic signals. The cable impedance needs to match the impedance of the transceiver input/output and the transducer itself to minimize signal reflections at the proximal and distal ends of the cable. Because cables are generally available with $50 \Omega$ characteristic impedances, matching at the transceiver end is typically not a problem. However, because piezoelectric transducers present a high resistance $(\mathrm{M} \Omega)$ and low capacitive load $(\mathrm{nF})$, impedance matching at the transducer end may require passive matching components.

Two types of excitation/signal cable appear to be adequate for a high-temperature $\left(600{ }^{\circ} \mathrm{C}\right)$ and high-radiation environment. ${ }^{74}$ Both of these cable types are also widely used in nuclear reactor facilities worldwide. The first is two-conductor "mineral cable". ${ }^{75}$ Solid conductor rods of nickel or copper are inserted into a vertical sheath tube and kept at the correct (side-by-side) spacing with mineral-insulated block inserts. The tube is packed with magnesium oxide, which acts as a seal and fireproof insulator. The end of the sheath tube is sealed off and drawn down to the desired diameter. Connectors are soldered or welded to each end. 
Because the magnesium oxide is hygroscopic, the cable must maintain its hermetic seal to maintain electrical integrity. This requires the use of special electrical connectors and factory termination.

Coaxial cable is also available for the high-temperature, high-radiation environment of sodium-cooled fast reactors. ${ }^{76}$ This cable uses $\mathrm{SiO}_{2}$ as the annular dielectric and can be obtained with $50 \Omega$ impedance in various diameters. Larger diameters are less flexible while smaller diameters exhibit higher insertion loss.

Once again, this cable must be hermetically sealed to maintain electrical integrity, which requires factory termination.

Two common connectors, BNC (Baynet Neill-Concelman) and microdot coaxial connectors (Tyco Electronics), are used for ultrasonic transducers. The BNC connector exists in 50 and $75 \mathrm{ohm}$ versions, matched well with the two cables recommended above. These two versions show negligible effects of impedance mismatch at frequencies below $10 \mathrm{MHz}$. Both comply with the 1978 standard, IEC 169-8 and are highly reliable and compatible with most electronics.

Microdot coaxial connectors are designed to accept 50, 70, and $93 \mathrm{ohm}$ miniature coaxial cables. The S-50 series with 10-32 thread is the most common version and is used worldwide for accelerometer, microphone and various transducers. This type of connectors is smaller than BNC connector and uses smaller cable. This connector will be a better option if many transducers will be tested or there is constraint of feed through space. Because most of ultrasonic electronics are equipped with BNC connectors, a BNC-Microdot converter needs to be used when connecting a transducer with Microdot connector to an ultrasonic electronics.

All of the commercially available BNC and Microdot connectors contain organic components, such as Teflon or nylon insulation ring, that will deteriorate, crack or melt when used in high-temperature, high-radiation environment. Therefore, these organic components have to be replaced by special order ceramic components.

As the transducers designed for this test may be contained within sealed housings, and due to the limited space available for the samples, it is preferable to connect the transducer element (electrodes for piezoelectric transducers or signal coil for magnetostrictive transducers) to the signal cable by way of direct welding (i.e. laser welding) or soldering in order to reduce the transducer size. In the case of a magnetostrictive transducer, which requires a pre-biasing magnetic field, a biasing coil may be necessary if a permanent magnet cannot be used. This will complicate the transducer design in that two sets of leads will need to be connected instead of one.

\subsection{Coupling}

The coupling is another important factor that affects ultrasonic energy transmission efficiency, ultrasonic signal quality, transducer design and complexity, and transducer reliability and life.

\subsubsection{Piezoelectric}

The transducer faceplate couples acoustic energy from the piezoelectric material to a surrounding liquid medium or solid waveguide. In general, the faceplate is flat, and the central lobe of the near-field diffraction pattern determines the spot size and thus the lateral resolution of the transducer. In some applications, to increase detection resolution, the faceplate is curved in order to focus the ultrasonic energy to a spot with minimum lateral dimensions. Of special importance is the material from which the faceplate is made. In high temperature environment, the linear thermal expansion coefficient of the faceplate must be closely matched to that of the transducer material to avoid inducing excessive internal stresses, cracking, and detaching of the transducer. In practice, exact matching of the thermal expansion coefficients is difficult to achieve. Traditionally, the piezoelectric material and faceplate are bonded by epoxy, which is either softened or cracked at high temperature. The ultrasonic energy can thus be transmitted. Instead, high-temperature grease $^{77}$ and various silver solder alloys ${ }^{78,79}$ have been used for high-temperature applications. The 
ductility of a high-temperature grease will minimize thermally induced shear stresses in the transducer face. If a tin-alloy solder is utilized, it may interact with (e.g., dissolve) the transducer front face electrode (often a diffused layer of silver) and degrade the electrical connection. ${ }^{78}$ The low ductility of tin-alloy solders can also precipitate cracking of the transducer due to thermal shock. Nevertheless, neither high-temperature grease or silver solder alloys can give a consistent coupling in a high-temperature environment.

To keep the whole transducer assembly, especially piezoelectric material and faceplate, in contact at high-temperature, a compressed loading mechanism should be used. Between the faceplate, piezoelectric material and backing material, thin gold foils are often used as a coupling medium. The contact surfaces of these three components may need to be polished in order to achieve optimal coupling and to maximize the ultrasonic energy transmission. The backing material is then compressed by a spring-loaded plate to maintain consistent loading. In some transducers, the spring loading can be adjusted by a setting screw for optimal coupling/contact. Figure 3-4 shows some early ultrasonic sensors developed at Argonne National Laboratory (ANL) for high temperature flow monitoring and at the Hanford Engineering Development Laboratory (HEDL) for under-sodium viewing (USV). Recently, Parks and Tittmann designed a transducer for irradiation testing of AlN. ${ }^{37}$ These transducers use a mechanical loading mechanism to keep consistent loading and share many similar constraints with respect to thermal and neutron radiation tolerance. Schematics of the transducers used by HEDL and PSU ${ }^{37}$ are shown in Figure 3-5. The transducers rely on spring loading pressure for coupling the piezoelectric element to the faceplate or test piece. Electrical contact with the piezoelectric element is achieved through application of pressure. A backing layer behind the piezoelectric sensor provides acoustic damping and prevents excessive "ringing" of the transducer. In their design, ${ }^{37}$ the backing layer material is carbon/carbon composite, whereas other designs incorporate a stainless steel "sponge".
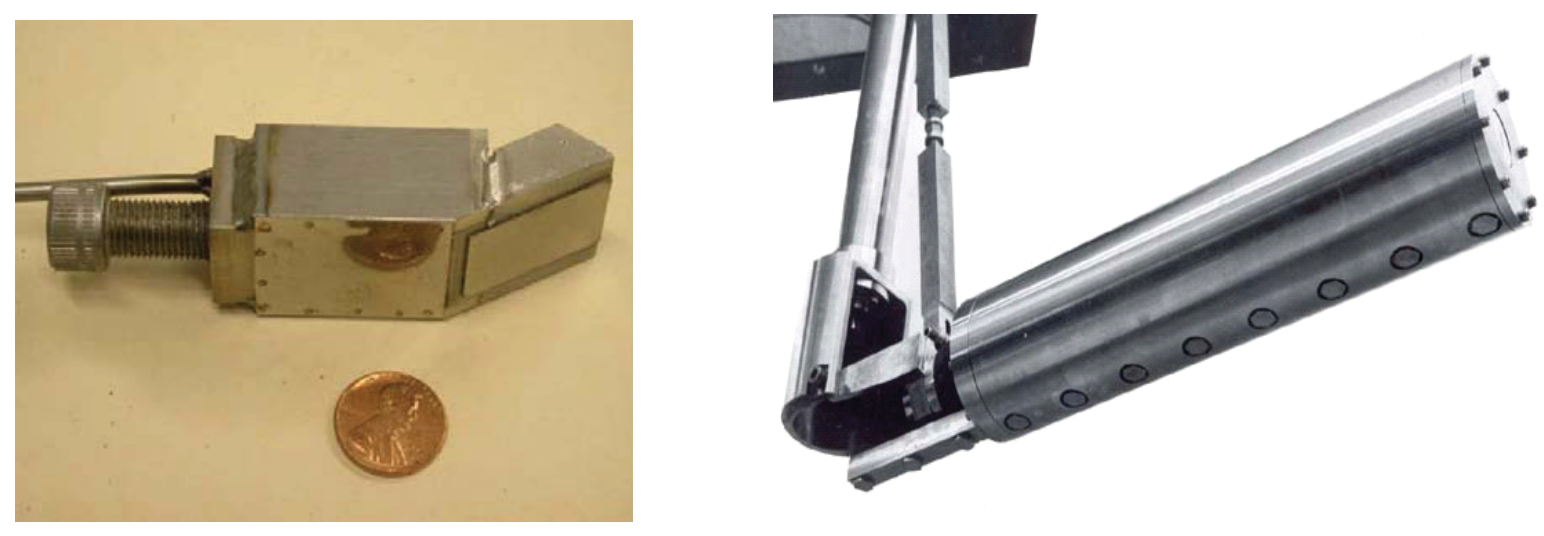

Figure 3-4. High-temperature ultrasonic sensor developed at ANL (left) and HEDL (right).

\subsubsection{Magnetostrictive}

Magnetostrictive transducers are used primarily in waveguide applications, the acoustic signal is transmitted through a (typically metallic) rod or wire. Because the magnetostrictive wire is also metallic, excellent coupling may be achieved by welding or brazing the waveguide to the magnetostrictive wire. Alternatively, the magnetostrictive element may be fabricated in the form of an annulus, or sleeve. The waveguide may be inserted into the sleeve. With a tight fit, acoustic energy may be satisfactorily transmitted from the sleeve to the waveguide. 

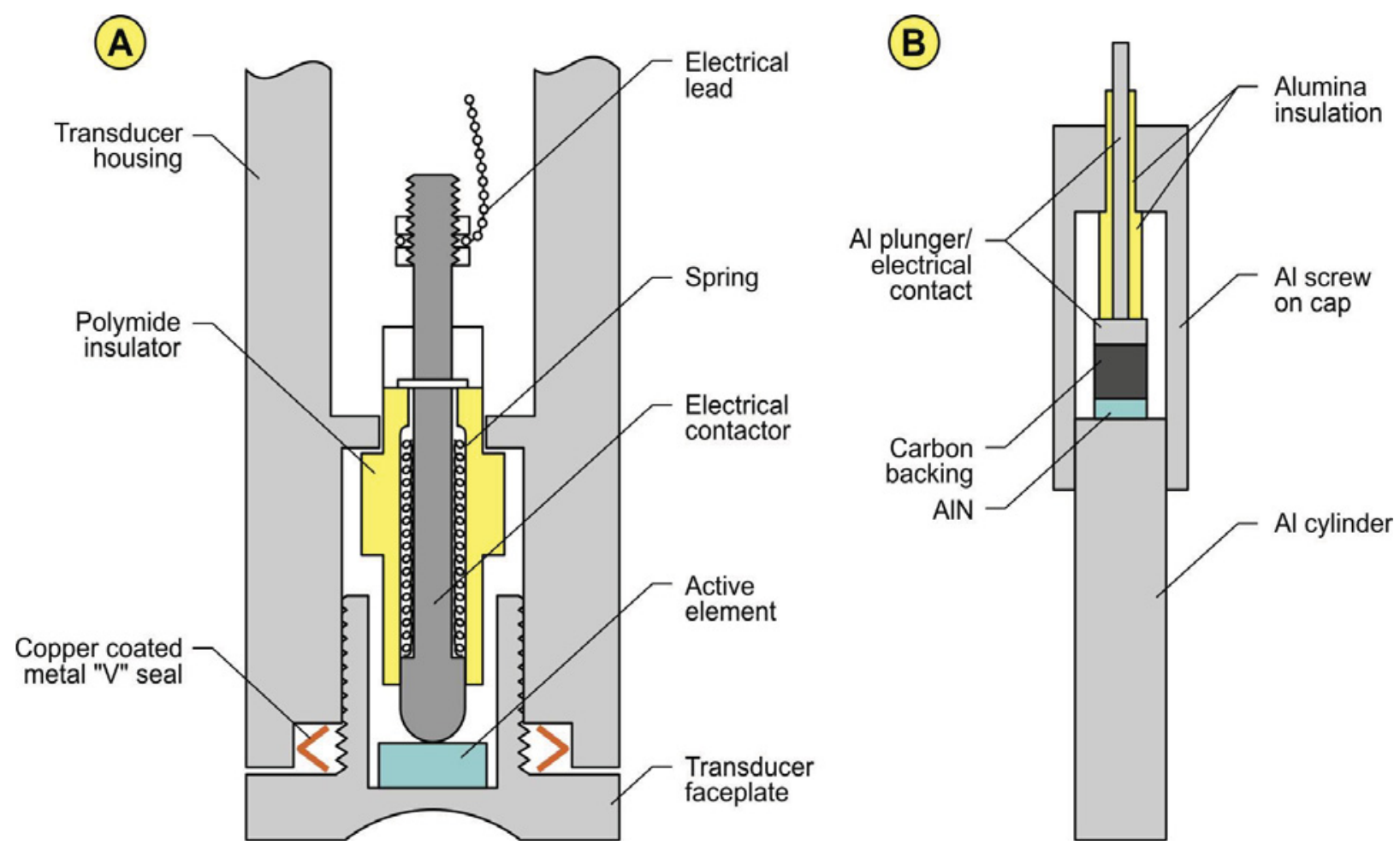

Figure 3-5. Schematics of the HEDL single ultrasonic transducer developed for under-sodium viewing applications (left), ${ }^{38}$ the transducer design for irradiation testing of AlN (right). ${ }^{37}$

\subsection{Required Out of Pile Tests}

Several tests must be conducted out-of-pile either prior to or in conjunction with the irradiation test (prior to the test being preferable, as it would allow identification of any systematic problems before the full test is installed in the reactor). These tests are needed to help separate the effects of the neutron radiation from effects of the elevated temperature the test will likely reach while in the reactor. A list of proposed out-of-pile tests is given in Table 3-6. Details on specific measurements and signals to be monitored will be provided in FY13.

The primary out-of-pile test will provide insights about the effects of long term (on the same time scale as the irradiation test) operation of prototypic transducers at a temperature closely approximating the expected irradiation temperature $\left(\sim 300-350{ }^{\circ} \mathrm{C}\right)$. This test will provide an understanding of the effects of long term temperature effects on transducer and allow separation of the effects of temperature from the effects caused by the irradiation. The design of test transducers and fixturing (e.g., the graphite holder) should match that used in the MITR irradiation (i.e. same batch of material, same design, similar instrumentation). Further long term tests could be held at room temperature and at higher temperatures to help quantify the performance of the various candidate transducer and coupling materials.

A second out-of-pile test should be a temperature ramping test in which the transducers would be heated over a short time period (on the order of hours) from room temperature to the maximum operating temperature (i.e., Curie temperature). This test will further enable a separation of the temperature effects on the transducers from the irradiation effects, and identification of the maximum operating temperature of each candidate transducer materials. It will also allow a more comprehensive study of the performance of the candidate transducers at temperatures near the estimated irradiation temperature. 
Table 3-6. Proposed out-of-pile tests.

\begin{tabular}{|c|c|c|}
\hline Test & Materials & Description \\
\hline $\begin{array}{l}\text { Endurance test } \\
\text { (ET) }\end{array}$ & All candidate materials & $\begin{array}{l}\text { The ET include operation of candidate transducers at } 300{ }^{\circ} \mathrm{C} \text {. } \\
\text { This test is to be used as reference for the data collected during } \\
\text { the irradiation test. Two types of endurance tests can be } \\
\text { performed, one at an elevated temperature relative to the nuclear } \\
\text { reactor environmental conditions to accelerate the degradation } \\
\text { process. The other is to be at anticipated irradiation temperature } \\
\text { of } 300^{\circ} \mathrm{C} \text {. The time necessary for each of this test is at least } \\
\text { several weeks if not for a month. The samples are to be inserted } \\
\text { in the reactor for about a year, so a several month long test is } \\
\text { proposed. } \\
\text { This test will allow separation of temperature induced changes } \\
\text { from radiation induced changes, as well as identification of } \\
\text { design flaws. }\end{array}$ \\
\hline $\begin{array}{l}\text { Maximum } \\
\text { operating } \\
\text { temperature } \\
\text { (MOT) }\end{array}$ & All candidate materials & $\begin{array}{l}\text { The MOT is determined by placing the transducer in the tube } \\
\text { furnace and increasing the temperature linearly at a slow rate so } \\
\text { that at each measurement could be considered isothermal. In the } \\
\text { past rates such as } 1 \text { degree per minute have been used. As such, } \\
\text { the time necessary for each experiment will depend on the Curie } \\
\text { temperature; on the order of 500-1000 minutes or 8-16 hours. } \\
\text { This test will allow identification of possible temperature } \\
\text { induced changes at temperatures near irradiation temperature, } \\
\text { effects of temperature transients, and maximum operating } \\
\text { temperature }\end{array}$ \\
\hline $\begin{array}{c}\text { Saturation } \\
\text { magnetostriction }\end{array}$ & $\begin{array}{l}\text { All magnetostrictive } \\
\text { candidate materials }\end{array}$ & $\begin{array}{l}\text { This test involves measurement of magnetostriction of candidate } \\
\text { materials as a function of applied DC magnetic field using a DC } \\
\text { current supply and a pushrod dilatometer. } \\
\text { Characterization of performance of candidate magnetostrictive } \\
\text { materials }\end{array}$ \\
\hline $\begin{array}{c}\text { Hysteresis } \\
\text { measurement }\end{array}$ & All candidate materials & $\begin{array}{c}\text { The HM characterizes remnant polarization and indicates } \\
\text { changes in material structure. This test can be performed with } \\
\text { the transducer in situ and will be completed alongside the MOT } \\
\text { and ET. }\end{array}$ \\
\hline
\end{tabular}

Hysteresis measurements may be made simultaneously during the previously-described tests. These measurements will help identify changes in material structure.

Tests specific to magnetostrictive candidates include measurement of saturation magnetostriction and a comparison of biasing magnetic field options. Saturation magnetostriction test requires measurement of the elongation of magnetostrictive material under an applied DC magnetic field using a current controlled power source, a biasing coil, and pushrod dilatometer. Testing of the different biasing field options should be performed prior to fabrication of the magnetostrictive test samples, as identifying a superior biasing magnet will allow the optimization of transducer dimensions. 


\subsection{Post Irradiation Examination (PIE)}

PIE will be needed to quantify the irradiation effects on the piezoelectric candidate materials. The magnetostrictive candidates typically contain significant amounts of cobalt (or other problematic constituents), and PIE will not be possible. PIE will be used to measure material property changes for comparison with pre-irradiation values. A list of identified PIE is shown in Table 3-7.

Table 3-7. Post Irradiation Examination Measurements.

\begin{tabular}{|c|c|}
\hline Measurement & Information \\
\hline $\begin{array}{c}\text { Ultrasonic pulse-echo } \\
\text { amplitude }\end{array}$ & $\begin{array}{c}\text { Signal to noise ratio, resonance } \\
\text { frequency, bandwidth, signal quality }\end{array}$ \\
\hline Density & Calculate bulk modulus \\
\hline Impedance & Loss tangent, material properties \\
\hline Efficiency $\mathrm{d}_{33}$ & $\mathrm{~d}_{33}$ \\
\hline Hysteresis & field \\
\hline Optical & Color changes \\
\hline $\begin{array}{c}\text { Scanning electron } \\
\text { microscopy (SEM) }\end{array}$ & Surface grain structure \\
\hline
\end{tabular}

A description of each measurement follows:

\section{Pulse-echo}

These measurements are simple and reveal lots of information about the quality of the transducer without having to disassemble it. The pulse-echo measurement is used to measure signal to noise ratio (indicating sensitivity of the transducer), resonance frequency, bandwidth, and the quality factor. These are used as a go/no go test for sensor performance and are most important in ascertaining transducer performance.

\section{Density}

Density data are needed to determine material properties from the pulse-echo and impedance measurements. During temperature testing, it is common to see variations in densities of many piezoelectric materials and is important to characterize these changes. However, the transducer assembly needs to be taken apart, and the sensor needs to be individually measured.

\section{Impedance}

Impedance can be used to calculate the loss tangent which is related to the dielectric property changes, as well as the resonance frequency, stiffness, and dielectric constant. This is important in determining loss mechanisms. This measurement can be made with the sensor still in the transducer casing.

\section{Efficiency $d_{33}$}

The $\mathrm{d}_{33}$ parameter is a material constant and important to transducer signal amplitude. This parameter is most significantly affected during neutron testing in most materials and is important to characterize. It will be necessary to remove the sensor material from the transducer in order to measure this material property. 


\section{Hysteresis}

Hysteresis can show remnant polarization which is necessary for transduction in ferroelectrics as well as the degradation mechanism such as metamictization vs. antiferroelectric tendencies. The sensor does not need to be removed from the transducer assemble to make this measurement.

\section{Optical}

Some materials change color when irradiated which can indicate absorption of oxygen and other contaminants. The sensor material would need to be removed from the assembly and photographed with a high resolution camera.

\section{SEM}

SEM is important to characterizing the grain structure of the sensor and changes that occur during irradiation. SEM examinations may provide insights about the damage mechanisms and how polar domains change during the radiation process. The sensor would need to be removed from the assembly

\subsection{Summary}

As describe in this section, this project is supporting an ultrasonic transducer irradiation test that will be performed in the MITR. During FY12, funding was used to define irradiation test conditions and test locations were defined. Candidate piezoelectric and magnetostrictive transducer materials were selected based on material properties, expected radiation resistance, and prior testing. A proposed test capsule design was developed, which will accommodate all test specimens, as well as extensive instrumentation for monitoring test temperatures and flux conditions in real time. A series of out-of pile tests was described, which will help distinguish the effects of non-radiation factors, such as temperature) and characterize the pre-irradiation performance of each candidate. Post irradiation tests were also selected, which will help characterize the effects of the neutron radiation on the piezoelectric test specimens. 
NEET In-Pile Ultrasonic Sensor Enablement-FY 2012 Status Report

September 2012 


\section{TASK 2: ULTRASONICS SIGNAL PROCESSING SOFTWARE}

Task 2 of this project supports efforts to develop software that can be used for various types of ultrasonic sensors. As noted above, it is ultimately anticipated that ultrasonic techniques can be used to detect a wide-range of parameters during an irradiation. Enhanced software that is applicable to a range of measurable parameters is of interest to support such endeavors. This task will define software requirements for different applications (based on input obtained from various DOE-NE programs that would like to deploy in-pile ultrasonics-based sensors, see Section 2) and explore options to meet these requirements. Ultimately, enhanced software will be developed that is capable of acquiring and processing signals specific to in-pile measurements of interest to DOE-NE programs.

The goal of any signal processing is to enhance the received signal to improve the signal-to-noise ratio (SNR). Traditionally, signal processing has revolved around frequency-based analysis using Fourier analysis, and the use of frequency-based filtering to improve the SNR for the desired signal. While analog filters (and signal processing tools) have received more attention in recent years (primarily due to developments in the last decade+ in analog and mixed-signal circuit design, and the desire to incorporate signal processing techniques close to the sensor), the dominant suite of tools for signal processing are still primarily digital in nature.

In the context of NDE, the primary goal of signal processing is to improve the SNR for signals from flaws. Additional stages of processing are typically also considered, for signal classification and flaw characterization. A generic approach to signal processing in NDE systems is shown in Figure 4-1. In any NDE system, an input transducer is used to apply energy from a source to the material under test. In the case of ultrasonic NDE, transducers are used to convert an applied electrical signal to stress waves in the material under test. The response of the material to the applied energy is recorded by a transducer (same or different), processed to improve SNR and optionally, the signal of interest is applied to a signal recognition block to identify signals from flaws and/or characterize the flaw.

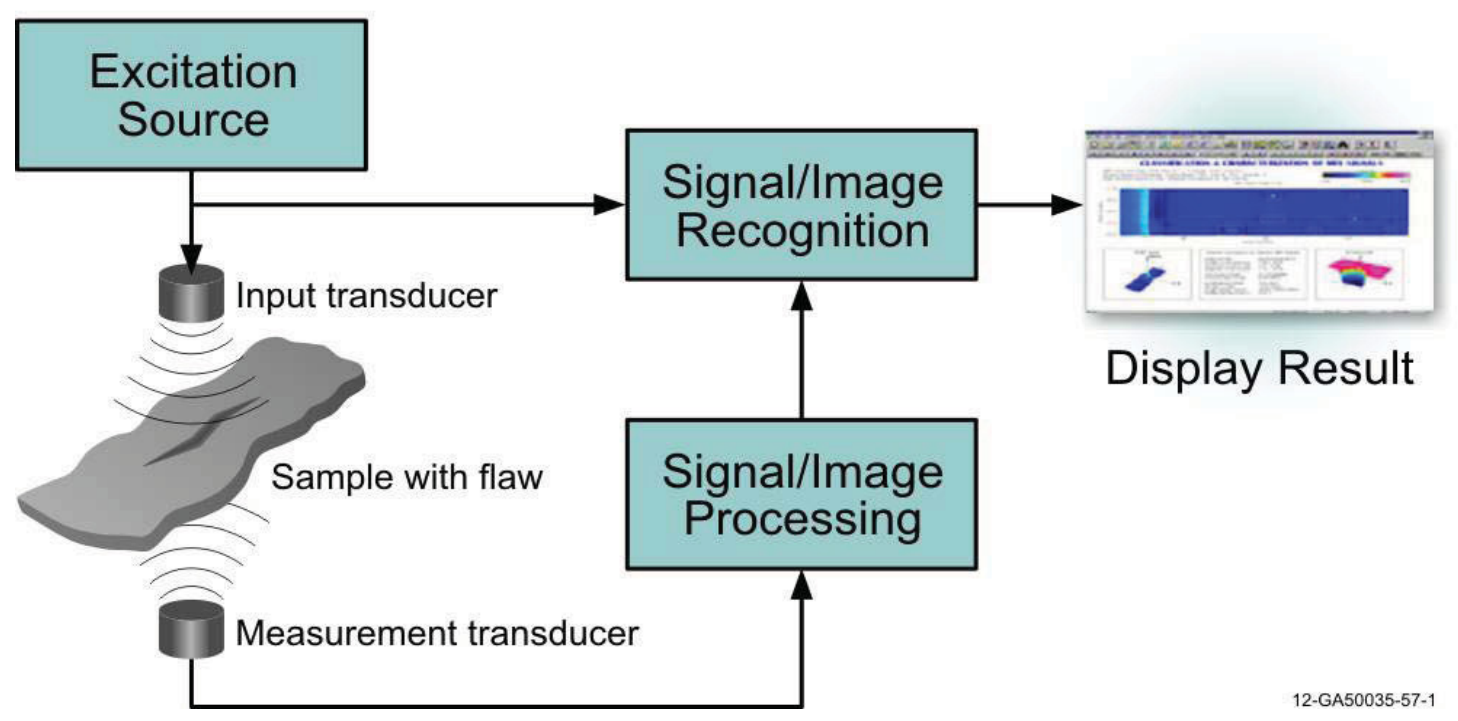

Figure 4-1. Generic schematic of signal processing flow in NDE systems. 


\subsection{Overall Plan and Schedule}

Section 2 identifies typical parameters that ultrasonics-based sensors would be used to measure in fuel and materials irradiations. As indicated in Section 2, parameters of interest include dimensional changes, fission gas composition and pressure, microstructural changes, and temperature. The accuracies of such measurements may need to be on the order of micrometers and degrees $\mathrm{C}$. Resolutions on the order of a few $\mathrm{mm}$ or smaller may be required.

From an ultrasonic perspective, the key parameters that are measured and correlated to physical phenomena are:

- Time of flight (or equivalently, sound speed)

- Attenuation (and signal amplitude)

- Frequency content (including the presence of harmonics)

- Optionally, the variation of these parameters as a function of time and location

These parameters have been correlated to the quantities listed above. It should be noted that the sampling frequency may affect the resolution with which attenuation and time-of-flight may be measured. In addition, as discussed previously in this document, there are several other phenomena, such as transducer and cabling degradation with temperature, neutron and gamma exposure, cabling length, etc. that can affect ultrasonic measurements.

Within the context of this section, the following assumptions are made:

- The measurements will be processed in an automated fashion, to extract one or more of the parameters listed above and correlate with the desired quantity (or quantities),

- Ultrasonic measurements are acquired using a computer-controlled data acquisition system,

- Data acquisition (DAQ) parameters (i.e. sampling frequency and bit depth) are sufficient,

- Location of transducer is appropriate (the location and configuration of the transducer may affect its sensitivity).

These factors may affect the resolution with which attenuation and time-of-flight may be measured.

\subsection{Background}

Given that ultrasonic in-pile measurements are in their infancy, the current state of the art and gaps in ultrasonic signal processing will have to be inferred from other applications of ultrasonic NDE, as well as from the limited ultrasonic PIE measurements that have been performed to date.

As of the writing of this report, flaw detection and diagnostics in most commercial applications of ultrasonic NDE is generally performed manually; that is, by one or more analysts examining the measured data to identify signals of interest, followed by a more comprehensive evaluation (also manual) of the measured data to determine if the signal is from a flaw of interest.

In recent years, there has been increased interest in the use of automated algorithms to analyze ultrasonic NDE measurements. While most of the work is still in the research phase, there are some notable successes in other areas of NDE, where the automated analysis technology is being transitioned to use in a field setting. ${ }^{80-83}$ Automated algorithms for flaw detection are usually applied off-line; that is, after all of the measurement data has been acquired (though some recent applications in the nuclear power area are emerging where the goal is near-real time flaw detection). ${ }^{81,83}$ In general, automated analysis also follows a two-step process as in the manual case, where the first step is to identify signals of interest (detection) followed by a second step of careful analysis to determine if the identified signal is a flaw and, if so, to characterize the severity of the identified flaw. Note that, in the literature, such a division is often not explicitly described 
and, indeed, the line dividing the two steps is somewhat fuzzy at best. However, the distinction is made here to clearly identify the key stages in ultrasonic NDE signal processing.

The problem of flaw detection from ultrasonic measurements has seen a number of approaches, which are usually empirical in nature. Typically some signal enhancement operations (prefiltering) are performed first $^{84}$ (either explicitly, or implicitly as part of the thresholding phase applied next). The goal here is to reduce the impact of measurement noise and enhance the overall SNR. Often, this step also results in a reduced set of signals that need to be evaluated, as obvious non-flaw signals are eliminated. This is usually followed by some form of thresholding (either in the time domain or in an alternative domain such as frequency or wavelet) to clearly identify the signals of interest. The benefits of this approach are most often apparent in the analysis of imaging data, as this step can eliminate all but a few regions of the image for follow-on analysis. ${ }^{85}$

Approaches that have been proposed for detection are based on a range of filtering and transform algorithms, including adaptive filtering (for instance, Shekhar ${ }^{86}$ ), template-based algorithms (for instance, Baskaran ${ }^{87}$ ), time-frequency transforms (for instance, Legendre ${ }^{88}$ ), and other transforms such as the Hilbert-Huang Transform. ${ }^{89}$ The diversity of approaches is partly due to the diversity in available nondestructive measurement techniques. In the area of ultrasonic NDE alone, a number of SNR enhancement techniques have been assessed. Spatial and frequency compounding methods use weighted averages of several measurements to improve SNR. ${ }^{90,91}$ Deconvolution methods assume a linear model for each of the measurement subsystems, and attempt to compensate for their effect on the measured data. Deterministic deconvolution techniques that assume a convolving filter did not result in an improvement in SNR with model data, particularly for low amplitude responses from cast austenitic stainless steel (CASS) specimens. ${ }^{92}$ Similar results were observed when deconvolution using a minimum phase filter was applied, and the most promising results were obtained by a minimum entropy deconvolution technique. ${ }^{92}$ Other studies have also indicated the potential for improvement in flaw detection through deconvolution. ${ }^{93}$ Wavelet and related time-frequency techniques have also been successfully applied to reduce speckle noise and enhance ultrasonic signal SNR. ${ }^{94,95}$ Other methods, such as the split spectrum processing technique ${ }^{96,97}$ as well as the more general class of synthetic frequency diversity algorithms ${ }^{98}$ also show some potential. Time-averaged mean and mean-squared values were effective when the back surface response was relatively strong but were relatively ineffective for low amplitude signals. ${ }^{92}$ However, split-spectrum based polarity thresholding, ${ }^{97}$ either alone or in combination with other processing techniques such as minimization ${ }^{99}$ appears to significantly improve detectability in challenging materials, such as CASS specimens. A maximum entropy model of spectral analysis also had limited success. ${ }^{92}$ Miralles et al. ${ }^{100}$ discuss the application of higher order statistics (HOS) for analyzing ultrasonic backscatter. Though the focus of the work is on classifying scatterer (or grain) sizes based on HOS, similar approaches may potentially be applied to improve SNR or characterize microstructure. The use of nonlinear homomorphic filters ${ }^{101}$ for reducing distortion and improving the imaging of strong scatterers have also been proposed. Note that SAFT techniques for CASS inspection ${ }^{102,103}$ also make use of signal processing tools to improve the beam-forming capabilities and reduce clutter.

Typically, in most automated systems, the next step (after filtering and SNR enhancement) is one of diagnostics or classification. The goal is to determine whether a highlighted signal of interest contains evidence of material damage (i.e.,flaw), and if so, whether the severity of the damage (in terms of location, size, and shape) can be quantified. This problem of flaw detection is part of a general class of problems referred to as inverse problems. ${ }^{104,105,106}$ Inverse problems in general are ill-posed, ${ }^{107}$ lacking both uniqueness and continuous dependence of the measured signals on the inputs. ${ }^{108}$ This has resulted in the development of a variety of solution techniques for inverse problems in NDE. ${ }^{105}$ The simplest approach makes use of measurements from a calibration standard. Measurements from the component under test are compared to those from the calibration standard to determine whether a response is flaw-like or not. In recent years, the 
use of data from a calibration standard has also been proposed for automated analysis and is an example of a direct approach for flaw diagnostics, which maps the measurement to the material property space. ${ }^{105,106,109,110}$ Direct approaches apply a feature extraction step to extract relevant attributes of the measurement signal that has been identified as high interest during the detection phase. Physical features (such as rise time and energy), frequency-domain features, statistical features (high-order moments), and time-frequency features (wavelets, etc.) have all been applied to this task. ${ }^{111,112,113}$ The final step of flaw signal detection is performed using one of several approaches, including hypothesis testing, neural networks, fuzzy systems, expert systems, etc. ${ }^{106,111}$

However, direct techniques are limited in that they require data from known damage (training data) to determine the mapping parameters, are sensitive to noise, and can only be used when measurements are acquired from flaws similar to those used in the training process. Assuming a flaw has been identified, the next question that typically needs addressing is the size and shape of the flaw (as this has implications for the structural integrity of the component). Physics-based iterative methods typically employ a forward model that simulates the imaging process. ${ }^{114}$ The model is used to estimate the measurement given the damage profile, which is iteratively derived by minimizing the difference between the estimated and actual measurements using optimization techniques such as conjugate gradient, simulated annealing, ${ }^{115}$ or genetic algorithms. ${ }^{116}$ Numerical models such as a finite element model or integral equation models ${ }^{114,117-124}$ have been proposed to model the imaging physics, and although accurate, tend to be computationally expensive because the models must be solved during each iteration. Alternative forward models based on neural networks have also been proposed. ${ }^{106,125-128}$ Other non-iterative forward model-based inversion techniques have also been proposed, including tomographic reconstruction using the Fourier slice theorem, ${ }^{122,123,129}$ point source technique, ${ }^{130}$ and linear sampling. ${ }^{131,132}$ Constraints on material properties in the form of Markov random fields, ${ }^{133}$ as well as other regularization methods, have also been attempted. ${ }^{108,129,134,135}$ These methods are not recursive (i.e., they attempt to solve the inverse problem over the entire problem domain using all of the data) and are generally computationally expensive.

\subsection{Thermometry}

\subsubsection{Background}

The time of flight based thermometry system is the most widely studied form of ultrasonic thermometry for use in nuclear applications. Temperature measurements are accomplished by propagating an acoustic pulse along a thin cylindrical waveguide with one or more acoustic discontinuities (such as a diameter change) placed along the length of the waveguide. A diagram of a typical system is shown in Figure 4-2. The acoustic pulse travels down the waveguide where a portion of the energy is reflected at each discontinuity. By measuring the delay time between successive reflections, the average acoustic velocity through the waveguide material may be easily calculated and related to temperature. The same method may be used in any medium in which there is a well defined distance between reflectors (i.e. the liquid coupling between a transducer face and a solid sample, or across a combustion gas gap).

Prior US and international research into UT applications have demonstrated the viability of this technology for LWR, gas cooled reactor (GCR) and SFR test conditions. ${ }^{136-160}$ However, prior in-pile applications were primarily limited to fuel damage tests that ceased several decades ago. Although these tests clearly demonstrated the ability of UTs to withstand high temperatures (up to nearly $2900{ }^{\circ} \mathrm{C}$ ), test durations were typical limited to less than 100 hours; and data acquisition was cumbersome due to the limitations of signal processing systems available at the time.

A similar thermometry method utilizes the resonance to infer temperature. ${ }^{28,161}$ In this case the generated acoustic pulse causes a resonant vibration in a resonator at the sensor end of the waveguide This resonator may consist of various geometries, including a wire segment with a different diameter than the lead-in 


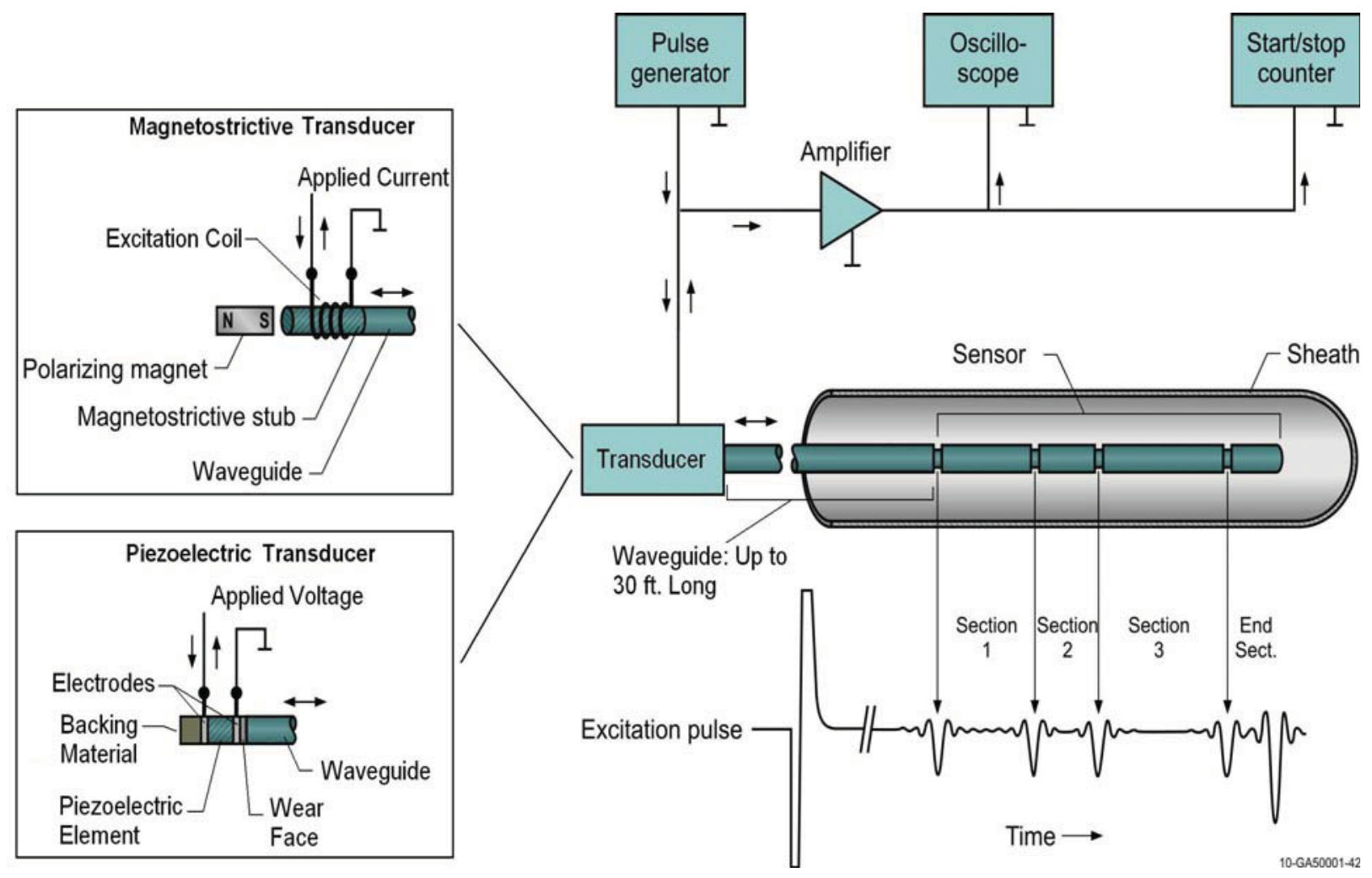

Figure 4-2. A typical time-of-flight based ultrasonic thermometry system.

waveguide, a "tuning fork," 162 or various others. The primary disadvantages of this method, compared to the time of flight method, are the relatively large size of the sensor and the fact that temperature may be measured at only one position.

A second resonant method utilizes the temperature dependence of the resonant frequency of a piezoelectric crystal (typically quartz). The advantage of this technique is the accuracy of the measurement, approximately $10^{-4}{ }^{\circ} \mathrm{C} .{ }^{28,161}$ This method has the same drawbacks as the previous resonant method. It is additionally limited by the maximum operating temperature of the crystal.

Temperature is measured ultrasonically using two primary signal characteristics: time of flight or resonance.

Temperature is derived through time of flight by tracking the delay time between reflected signal pulses. This has typically been accomplished either by tracking specific zero-crossings or signal peaks. This was typically accomplished visually using an oscilloscope or during post processing. There are two primary factors affecting the identification of reflections. The first is the SNR, as described in Section 4.2. The second factor is reflection reverberations. With the use of a multi-segment sensor, there is the possibility of multiply reflected echoes overlapping and obscuring the primary signal.

The resonant frequency techniques allow temperature to be simply correlated to the frequency of peak amplitude. The temperature is tracked by identifying the signal (either the direct signal from a piezoelectric oscillator or a reflected signal from a resonator), performing a Fourier transform of the signal, and tracking the frequency corresponding to maximum amplitude. 


\subsubsection{Current Investigations}

A signal processing method, described by Roberts, et al., ${ }^{163}$ was implemented in ultrasonic thermometry development efforts at INL (using the time-of-flight method). This method consists of cross-correlating the time series data to a known signal (typically either the input signal or the expected reflection), then squaring and low pass filtering the correlated data. This method greatly increases the SNR and simplifies identification of reflections, even in the presence of significant noise. This makes the technique especially useful when reflected wavelets are noisy and when reflection shape varies between test specimens. The input signal used in this test was a simple square pulse, and could not be used in the cross-correlation. The reflection signals were observed to vary from sample to sample, due to differences in material, reflector geometry, quality of welds between samples and the magnetostrictive wire used to generate signals, etc. Therefore, a computer program (using commercially available mathematics software) was developed that allows the graphical selection of a feature, ideally a relatively clear reflection, of the recorded data to use for cross-correlation. Conditioning of the data is then done automatically. Maxima of the filtered data can then be graphically selected, and the velocity is calculated from the delay time between these maxima. A graphical example of this process is shown in Figure 4-3.
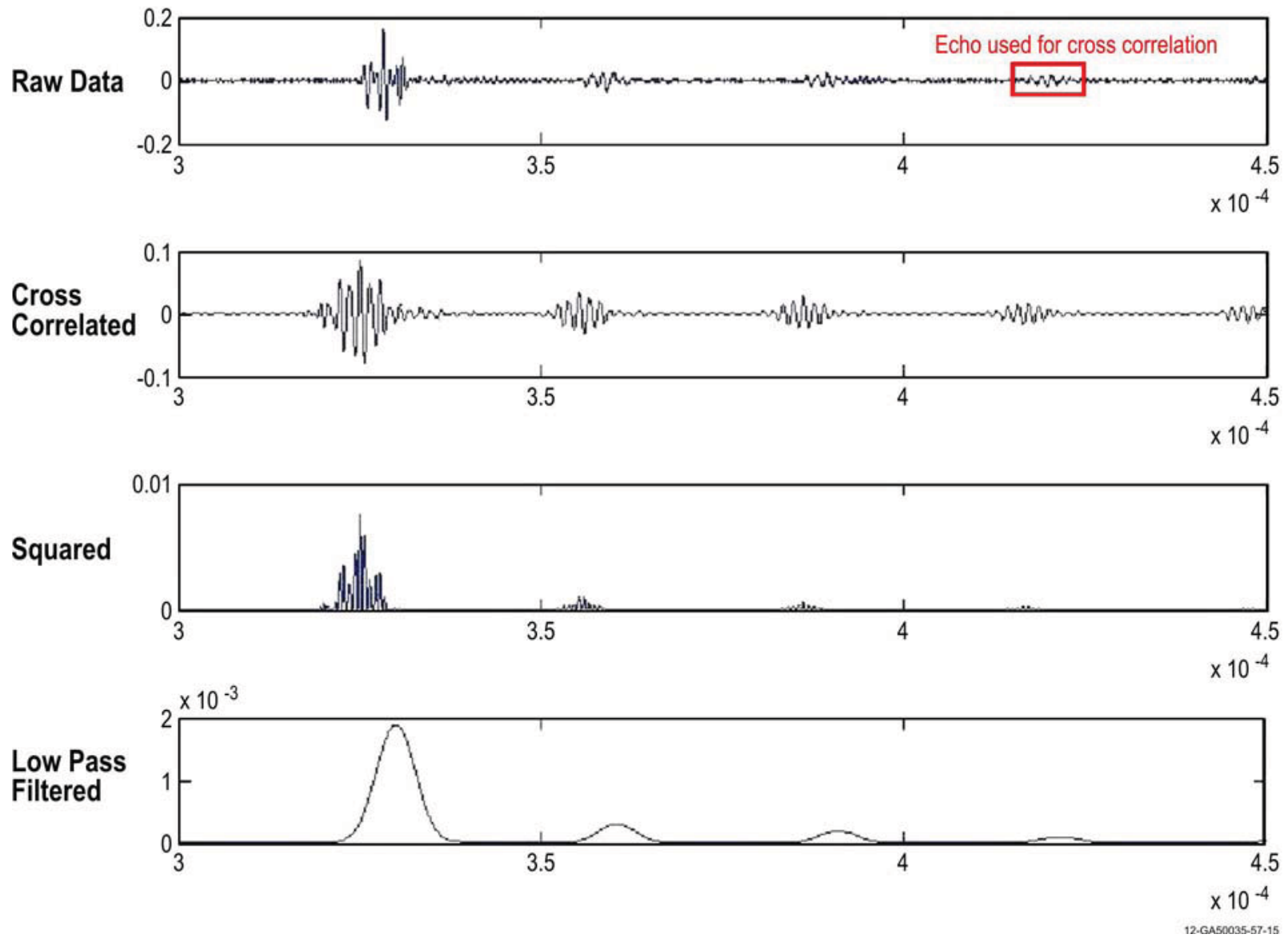

Figure 4-3. Signal processing method used in ultrasonic thermometry testing at INL. 


\subsection{Dimensional Measurements}

\subsubsection{Background}

In-core dimensional measurements typically include changes in length or diameter of various components (such as fuel pellets or fuel cladding) or test samples (such as creep testing samples of structural materials). Ultrasound-based dimensional measurements are typically made using TOF methods. In fact, the basic technique is identical to that used for ultrasonic thermometry, with the exception that the temperature of the sample must be well known instead of the propagation distance. The measured dimension is then simply calculated from the TOF and the known acoustic velocity of the material at the test temperature. Alternatively, the dimensional measurement may be made using a transducer separated from the sample by using the time of flight through the surrounding media (liquid or gas) to infer dimensional changes in the sample.

\subsubsection{Current Investigations}

Current efforts to use ultrasound for in-pile dimensional measurements have focused on waveguide based techniques, specifically creep testing samples. Although the technique is similar to thermometry, the sample geometries are, by necessity, more complicated. This leads to the received ultrasonic signals being much more noisy, as multiple reflections and wave mode conversion create complex interference. As a result of this, current efforts have focused on simplifying the physical geometry of the samples rather than attempting to resolve the difficulties through application of signal processing methods.

\subsection{Gas Pressure and Composition}

\subsubsection{Background}

For a pure ideal gas, acoustic velocity is primarily a function of temperature. For gas mixtures, the acoustic velocity is also a function of the composition (gas types and amounts present). However, if the temperature is known, the average molecular weight may be calculated from acoustic velocity measurements. From this information, the gas composition may be inferred, directly for a binary gas or from a calibration database if more components are present (this requires that some knowledge of the likely components exists). ${ }^{27}$ For non-ideal gases, the simple model will introduce some small error, which may be eliminated with a more sophisticated model. ${ }^{164,165}$

It is possible to simultaneously estimate gas pressure. This is done using the attenuation factor of the gas (i.e. change in signal amplitude between successive reflections). The attenuation is also a function of the gas composition, so the pressure measurement accuracy is limited by the accuracy of the composition measurement. Processing gas analysis data consists of delay time measurement (as with temperature and displacement measurements) as well as measurement of amplitude changes between reverberation echoes.

\subsubsection{Current Investigations}

Work on this technology is currently limited to testing by CEA in the OSIRIS reactor. ${ }^{27}$ The current CEA acoustic gas analysis sensor is shown on Figure 4-4. As indicated in Section 2, such measurements are of interest to the FCRD program.

\subsection{Crack Initiation and Growth}

\subsubsection{Background}

For this problem, two categories may be identified. The first uses a high-frequency measurement (with crack dimension-wavelength ratio much greater than 1 . The crack dimension in this case is generally the minimum crack length of interest. While attenuation will typically be high, the measurement parameter here is generally the amplitude and time of flight of an echo from the discontinuity (crack) of interest. 


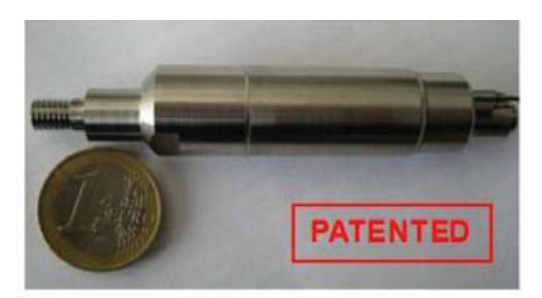

The sensor can be implemented on a
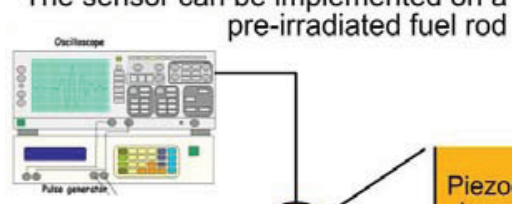

Acoustic system

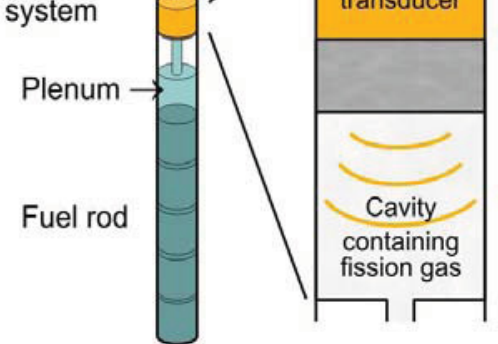

- Acoustic waves velocity $\rightarrow$ gas composition (= molar mass)

- Echoes attenuation gas $\rightarrow$ pressure

Status: Out-of-pile and hot labs tests completed $1^{\text {st }}$ experiment REMORA-3 (OSIRIS, France) started in 2010

\section{Composition detection accurate to $1 \%$}
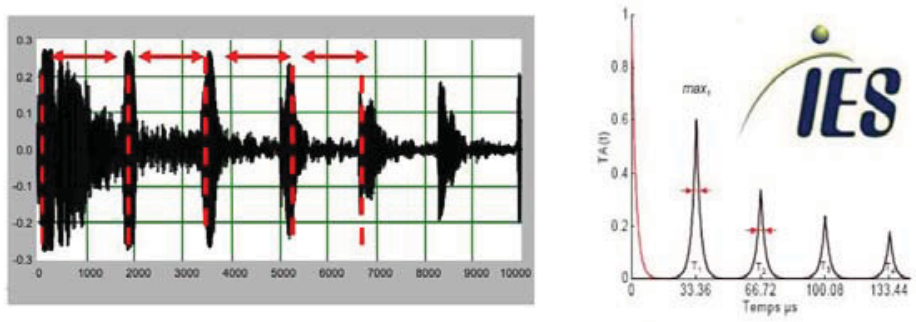

Echography

Figure 4-4. CEA acoustic gas analysis sensor. ${ }^{27}$

However, the possibility exists where the frequency and power required to make this measurement may be prohibitively high. The second possibility is a measurement where the dimension-frequency ratio is less than 1. In this case, individual echoes from cracks may not be distinguishable; instead, changes in TOF and attenuation are correlated with crack density (i.e., number of cracks per unit volume). The advantage of this approach is that the frequency and power requirements may not be a limiting factor. Noise from the microstructure is likely to be high in both cases.

\subsection{Microstructure Evolution}

\subsubsection{Background}

Published data on fuels using PIE has indicated that ultrasonic attenuation and velocity can be correlated to microstructural changes (specifically, the level and amount of porosity). Ultrasonic wave speed is a fundamental material property that is dependent on material density and microstructural variations. Wave propagation speed in isotropic homogeneous materials is a constant that depends on the wave mode. However, in anisotropic and heterogeneous materials, the wave speed depends on the wave mode, propagation angle (anisotropy), and spatial location (heterogeneity). Longitudinal wave and horizontally polarized shear wave sound speeds vary a relatively small percentage as a function of orientation with respect to the crystal axes. The vertically polarized shear wave sound speed, however, varies by a large percentage as a function of orientation with respect to the crystal axes.

The use of velocity variations to characterize microstructure (grain type) has been investigated by several researchers [for instance, Ramuhalli, ${ }^{166}$, Kupperman ${ }^{167}$ ]. Wave speed has been correlated to microstructural parameters such as grain size in polycrystalline materials, ${ }^{169}$ annealing and degree of recrystallization, ${ }^{170,171}$ precipitation and precipitation hardening, ${ }^{171,172}$ degree of cold work, ${ }^{169}$ residual stress and texture, ${ }^{171}$ and sensitization. ${ }^{173}$ Often, the measurement of wave speed (particularly for small specimens) can be difficult, and methods for reliably measurement are needed. Frenet, ${ }^{174}$ for instance, present a leaky Rayleigh wave velocity measurement technique that does not require moving the (focused) transducer. Note that wave speed measurements for multiple wave modes (longitudinal and shear) are often used to 
determine time-of-flight ratios, which are then correlated to the microstructural damage or evolution. ${ }^{166,171}$ The use of ratios removes dependency on specimen thickness or variations in path length. Further, wave speed measurements at several frequencies (so-called ultrasonic spectroscopy) have also been proposed for material characterization. ${ }^{175}$

Attenuation of acoustic waves in polycrystalline materials results from a number of factors, including absorption, scattering, beam divergence, and other effects such as magnetoelastic hysteresis. Attenuation due to scattering in metals varies generally as the fourth power of frequency (for both longitudinal and shear waves). ${ }^{25}$ It is a function of the scattering cross-section, orientation of the grains/grain boundaries, and anisotropic nature of the material. Attenuation can be determined by measuring the decay of the back-surface reflection in a normal incidence ultrasonic measurement, though such measurements typically require correction for beam spreading ${ }^{176-181}$ and component/reflector curvature. ${ }^{182}$ Typically, attenuation measurements using back-wall reflections use a buffer rod to help distinguish the front and back surface reflections, and provide a reference amplitude. ${ }^{179}$ Often, attenuation is measured as a function of frequency; this is also sometimes referred to as ultrasonic spectroscopy. ${ }^{175}$

Scattering of ultrasonic waves is an often-used approach to characterizing microstructure. Ultrasonic waves are reflected, diffracted, or scattered due to changes in acoustic impedance. Such changes in acoustic impedance occur, for instance, at grain boundaries. The interaction of ultrasonic waves with materials may be broadly classed into three regimes: ${ }^{25}$ Rayleigh, geometric, and stochastic, depending on the grain size relative to the wavelength. Scattering in the direction of the transmitting transducer is often referred to as backscatter. However, the scattered energy at any angle (relative to the transmit direction) can be measured, if a receiver can be placed appropriately.

Backscatter measurements have been used for a range of material characterization applications. The backscattered signal has been correlated with grain size, ${ }^{183,184}$ though the technique is not recommended for large grains where multiple scattering is significant. Moysan and Corneloup ${ }^{185}$ discuss the use of backscatter attenuation to characterize texture and orientation in transversely isotropic welds. Backscattered acoustic signals from annealed polycrystalline aluminum possess fractal characteristics, ${ }^{186}$ and a grain size distribution can be deduced to match the distribution obtained experimentally in polycrystalline materials.

A related measurement to scattering is that of ultrasonic diffuse field measurements. Diffuse field measurements have been proposed for characterization of rocks, ${ }^{187,188}$ polycrystalline metals, ${ }^{189,190,191}$ and concrete. When a material is insonified with ultrasonic energy, grain scattering results in a portion of the energy being multiply scattered before returning to the receive transducer. At times that are large when compared to the first direct reflection, ${ }^{192}$ the propagation behavior of the scattered energy satisfies a diffusion equation, and the resulting field measurement is referred to as the diffuse field measurement. However, the diffuse field measurement is a stochastic quantity due to the random nature of the multiple scattering.

Theoretical analysis and modeling of diffuse field phenomena ${ }^{189-193}$ shows that the diffuse field depends on a range of factors including microstructure type, grain size-wavelength ratio, and temperature. ${ }^{194}$ Diffuse field measurements have been applied in the experimental characterization of high scattering materials with random structure such as cement-based materials ${ }^{195}$ and have been shown to correlate with crack length in concrete. ${ }^{196}$ Diffuse fields have also been studied in polycrystalline media. ${ }^{190}$ These studies present both theoretical development of diffuse field theory and some experimental verification of the diffuse field phenomenon. Multiple scattering is typically considered in any diffuse field theoretical development. Ghoshal and Turner ${ }^{191}$ discuss the theoretical investigation of backscatter in polycrystalline materials. Similar measurements for semi-solid materials (such as slurries) have also been conducted, with diffusion parameters recovered from the data. ${ }^{197}$ Ghoshal and Turner ${ }^{191}$ investigate theoretically (and confirm experimentally) diffuse field backscatter in polycrystalline materials. 
One other option for microstructure characterization in fuels is nonlinear acoustics. Nonlinear acoustics has been used in recent years as an important NDE tool for fatigue crack detection in polycrystalline materials ${ }^{198}$ as well as material degradation detection. ${ }^{199,200}$ In nonlinear acoustics, an incident single-tone ultrasonic beam is applied to the material under test. A nonlinear response typically results in the presence of higher harmonics, from which a nonlinearity parameter can be computed ${ }^{198}$ (though sub-harmonic generation has also been investigated by a number of researchers). The nonlinear elastic response is postulated to be due to structural inhomogeneities and defects as well as adsorbed and free fluids contained in the soft inclusions. ${ }^{201}$ Nonlinear acoustics measurements appear to have seen relatively little application to microstructure characterization, though Reference 202 discusses nonlinear SAW generation and acoustic/elastic constant determination in coarse-grained steel.

From a processing perspective, the goal here is, in some respects, the opposite of that for crack detection. With the exception of time of flight or attenuation measurements (which utilize back-wall signal location and amplitude), the requirement for all other measurements is to analyze the scattered energy between the back-wall signals. While some filtering tools are necessary to further reduce the impact of noise (beyond what is achieved from averaging alone), functions that enable frequency-domain analysis and computation of quantities such as the scattering coefficient are necessary.

\subsection{Signal Processing Needs}

Regardless of the measured quantity, a common hardware platform will be required, and includes:

- High frequency ultrasonic system (frequency ranges have not yet been determined, but will depend on the measurement type and wavelength relative to the feature size of interest) with adjustable amplitude and frequency. High power pulsers (tone burst excitation and pulse excitation) are available commercially.

- Digital to analog (D-A) conversion and DAQs with high sample rate (1 GHz or greater) and bit depth (16 bits or greater). These DAQ cards are currently available commercially. The goal is to be able to acquire time-domain data (a-scans). On-board memory depth on the cards will need to be high (in excess of $16 \mathrm{MB}$ ) to enable acquisition of extended lengths (corresponding to long-duration signals). Ideally, the associated software will enable the averaging of multiple signals to reduce noise levels.

- Software tools to enable control of the pulser/receiver system as well as the DAQ. While individual commercial units are typically available with computer controlled software, some software development will be needed to link the different modules together.

\subsection{Incorporation to Common Platform}

In general, a NDE system consists of five major units: sensor unit, instrumentation unit, scanning unit, data logging/acquisition unit, and signal/image processing unit. For example, an ultrasonic NDE system consists of ultrasonic transducer, ultrasonic pulser/receiver, automated scanning device, high-speed data acquisition unit, and signal/image processing package. The last four units are usually integrated together and controlled by a computer. To conduct the proposed irradiation test and to develop advanced ultrasonic signal/image processing software, we need to adapt or incorporate with common platforms that are available in the industry.

For use in an irradiation test some additional information, other than ultrasonic signals, such as DC resistance, DC capacitance, temperature, transducer resonance frequency, and piezoelectric coefficient $\left(\mathrm{d}_{33}\right)$, need to be acquired to study and determine the characteristics of piezoelectric material and the integrity of the transducer. Therefore, a data logging/acquisition system with multiple channels and various speeds needs to be developed. However, to permit real-time or post-processing, high-speed digitization of the 
received waveform and physical parameters is required. Currently, for data logging/acquisition and post-processing tasks, there are several common platforms:

- Fast Cross-Platform $\mathrm{C} / \mathrm{C}++$ Libraries

- $\quad$ LabVIEW $^{\circledR}$ (National Instruments)

- $\quad$ MATLAB $^{\circledR}$ and Simulink ${ }^{\circledR}$ (MathWorks)

- Scilab

- Python

The fast cross-platform $\mathbf{C} / \mathbf{C}++$ Libraries, such as IT++, is widely used by researchers and universities. It also more often used by industry to develop a stand-alone package for a specific application or/and for protection of proprietary information. In general, an end user can not access its source codes and has very little accessibility for making changes.

MATLAB and LabVIEW are two platforms widely used by R\&D institutes and various industries. MATLAB and LabVIEW were initially created to address different issues. However, both of them can now be used for tasks such as system control, data acquisition, and real-time or post signal/image processing.

Scilab, an open source alternative to MATLAB, is a cross-platform, high-level numerical computational package. It has been used for signal/image processing, numerical simulations and optimization, and symbolic manipulations.

Python is a general-purpose, high-level programming language that supports multiple programming paradigms. It is an open source and often used as a scripting language for web applications, but is also used in a wide range of non-scripting contexts. It has successfully embedded in a number of software products, including finite element method, 2D image processing, 3D animation, and video games. Python has greatly gained popularity in scientific and engineering world, which has developed many open source Py-libraries, such as SciPy, of algorithms and mathematical tools.

There are also many other popular numerical computing applications such as S-PLUS and IDL, as well as free and open source alternatives such as FreeMat and GNU Octave. However, to date, they are not yet as popular as MATLAB and LabVIEW for NDE applications.

MATLAB (MATrix LABoratory), as its name suggests, was designed for handling matrices and linear algebra. LabVIEW (Laboratory Virtual Instrumentation Engineering Workbench) was designed for data acquisition and instrument control. Over the years the two systems have grown towards each other such that now one can get Toolboxes for MATLAB to perform data acquisition and one can purchase versions of LabVIEW that contain linear algebra functions. These two systems are the most commonly used systems; and are, therefore, the preferred choices for this effort.

\subsubsection{LabVIEW}

LabVIEW's primary features are oriented towards instrumentation and measurement. LabVIEW programs are called Virtual Instruments (VIs). It uses the metaphor of an electrical diagram for programming, which makes it easy to visualize data flow. Extending this metaphor, building the user interface is much like assembling rack components. Front panel interfaces can be quickly created and then wired together to make the data connections you need. However, since the "G" language is primarily icon-based, it can be time-consuming to find the appropriate icon, as opposed to a text-based language. One benefit from this approach is that it encourages the programmer to use sub-VIs to reuse code rather than repeating the same code multiple times, thereby creating more robust code. Since National Instruments (the maker of LabVIEW) also makes data acquisition (DAQ) hardware, drivers and libraries for LabVIEW are readily available, and LabVIEW is encouraged as the primary development environment for such devices. Since LabVIEW was designed for instrumentation, it has had multithreading from very early on and has a robust 
library of support functions, such as rendezvous functions, notifiers, semaphores, occurrences, queues, and etc, available even in the base package. What makes this ideal for DAQ is that the application can be processing data while collecting data in another thread and saving the data in yet another thread. However, the programmer must be careful about race conditions, since everything is multi-threaded by default. One side-effect of this multi-threading is that it is easy to flood memory if one is not careful. Text-based code can also be written in LabVIEW using scripting nodes. However, many of the math and signal processing functions are not included in the base version of LabVIEW. LabVIEW can even call MATLAB functions, but this functionality is not included in the base package.

\subsubsection{MATLAB}

Since MATLAB was designed for matrices, it is optimized for linear algebra. (LabVIEW's linear algebra functions are not even available in the Base package.) As LabVIEW has a wealth of data acquisition and driver libraries, so MATLAB has a wealth of data manipulation libraries. As a text-based language, it is easier than LabVIEW to modify and/or insert new code, leading to faster programming. However, it is too easy to write monolithic scripts with no modularization, leading to poor programming practices. The interactive command console also makes algorithm development much easier. Unlike LabVIEW, one needs to purchase a separate toolkit for parallel processing. Running separate sections of code simultaneously (multi-threading) is not built in and requires awkward approaches to the code. ${ }^{203,204}$ Unlike LabVIEW, which can use 'references', MATLAB does not really have a call-by-reference capability, meaning there can be excessive memory usage and time spent in duplicating data that is passed between functions. MAT$\mathrm{LAB}$ can use global variables to alleviate this problem, but such practices are discouraged. Finally, due to MATLAB's emphasis on matrices and large data sets, even element-by-element operations on data can be expressed much more simply in MATLAB than in other languages. Such capabilities make development of post-processing algorithms much faster and more robust in MATLAB.

Instead of developing a completely new package, there are packages that have been developed under either MALTAB or LabVIEW platform for various NDE/NDT applications. For example, NASA Glenn

Research Center has been developed a package, named NDE Wave \& Image Processor (NDEWIP), under LabVIEW platform. NDEWIP provides advanced signal and image processing, analysis, and visualization capability to NDE \& health monitoring. It has some unique capabilities, such as interactive wavelet-based signal and image processing, and model-based curve fitting of spectroscopy data. Argonne has been developing two packages, called SCIUI and imagingGUI. Scanning, controlling, and Imaging User Interface (SCIUI) is a LabVIEW based package that is capable of instrument integration and control, scanning control, data acquisition and filtering, image processing, and data visualizing. SCIUI can acquire and save data directly into the correct format, translate existing data into proper format of different platforms, then conduct signal and image processing in real-time. The program, imagingGUI, is a MATLAB based package for advanced data image processing and 2D/3D data visualization. Applications for various NDT techniques, such as millimeter wave ( $\mathrm{mmW}$ ), ultrasonics, eddy current, and photoacoustics, various toolboxes and plug-in features were developed and embedded in imagingGUI. It contains plug-ins to translate existing data from different platforms into the proper format. Different data types acquired from various NDT techniques (Figure 4-5) or different layouts of one particular data type (Figure 4-6) can be processed and displayed with imagingGUI. Various user-generated filters and functions are available with different data types and different NDT techniques (Figure 4-7).

These packages, especially SCIUI, can be used as a base to explore advanced NDT solutions or to develop advanced algorithms. This approach will offer the capability of system integration and control, provide flexibility for adding customized software, allow cross-linking between different platforms, enhance data and sensor fusion, and save software developing time and cost. 

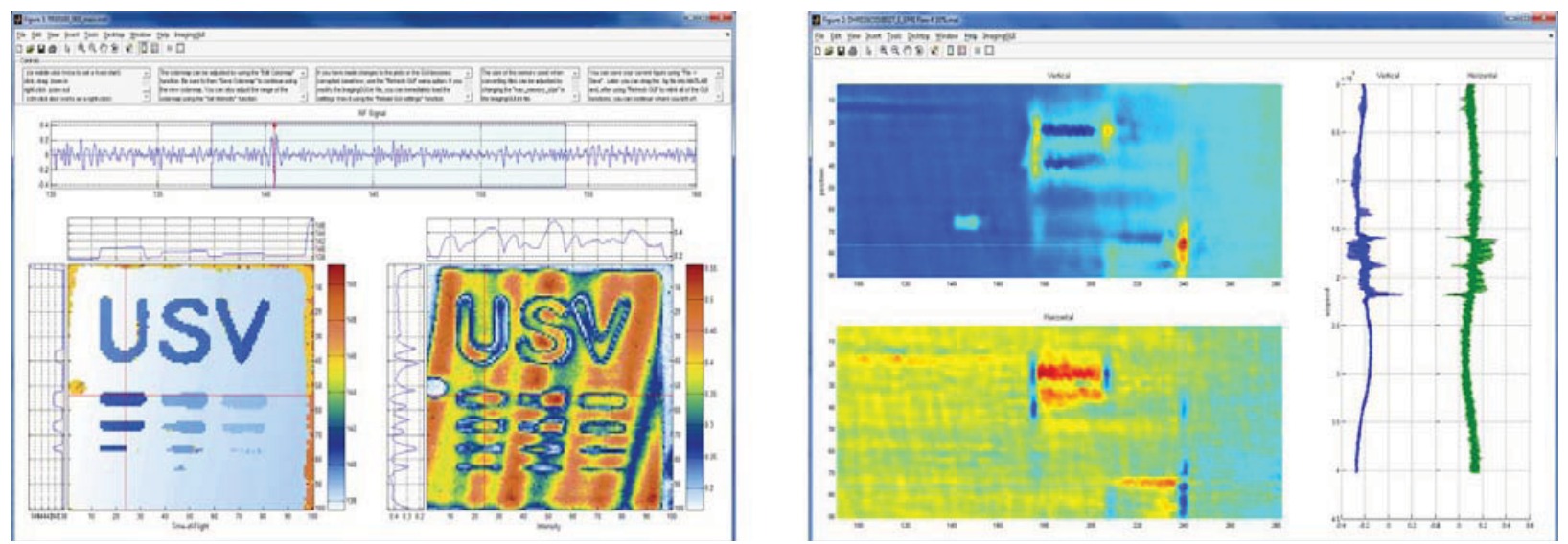

Figure 4-5. Examples of two different data types using imagingGUI.
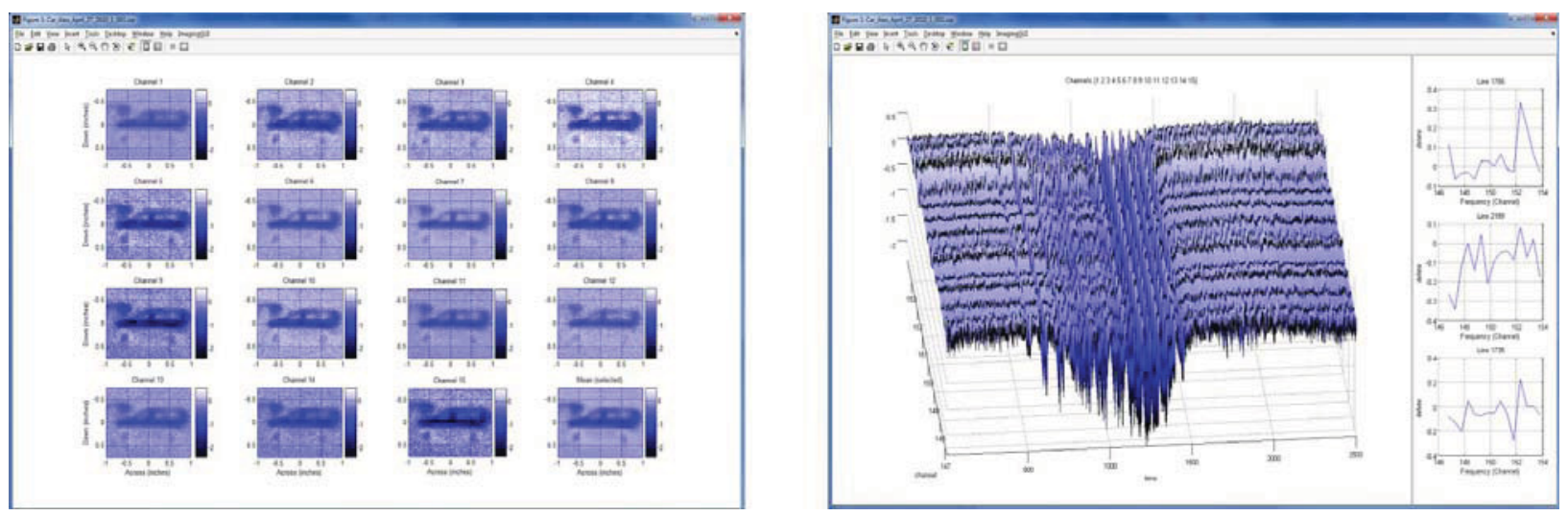

Figure 4-6. Examples of two different layouts available to one data type.

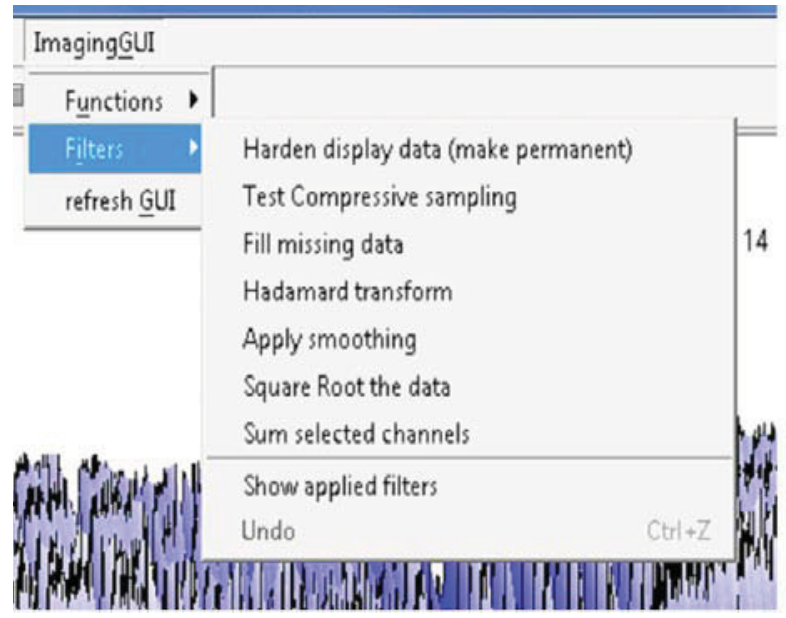

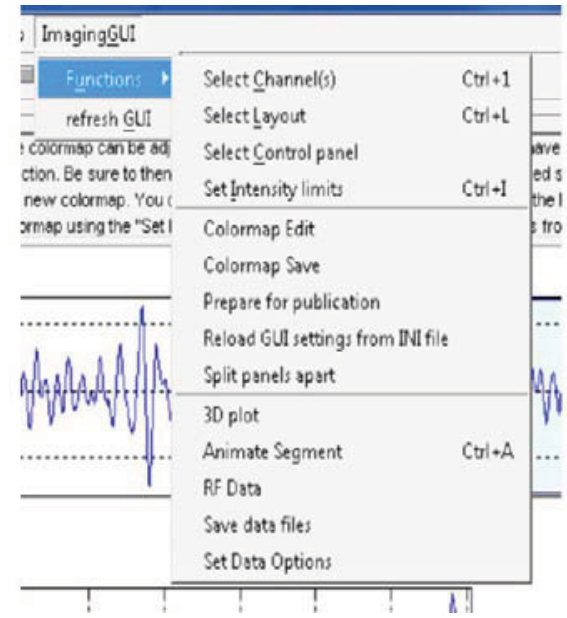

Figure 4-7. Examples of different user-generated Filters and Functions available with different data types. 


\subsection{Summary}

This section details background information on general ultrasonic signal processing and the challenges in obtaining useful information from the raw data. Information is also presented regarding some of the specific parameters to be measured ultrasonically. These parameters include temperature, dimensional changes, fission gas evolution, crack initiation and growth, and microstructural evolution (i.e. grain growth and porosity). Hardware and software requirements are also discussed. Finally, incorporation of signal processing software to a common platform is discussed. This includes discussions of commonly used commercial software packages as well as custom software packages developed in-house. 


\section{SUMMARY}

\subsection{Irradiation Test}

Task 1 of this project supports efforts to develop a test capsule design and define irradiation conditions for evaluating most promising candidate piezoelectric and magnetostrictive transducer materials and designs. This test capsule will be irradiated in the MIT test reactor for approximately 310 full power days, accumulating a total fluence of greater than $1 \times 10^{21} \mathrm{n} / \mathrm{cm}^{2}$.

The proposed testing conditions are:

- Temperature: $300{ }^{\circ} \mathrm{C}-350{ }^{\circ} \mathrm{C}$,

- $\quad$ Fast Flux $(>1 \mathrm{MeV}): 4 \times 10^{13} \mathrm{n} / \mathrm{cm}^{2 *} \mathrm{sec}$,

- Gas Environment: Helium (possibly including a small amount of neon for temperature control)

The proposed test capsule is a cylindrical graphite sample holder designed to accommodate up to six piezoelectric and three magnetostrictive sub-capsules (see Figure 5-1). The capsule will also allow instrumentation to monitor capsule temperature, fast and thermal flux, and gamma heating.

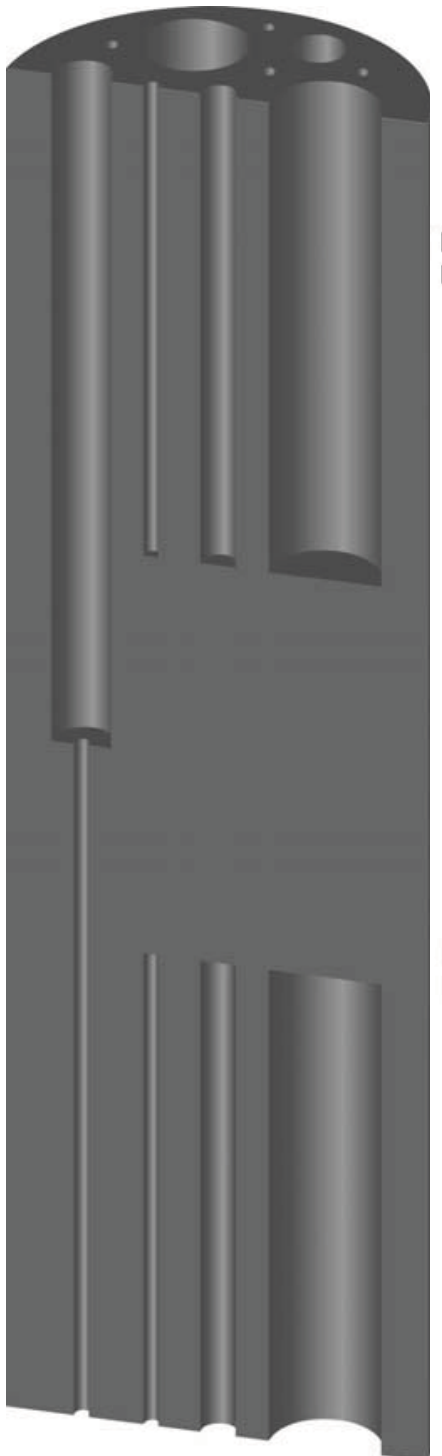

Graphite Upper Section: 45 mm Diameter, $54 \mathrm{~mm}$

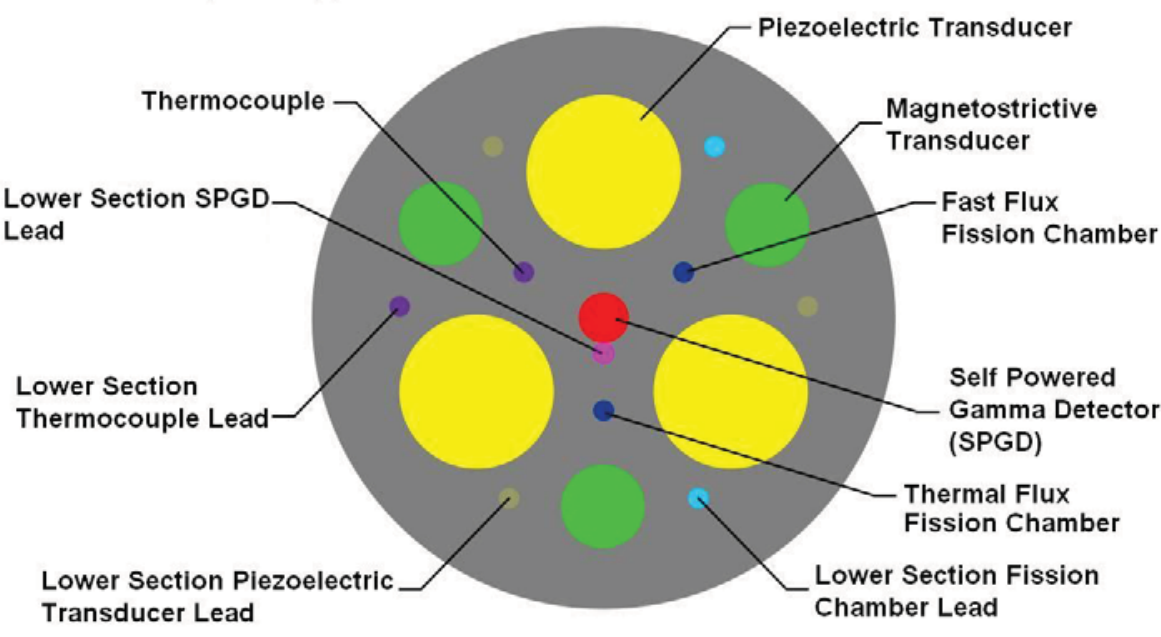

Graphite Lower Section: 45 mm Diameter, 54 mm

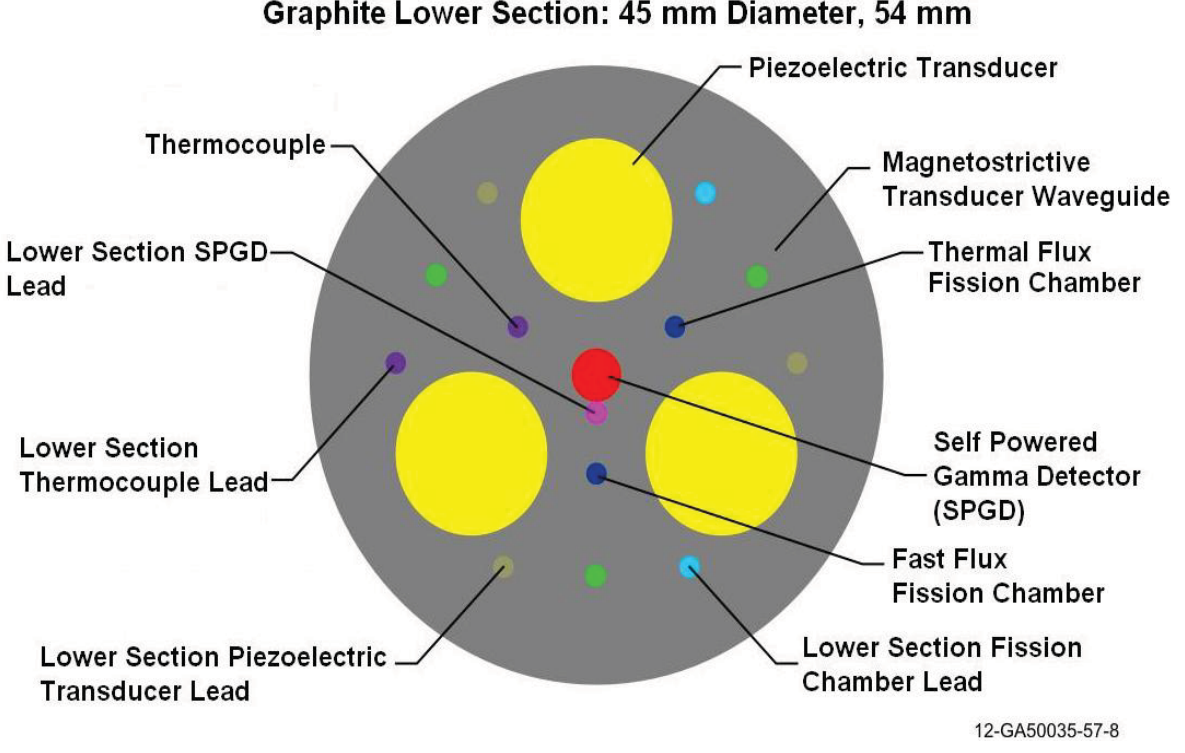

Figure 5-1. Conceptual sketch of graphite sample holder. 
Materials to be tested were selected based on material compatibility with the testing environment (i.e., Curie temperature above irradiation temperature, minimal neutron reactive elements, etc.), performance as a transducer material, and anticipated radiation tolerance. Selected materials are listed in Table 5-1.

Table 5-1. Materials selected for inclusion in irradiation test.

\begin{tabular}{|c|c|c|}
\hline Magnetostrictive Materials & Piezoelectric Materials & Magnet Materials \\
\hline Remendur (or Vacoflux 50) & $\mathrm{AlN}$ (Aluminum Nitride) & Alnico \\
\hline Arnokrome 4 (or Arnokrome 5) & $\mathrm{Bi}_{3} \mathrm{TiNbO}_{9}$ (Bismuth Titanate Niobate) & Samarium-Cobalt \\
\hline Galfenol & $\mathrm{ZnO}$ (Zinc Oxide) & \multicolumn{1}{|}{} \\
\cline { 1 - 3 } &
\end{tabular}

A series of out of pile tests has been identified which are designed to help identify potential design flaws in the test capsule, characterize the transducer materials, and help separate non-radiation induced effects from irradiation test results. A list of the identified tests is given in Table 5-2.

Table 5-2. Proposed out-of-pile tests.

\begin{tabular}{|c|c|c|}
\hline Test & Materials & Description \\
\hline $\begin{array}{l}\text { Endurance test } \\
\text { (ET) }\end{array}$ & $\begin{array}{l}\text { All candidate } \\
\text { materials }\end{array}$ & $\begin{array}{l}\text { The ET include operation of candidate transducers at } \\
300{ }^{\circ} \mathrm{C} \text {. This test is to be used as reference for the data } \\
\text { collected during the irradiation test. Two types of } \\
\text { endurance tests can be performed, one at an elevated } \\
\text { temperature relative to the nuclear reactor environmental } \\
\text { conditions to accelerate the degradation process. The other } \\
\text { is to be at anticipated irradiation temperature of } 300{ }^{\circ} \mathrm{C} \text {. } \\
\text { The time necessary for each of this test is at least several } \\
\text { weeks if not for a month. The samples are to be inserted in } \\
\text { the reactor for about a year, so a several month long test is } \\
\text { proposed. } \\
\text { This test will allow separation of temperature induced } \\
\text { changes from radiation induced changes, as well as } \\
\text { identification of design flaws. }\end{array}$ \\
\hline $\begin{array}{l}\text { Maximum } \\
\text { operating } \\
\text { temperature } \\
(\mathrm{MOT})\end{array}$ & $\begin{array}{l}\text { All candidate } \\
\text { materials }\end{array}$ & $\begin{array}{l}\text { The MOT is determined by placing the transducer in the } \\
\text { tube furnace and increasing the temperature linearly at a } \\
\text { slow rate so that at each measurement could be considered } \\
\text { isothermal. In the past rates such as } 1 \text { degree per minute } \\
\text { have been used. As such, the time necessary for each } \\
\text { experiment will depend on the Curie temperature; on the } \\
\text { order of 500-1000 minutes or } 8-16 \text { hours. } \\
\text { This test will allow identification of possible temperature } \\
\text { induced changes at temperatures near irradiation } \\
\text { temperature, effects of temperature transients, and } \\
\text { maximum operating temperature }\end{array}$ \\
\hline
\end{tabular}


Table 5-2. Proposed out-of-pile tests.

\begin{tabular}{|c|c|l|}
\hline Test & \multicolumn{1}{|c|}{ Materials } & \multicolumn{1}{c|}{ Description } \\
\hline $\begin{array}{c}\text { Saturation } \\
\text { magnetostriction }\end{array}$ & $\begin{array}{c}\text { All magnetostrictive } \\
\text { candidate materials }\end{array}$ & $\begin{array}{l}\text { This test involves measurement of magnetostriction of } \\
\text { candidate materials as a function of applied DC magnetic } \\
\text { field using a DC current supply and a pushrod dilatometer. } \\
\text { Characterization of performance of candidate } \\
\text { magnetostrictive materials }\end{array}$ \\
\hline $\begin{array}{c}\text { Hysteresis } \\
\text { measurement }\end{array}$ & $\begin{array}{c}\text { All candidate } \\
\text { materials }\end{array}$ & $\begin{array}{l}\text { The HM characterizes remnant polarization and indicates } \\
\text { changes in material structure. This test can be performed } \\
\text { with the transducer in situ and will be completed alongside } \\
\text { the MOT and ET. }\end{array}$ \\
\hline
\end{tabular}

Several other items of concern were also addressed in Section 3. These include the electrical connections and cables required for coupling the test transducers to ultrasonic equipment outside the reactor, as well as potential difficulties in acoustically coupling the transducers to waveguides (necessary for monitoring signals).

\subsection{Signal Processing Development}

Progress on this task was limited by the need to match an accelerated schedule for Task 1. An extensive description of general ultrasonic signal processing methods was developed, along with some specific information about the parameters to eventually be measured in-pile. Methods for incorporating various signal processing techniques into a common platform were also described.

\subsection{Future Work}

Future work currently focuses on supporting the transducer irradiation test. This will primarily consist of construction and qualification of test specimens and the test capsule, performance of the out of pile tests identified in Section 3, and analysis of signals generated during the in-pile test.

Due to the acceleration of the irradiation test schedule for this effort in FY13, signal processing development will be deferred. 
NEET In-Pile Ultrasonic Sensor Enablement-FY 2012 Status Report

September 2012 


\section{REFERENCES}

1. J. Rempe, H. MacLean, R. Schley, D. Hurley, J. Daw, S. Taylor, J. Smith, J. Svoboda, D. Kotter, D. Knudson, S. C. Wilkins, M. Guers, L. Bond, L. Ott, J. McDuffee, E. Parma, and G. Rochau, New In-Pile Instrumentation to Support Fuel Cycle Research and Development, FCRD-FUEL-2011-000033 (also issued as INL/EXT-10-19149), January 2011.

2. C. Grandy, Argonne National Laboratory, personal communication to J. Rempe, Idaho National Laboratory, July 2012.

3. K. Natesan, M. Li, S. Majumdar, R.K. Nanstad, and T.-L. Sham, "Code Qualification of Structural Materials for AFCI Advanced Recycling Reactors,” ANL-AFCI-244, September 2008.

4. Light Water Reactor Sustainability Program Integrated Program Plan, INL/EXT-11-23452, January 2012.

5. Technical Program Plan for the Next Generation Nuclear Plant/Advanced Gas Reactor Fuel Development and Qualification Program, PLN-3636, September 30, 2010.

6. Summary for the Next Generation Nuclear Plant Project In Review, INL/EXT-10-19142, Rev 1, September 2010 .

7. Next Generation Nuclear Plant Project Research and Development Status, INL/EXT-10-19259, August 2010.

8. K. Natesan, S. Majumdar, P.S. Shankar, and V.N. Shah, "Preliminary Materials Selection Issues for the Next Generation Nuclear Plant Reactor Pressure Vessel,” ANL/EXT-06/45, September 2006.

9. US Department of Energy, Office of Nuclera Energy, "Nuclear Energy Enabling Technologies Office of Nuclear Energy Advanced Sensors and Instrumentation Integrated Research Plan," September 2012.

10. K. Maeda, S. Sasaki, M. Kato, Y. Kihara. J. Nucl. Mater. 389 (2009) 78.

11. P. Millet, INL, informal communication to J. Rempe, INL, June 2010.FY2009 Advanced Test Reactor National Scientific User Facility User's Guide, INL/EXT-08-14709, Idaho National Laboratory (2009).

12. N. Chauvin, A. Courcelle, M. Pelletier, Y. Guerin, JM. Escleine, M. Phelip, F. Michel, S. Bejaoui, and M. Lainet, "Fuel Design, Irradiation Programme and Modelling, Application to Several Fuels for GENIV Systems," presentation at 2010 ATR NSUF User's Week, June 2010.

13. A. J. Palmer, G. L. McCormick, S. J. Corrigan, "Hydraulic Shuttle Irradiation System (HSIS) Recently Installed in the Advanced Test Reactor (ATR)," Proceedings of ICAPP '10, Paper 10354, San Diego, CA, USA, June 13-17, 2010

14. http://www.iaea.org/worldatom/rrdb/, International Atomic Energy Agency, "Nuclear Research Reactors in the World", accessed April 30, 2009.

15. J. F. Villard, "Progress in Instrumentation Development for the Future Jules Horwitz Reactor," presentation at Joint IANS/IEEE Meeting, Idaho Falls, ID, September 11, 2012. 
16. J-F Villard and M. Schyns, "Advanced In-Pile Measurements of Fast Flux, Dimensions, and Fission Gas Release," Proceedings of the ANS NPIC HMIT 2009 Topical Meeting on Nuclear Plant Instrumentation, Controls, and Human Machine Interface Technology, Knoxville, TN, April 2009.

17. S. Solstad \& R. Van Nieuwenhove, "Instrument Capabilities and Developments," Proceedings of the ANS 2009 Topical Meeting on Nuclear Plant Instrumentation, Controls, and Human Machine Interface Technology, Knoxville, TN, April 2009.

18. Future Transient Testing of Advanced Fuels - Summary of the May 4-5, 2009 Transient Testing Workshop Held at Idaho National Laboratory, INL/EXT-09-16392, September 2009.

19. D. Petti, INL, informal communication to J. Rempe, INL, July 27, 2012.

20. J.T. Busby and M.N. Gussev, "Assessment of Initial Test Conditions for Experiments to Assess Irradiation Assisted Stress Corrosion Cracking Mechanisms," ORNL/TM-2010/346, December 2010.

21. US NRC, "Safety Evaluation Report Related to the Construction of Clinch River Breeder Reactor Plant, Nuclear Regulatory Commission, USNRC Report, NUREG-0968,vol. 1, Main Report, March 1983.

22. R.K. Nanstad, "Reactor Pressure Vessel Task of Light Water Reactor Sustainability Program: Assessment of High Value Surveillance Materials,” ORNL/LTR-2011/172, June 2011.

23. S. Sham, ORNL, email, to J. Rempe, INL, dated August 5, 2012.

24. J. Rempe, D. Knudson, J. Daw, T. Unruh, B. Chase, K. Davis, and R. Schley, "New Instrumentation for Irradiation Testing in High Flux Materials and Test Reactors," 8th International Topical Meeting on Nuclear Plant Instrumentation, Control, and Human Machine Interface Technologies (NPIC\&HMIT 2012), San Diego, CA, July 22-26, 2012.

25. D. Ensminger, and L. J. Bond, Ultrasonics: Fundamentals, Technologies, and Applications, CRC Press, 2012.

26. K. Phani, et. al, "Estimation of Elastic Properties of Nuclear Fuel Material Using Longitudinal Ultrasonic Velocity - A New Approach," J. Nucl. Mat., 366, 2007, pp. 129-136.

27. J. F. Villard, et. al.,"Acoustic Sensor for In-Pile Fuel Rod Fission Gas Release Measurement," IEEE Transactions on Nuclear Science, 58, 2011, pp. 151-155.

28. L.C. Lynnworth, "Ultrasonic Measurements for Process Control: Theory, Techniques, and Applications," Academic Press, 1989.

29. MITR Users Guide Rev. 3 July 2012, Massachusetts Institute of Technology (2012).

30. N. Gopalsami, A.C. Raptis, "Acoustic Velocity and Attenuation Measurements in Thin Rods with Application to Temperature Profiling in Coal Gasification Systems," IEEE Transactions on Sonics and Ultrasonics, SU-31, 1984, pp. 32-39.

31. K. E. Holbert, S. Sankaranarayanan, S. S. McCready, "Response of Lead Metaniobate Acoustic Emission Sensors to Gamma Irradiation," IEEE Transactions on Nuclear Science, vol. 52, no. 6, 2005, pp. 2583-2590. 
32. Kulikov, et al., "Computer simulation of ferroelectric property changes in PLZT ceramics under neutron irradiation," Proceedings of SPIE, 4348, 2001, pp. 264-269.

33. H. Shea, "Radiation sensitivity of microelectromechanical system devices," J. Micro/Nanolith., 8, 2009, pp. 1-11.

34. Wittels \& Sherrill, "Fast Neutron Effects in Tetragonal Barium Titanate," Journal of Applied Physics, 28 [5], 1957, pp. 606-609.

35. W. Primak, T. Anderson, "Metamimictization of Lithium Niobate by Thermal Neutrons," Nuclear Technology, 23, 1975, pp. 235.

36. T.K. Bierney, "Instrumentation for the Measurement of Vibration in Severe Environments Such as Nuclear Reactors," Endevco Technical Paper 272, 1976, pp. 1-8.

37. D.A. Parks, B. R. Tittmann. "Ultrasonic NDE in a Reactor Core," Presented at Review of Progress in Quantitative Nondestructive Evaluation, July 17-22, Burlington, VT, 2011.

38. R.N. Ord, R.W. Smith, "Ultrasonic Under-Sodium Viewing System Development for the FFTF," HEDL-SA-335. Westinghouse Hanford Co., Richland, Washington, 1972

39. G. Broomfield, "The Effect of Temperature and Irradiation on Piezoelectric Acoustic Transducers and Materials," UKAEA Report AERE-R11 942, 1985.

40. R. Kažys, A. Voleišis, and B. Voleišiene, "High temperature ultrasonic transducers: review," ULTRAGARSAS (ULTRASOUND), Vol.63(2), 2008.

41. R. L. Thomas, "Vibration Instrumentation for Nuclear Reactors," Endevco Technical Paper 258, Pasadena: Endevco, 1973

42. L. W. Hobbs, F. W. Clinard, S. J. Zinkle, and R. C. Ewing, "Radiation effects in ceramics," Journal of Nuclear Materials, 216, 1994, pp. 291-321.

43. R. Moore, J. Benedetto, J. McGarrity, and F. McLean, "Neutron Irradiation Effects on PZT Thin Films for Nonvolatile-Memory Applications," IEEE Trans. Nucl. Soc., 38(6), 1991, pp.1078-1082.

44. M. Severson, "An Experimental Design for Measuring In Situ Radiation Damage to Piezoelectric Transducer," Masters Thesis, Air Force Institute of Technology, Department of the Air Force Air University, Wright-Patterson Air Force Base, Ohio, 2004.

45. R. Kazys, V. Voleisis, R. Sliteris, B. Voleisiene, L. Mazeika, and H. Abderrahim, "Research and Development of Radiation Resistant Ultrasonic Sensors for Quasi-Image Forming Systems in a Liquid Lead-Bismuth." Ultragarsas (Ultrasound), 62(3),2006, pp. 7-15.

46. J. Cheeke "Fundamentals and Applications of Ultrasonic Waves," CRC Press, Boca Raton. ISBN $0849301300,2002$.

47. P. Mix, "Introduction to Nondestructive Testing: A Training Guide. 2nd Ed.," Wiley, Hoboken, New Jersey. ISBN 0471420298, 2005.

48. K. Wong, "In Properties of Lithium Niobate," Institution of Engineering and Technology, 2002. 
49. L. Berger, “Semiconductor Materials.” CRC Press, ISBN 0-8493-8912-7, 1997, pp. 123-124.

50. R. Kazys, et al., "High Temperature Ultrasonic Transducers for Imaging and Measurements in a Liquid $\mathrm{Pb} / \mathrm{Bi}$ Eutectic Alloy," IEEE Transactions on Ultrasonics, Ferroelectrics, and Frequency Control, 2005, pp. 525-537

51. K. Trachenko, "Understanding resistance to amorphization by radiation damage," Journal of Physics: Condensed Matter, 16(49), 2004, pp. R1491-R1515.

52. S. Zhang and F. Yu, "Piezoelectric Materials for High Temperature Sensors," J. Am. Ceram. Soc., 94(10), 2011, pp. 3153-3170.

53. Y. P. Meleshko, S. G. Karpechko, G. K. Leont'ev, V. I. Nalivaev, A. D. Nikiforov, and V. M. , "Radiation Resistance of the Piezoelectric Ceramics TrsTS-21 and TNV-I," Translated from Atomnaya Energiya, 1986, pp. 50-52.

54. C. Jagadish, S. J. Pearton, Zinc Oxide Bulk, Thin Films and Nanostructures: Processing, Properties, and Applications, Elsevier, 2006

55. S. Zhang, et. al., "Characterization of piezoelectric single crystal YCa4O (BO3)3 for high temperature applications," Applied Physics Letters, 92(20), 2008.

56. N. D. Patel, and P. S. Nicholson, "High Frequency - High Temperature Ultrasonic Transducers," NDT International, pp. 262-266, 1990.

57. D. Stubbs, and R. Dutton , "High-Temperature Ultrasonic Sensor for in Situ Monitoring of Hot Isostatic Processing," SPIE, 1996, pp. 164-172

58. T. Yano, K. Inokuchi , M. Shikama, and J. Ukai, "Neutron irradiation effects on isotope tailored aluminum nitride ceramics by a fast reactor up to $2 \cdot 10^{26} \mathrm{n} / \mathrm{m}^{2}$," Journal of Nuclear Materials , 2004, pp. 1471-1475.

59. Y. Ito, et al., "Radiation Damage of Materials Due to High Energy Ion Irradiation," Nuclear Instruments and Methods in Physics Research, 530, 2002

60. R. Turner, P. Fuierer, R. Newnham, T. Shrout, "Materials for High Temperature Acoustic and Vibration Sensors: A Review," Applied Acoustics, 41, 1994, pp. 299-324.

61. A. Baba, C.T. Searfass, B.R. Tittmann, "High Temperature Ultrasonic Transducer up to $1000^{\circ} \mathrm{C}$ Using Lithium Niobate Single Crystal," Applied Physics Letters, 97 [23], 2010, pp. 232901-1 232901-3.

62. L.C. Lynnworth, E.H. Carnevale, M.S. McDonough, S.S. Fam, "Ultrasonic Thermometry for Nuclear Reactors," IEEE Transactions on Nuclear Science, Vol. NS-16, pp. 184-187, 1968.

63. L.C. Lynnworth, "Nuclear Reactor Thermometry," US Patent Application 3,597,316: 3 Aug 1971.

64. S.C. Rogers, G.N. Miller., "Ultrasonic Level, Temperature, and Density Sensor," IEEE Trans. on Nuclear Science, 29 (1), 1982, pp. 665-668.

65. J. Daw, J. Rempe, S. Taylor, J. Crepeau, and S.C. Wilkins., "Ultrasonic Thermometry for In-Pile Temperature Detection," Proceedings of NPIC\&HMIT 2010, 2010. 
66. R.D. Brown, J.R. Cost, J.T. Stanley, "Effects of neutron irradiation on magnetic permeability of amorphous and crystalline magnetic alloys," J. Appl. Phys., 55, 1984, pp. 1754-1756.

67. Vacuumschmelze, "SOFT MAGNETIC COBALT-IRON-ALLOYS," http://www.vacuumschmelze.com/fileadmin/Medienbiliothek_2010/Downloads/HT/PTH\%20004\%20Vacoflux-Vacodur\%20engl.pdf, Accessed 08/09/2012.

68. Arnokrome 3 Datasheet Rev. 01-11-11,www.arnoldmagnetics.com/WorkArea/DownloadAsset.aspx?id=5262, Accessed 08/09/2012.

69. Arnokrome 4 Specification Rev. 1/11/11,www.arnoldmagnetics.com/WorkArea/DownloadAsset.aspx?id=5263, Accessed 08/09/2012.

70. Arnokrome 5 Specification Rev. 2/24/11,www.arnoldmagnetics.com/WorkArea/DownloadAsset.aspx?id=5328, Accessed 08/09/2012.

71. "What is Galfenol?", Etrema Products, Inc., http://www.etrema-usa.com/core/galfenol/, Accessed 08/ $09 / 2012$.

72. R.S. Sery, et al., "Radiation Damage Thresholds for Permanent Magnets," NOLTR 61-45, 1961.

73. Liu, et al., "Thermal Stability and Radiation Resistance of Sm-Co Based Permanent Magnets," Paper 2036, Proceedings of Space Nuclear Conference, 2007.

74. Thermocoax http://www.thermocoax.com/doc-Signal_Transmission/E004-3-STC-low-capacitace-SIO2.pdf

75. M.I. Cable Company, 1225 Price Plaza Drive, Katy, Texas, www.micable.com

76. Meggitt Safety Systems, Simi Valley, California, www.stablecable.com

77. J. Taguchi, N. Uesugi, T. Miyazawa, K. Sato, S. Horikoshi, “An Ultrasonic Viewing System in Liquid Sodium,” IEEE. Trans. Nucl. Sci., 27(1), 1980, pp. 821-825.

78. C.K. Day, R.W. Smith, "Under-Sodium Viewing," IEEE Transactions on Sonics and Ultrasonics, SU21 (3), 1974.

79. Y. Ono, et al., "High-temperature and broadband immersion ultrasonic probes," IEEE Sensor Journal, 6(3), 2006, pp. 580-587.

80. Zetec, "RevospECT." http://www.zetec.com/2010/07/revospect/, Accessed March 15, 2012.

81. J. Benson, S. Ramakrishnan, et al., "Automated Analysis Systems for Characterizing Eddy Current SG Inspection Data," The 13th International Symposium on Applied Electromagnetics and Mechanics (ISEM 2007), East Lansing, Michigan: 157-158, 2007.

82. Electric Power Research Institute, Automated Analysis of Array Probe Eddy Current Data, Palo Alto, California, Electric Power Research Institute, Inc. (EPRI), 2008.

83. Electric Power Research Institute, Steam Generator Management Program: Automated Analysis Performance Demonstration Database, Palo Alto, California, Electric Power Research Institute, Inc., 2009. 
84. L. Udpa, "Chapter 7, Signal and Image Processing for Electromagnetic Testing," Nondestructive Testing Handbook, Third Edition: Volume 5, Electromagnetic Testing. S. S. Udpa and P. O. Moore. Columbus, Ohio, American Society for Nondestructive Testing, 2004.

85. T. Khan, et al., "Automated Flaw Detection Scheme for Cast Austenitic Stainless Steel Weld Specimens Using Hilbert-Huang Transform of Ultrasonic Phased Array Data," Review of Progress in Quantitative Nondestructive Evaluation, 31, AIP Conference Proceedings, 1430, 2012, pp. $1235-1242$.

86. H. Shekhar, R. Polikar, et al., "Dynamic Thresholding for Automated Analysis and Classification of Bobbin Probe Eddy Current Data." International Journal of Applied Electromagnetics and Mechanics 15, (1-4): 39-46, 2001.

87. G. Baskaran, K. Balasubramaniam, et al., "TOFD IMAGING: Ultrasonic TOFD Flaw Sizing and Imaging in Thin Plates Using Embedded Signal Identification Technique (ESIT)," Insight Non-Destructive Testing and Condition Monitoring 49(6): 537-542, 2004.

88. S. Legendre, D. Massicotte, et al. "Wavelet-Transform-Based Method of Analysis for Lamb-Wave Ultrasonic NDE Signals," IEEE Transactions on Instrumentation and Measurement 49(3): 524-530, 2000.

89. S. T. Quek, P. S. Tua, et al., "Detecting Anomalies in Beams and Plate Based on the Hilbert-Huang Transform of Real Signals." Smart Materials and Structures 12(3): 447-460, 2003.

90. U. Bencharit, J. L. Kaufman, et al., "Frequency and Spatial Compounding Techniques for Improved Ultrasonic Imaging," IEEE 1986 Ultrasonics Symposium, Williamsburg, Virginia, IEEE, New York: 1021-1026, 1986.

91. M. H. Choi, "Spatial Compounding from Ultrasonic RF Data for Speckle Reduction in Ultrasonic Diagnostic Imaging System," International Conference on Control, Automation and Systems, ICCAS 2007, Seoul, Korea, IEEE Computer Society, Piscataway, New Jersey: 1577-1580, 2007.

92. M. L. Hargreaves, "Digital Processing of Ultrasound Signals Back-scattered from Coarse Grained Austenitic Stainless Steel,” Keele, Staffordshire, England, University of Keele. Ph.D., 1988.

93. L. Ghouti, "High-Order Spectra-Based Deconvolution of Ultrasonic NDT Signals for Defect Identification," Ultrasonics 35(17): 525-531, 1997.

94. J. Chen Y. Shi, et al., "Noise Analysis of Digital Ultrasonic Nondestructive Evaluation System,’'International Journal of Pressure Vessels and Piping 76(9): 619-630, 1999.

95. S. C. Park, S. Lee, et al., "Threshold Varying Method of Stationary Wavelet Denoising for Ultrasonic Speckle Reduction," Materials Science Forum 449-452: 1153-1156, 2004.

96. N. M. Bilgutay, U. Bencharit, et al. "Enhanced Ultrasonic Imaging with Split Spectrum Processing and Polarity Thresholding," IEEE Transactions on Acoustics, Speech and Signal Processing 37(10): 1590-1592, 1989.

97. P. M. Shankar, P. Karpur, et al., "Split-Spectrum Processing: Analysis of Polarity Thresholding Algorithm for Improvement of Signal-to-Noise Ratio and Detectability in Ultrasonic Signals," IEEE Transactions on Ultrasonics, Ferroelectrics, and Frequency Control 36(1): 101-108, 1989. 
98. L. Ericsson, L., "Reduction of Material Noise in Ultrasonic Nondestructive Evaluation Using Synthetic Frequency Diversity Algorythms," Uppsala, Sweden, Teknikum Institute of Technology, Uppsala University, 1994.

99. V. L. Newhouse, P. Karpur, et al.,"A New Technique for Clutter Reduction in Ultrasonic Imaging," Proceedings of IEEE 1985 Ultrasonics Symposium, San Francisco, California, IEEE, New York. Vol. 2: 998-1003, 1985.

100. R. Miralles, L. Vergara, et al. (2004). "Material Grain Noise Analysis by Using Higher-Order Statistics." IEEE Transactions on Signal Processing 84(1): 197-205, 2004.

101. J. B. Morris, D. A. Pommet, et al., "Imaging of Strongly Scattering Object Using a Nonlinear Filtering Technique," Proceedings of SPIE - The International Society for Optical Engineering, San Diego, California, Society of Photo-Optical Instrumentation Engineers, Bellingham, Washington. Vol. 2570: 27-37, 1995.

102. S. D. Silverstein and L. J. Thomas, "Analytical Comparison of Sensor Signal Processing Enhancements for NDT Synthetic Aperture Ultrasonic Imaging." IEEE Transactions on Image Processing 2(1): 60-67, 1993.

103. M. T. Anderson, S. L. Crawford, et al., Assessment of Crack Detection in Heavy-Walled Cast Stainless Steel Piping Welds Using Advanced Low-Frequency Ultrasonic Methods, Washington, D.C., U.S. Nuclear Regulatory Commission, 2007.

104. National Research Council, Mathematics and Physics of Emerging Biomedical Imaging, Washington, D.C., National Academies Press, 1996.

105. L. Udpa and S. S. Udpa, "Application of Signal Processing and Pattern Recognition Techniques to Inverse Problems in NDE," International Journal of Applied Electromagnetics and Mechanics 8: 99-117, 1997.

106. P. Ramuhalli, "Neural Network Based Iterative Algorithms for Solving Electromagnetic NDE Inverse Problems”, Electrical Engineering, Ames, Iowa, Iowa State University. Ph.D., 2002.

107. A. Tarantola, Inverse Problem Theory: Methods for Data Fitting and Model Parameter Estimation, Elsevier Science BV, 1987.

108. C. Vogel, Computational Methods for Inverse Problems, Philadelphia, Society for Industrial and Applied Mathematics (SIAM), 2002.

109. K. Hwang, W. Lord, et al., "A Multiresolution Approach for Characterizing MFL Signatures from Gas Transmisson Pipeline Inspections," Review of Progress in Quantitative Nondestructive Evalua-

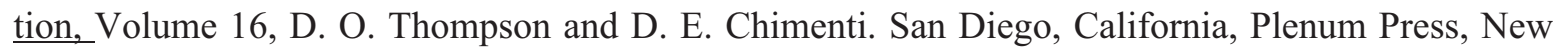
York. 16: 733-739, 1997.

110. H. Sohn, C. R. Farrar, et al., A Review of Structural Health Monitoring Literature: 1996-2001, Los Alamos, New Mexico, Los Alamos National Laboratory, 2003.

111. R. Polikar, L. Udpa, et al., "Frequency Invariant Classification of Ultrasonic Weld Inspection Signals," IEEE Transactions on Ultrasonics, Ferroelectrics and Frequency Control 45(3): 614-625, 1998. 
112. G. Simone, F. C. Morabito, et al., "Feature Extraction Techniques for Ultrasonic Signal Classification," International Journal of Applied Electromagnetics and Mechanics, 15(1-4): 291-294, 2001.

113. J. Kim, P. Ramuhalli, et al., "Automated Multichannel Signal Classification Systems for Ultrasonic Nondestructive Evaluation,” Key Engineering Materials 321-323: 1266-1269, 2006.

114. M. Yan, M. Afzal, et al., "Iterative algorithms for electromagnetic NDE signal inversion," Proceedings of the 3rd International Workshop on Electromagnetic Non-Destructive Evaluation II (ENDE (II), Reggio Calabria, Italy, IOS Press, Lansdale, Pennsylvania. 14: 287-296, 1998.

115. S. Kirkpatrick, C. D. Gelatt, et al. "Optimization by simulated annealing." Science 220(4598): 671-680, 1983.

116. R. L. Haupt, "An Introduction to Genetic Algorithms for Electromagnetics." IEEE Antennas and Propagation Magazine 37: 7-15, 1995.

117. S. Hoole, S. Subramaniam, et al. "Inverse Problem Methodology and Finite Elements in the Identification of Cracks, Sources, Materials and Their Geometry in Inaccessible Locations." IEEE Transactions on Magnetics 27(3): 3433-3443, 1991.

118. S. Caorsi, G. L. Gragnani, et al., "Microwave Imaging Based on a Markov Random Field Model." IEEE Transactions on Antennas and Propagation 42(3): 293-303, 1994.

119. V. Monebhrrun, B. Duchene, et al. "Three-Dimensional Inversion of Eddy Current Data for Nondestructive Evaluation of Steam Generator Tubes." Inverse Problems 14: 707-724, 1998.

120. S. Balasubramanian, B. Shanker, et al. "A Fast Integral Equation Based Scheme for Computing Magnetostatic Fields and Its Application to NDE Problems," Review of Progress in Quantitative Nondestructive Evaluation, Volume 21, D. O. Thompson and D. E. Chimenti. Brunswick, Maine, American Institute of Physics, Melville, New York. AIP Conference Proceedings 615: 331-337. 2001

121. Y. Li, G. Liu, et al. "An Adjoint Equation Based Method for 3D Eddy Current NDE Signal Inversion," Electromagnetic Nondestructive Evaluation (V), Budapest, Hungary, IOS Press, Amsterdam: 89-96, 2001.

122. Y. Kim, L. Jofre, et al. "Microwave Reflection Tomographic Array for Damage Detection of Civil Structures," IEEE Transactions on Antennas and Propagation 51(11): 3022-3032, 2003.

123. K. Arunachalam, K. Investigation of a Deformable Mirror Microwave Imaging and Therapy Technique for Breast Cancer, East Lansing, Michigan, Michigan State University. Ph.D., 2006.

124. G. D. Connolly, M. J. S. Lowe, et al. "Imaging of Simple Defects in Austenitic Steel Welds Using a Simulated Ultrasonic Array," Proceedings of the 35th Annual Review of Progress in Quantitative Nondestructive Evaluation, D. O. Thompson and D. E. Chimenti. Chicago, Illinois, American Institute of Physics, Melville, New York. AIP Conference Proceedings Volume 1096: 880-887, 2009.

125. W. Qing, S. Xueqin, et al., "Using Wavelet Neural Networks for the Optimal Design of Electromagnetic Devices." IEEE Transactions on Magnetics 33(2): 1928-1930, 1997.

126. Q. J. Zhang and K. C. Gupta, Neural Networks for RF and Microwave Design, Artech House, 2000. 
127. P. Ramuhalli, L. Udpa, et al., "Neural network based inversion algorithms in Magnetic Flux Leakage NDE." Journal of Applied Physics 93(10): 8274-8276, 2003.

128. A. Joshi, Inverse Problems in the Non-destructive Evaluation of Gas Transmission Pipelines Using Magnetic Flux Leakage, Electrical and Computer Engineering Department. East Lansing, Michigan, Michigan State University. Ph.D., 2006.

129. H. H. Barrett and K. J. Myes, Foundations of Image Science, Wiley-Interscience, 2004.

130. R. Potthast, Point Sources and Multipoles in Inverse Scattering Theory, Chapman and Hall/CRC, 2001.

131. D. Colton, and A. Kirsch, "A simple method for solving inverse scattering problems in the resonance region." Inverse Problems 12: 383-393, 1996.

132. D. Colton and R. Kress, Inverse Acoustic and Electromagnetic Scattering Theory, Springer-Verlag, 1998.

133. S. Caorsi, G. L. Gragnani, et al. "Microwave Imaging Based on a Markov Random Field Model," IEEE Transactions on Antennas and Propagation 42(3): 293-303, 1994.

134. A. N. Tikhonov and V. Arsenin, Solutions of Ill-Posed Problems, Wiley, 1977.

135. V. A. Morozov, Regularization Methods for Ill-Posed Problems, CRC Press, 1993.

136. H.A. Tasman, M. Campana, D. Pel, J. Richter, "Ultrasonic Thin-Wire Thermometry for Nuclear Applications," Temperature: Its Measurement and Control in Science and Industry, Vol. 5, Part 2, pp.1191-1196, 1982.

137. R.J. Grossman, "Ultrasonic-Thermometry Development for In-Situ Measurement of Nuclear-Fuel Temperatures (AWBA Development Program)," KAPL-4160, General Electric Company Knolls Atomic Power Laboratory, 1982.

138. E.P. Papdakis, L.C. Lynnworth, D.R. Patch, E.H. Carnevale, "Ultrasonic Thermometry in LMFBR Systems," Final Report NYO-3906-13, Panametrics Inc. 1972.

139. M. Laurie, D. Magallon, J. Rempe, S. Wilkins, J. Pierre, C. Marquié, S. Eymery, R. Morice, "Ultrasonic High Temperature Sensors: Past Experiments and Prospective for Future Use," International Journal of Thermophysics, 31 (8-9), pp. 1417-1427, Special Issue, September 2010.

140. G.A. Carlson, W.H. Sullivan, H.G. Plein, T.M. Kerley, "An Ultrasonic Thermometry System for Measuring Very High Temperatures in Reactor Safety Experiments," SAND79-0621, Sandia Laboratories, 1979.

141. A.E. Arave, F.E. Panisko, J.A. Christensen, "High-Temperature Ultrasonic Thermometer In-Reactor-Fuel Rod Centerline Temperature Test Results," ANCR-1091, Aerojet Nuclear Company, 1972.

142. M.Anselmi, E.R.Jorzik, "Ultrasonic Temperature Sensors (UTS): Manufacturing Procedure," 12/04/ 1996.

143. E.R.Jorzik, M.Anselmi, “UTS Assembly and Calibration Procedure,” 28/11/1995. 
144. I. Huhtiniemi, E. Jorzik, M Anselmi, "Special Instrumentation Developed for FARO and KROTOS FCI Experiments: High Temperature Ultrasonic Sensor and Dynamic Level Sensor," CSNI Specialist Meeting on Instrumentation, Santa Barbara, CA, USA, 1997.

145. G.A. Carlson, W.H. Sullivan, H.G. Plein, T.M. Kerley, "An Ultrasonic Thermometry System for Measuring Very High Temperatures in Reactor Safety Experiments," SAND79-0621, Sandia Laboratories, 1979.

146. G.A. Carlson, H.G. Plein, "Refractory Metals for Ultrasonic Thermometry Application," NUREG/ CR-0368 SAND78-1382 R-7, Sandia Laboratories, 1978.

147. R.J. Grossman, "Ultrasonic-Thermometry Development for In-Situ Measurement of Nuclear-Fuel Temperatures (AWBA Development Program)," KAPL-4160, General Electric Company Knolls Atomic Power Laboratory, 1982.

148. R.L. Shepard, C.J. Borkowski, J.K. East, R.J. Fox, J.L. Horton, "Ultrasonic and Johnson Noise Fuel Centerline Thermometry," International Colloquium on High-Temperature In-Pile Thermometry, EUR-5395, 1975.

149. G.A. Carlson, W.H. Sullivan, H.G. Plein, "Application of Ultrasonic Thermometry in LMFBR Safety Research," SAND-77 1157, Sandia Laboratories, 1977.

150. A.E. Arave, F.E. Panisko, J.A. Christiansen, "High-Temperature Ultrasonic Thermometer In-Reactor Fuel Rod Centerline Temperature Test Results," ANCR-1091, Aerojet Nuclear Company, 1972.

151. A.E. Arave, R.H. Meservey, "A High Temperature Ultrasonic Thermometer for Measuring Reactor Fuel Temperature," IN-1413, Idaho Nuclear Corporation, 1970.

152. A.E. Arave, "Comparison of Four Tungsten Alloys for Use as Ultrasonic Thermometer Sensors," ANCR-1225, Aerojet Nuclear Company, 1975.

153. A.E. Arave, J. Buchenauer, "Use of Tungsten-2\% Thoria Ultrasonic Transmission Line and Sensor to Improve the Performance of High-Temperature Ultrasonic Thermometry," TREE-NUREG-1021, Idaho National Engineering Laboratory, 1976.

154. H.A. Tasman, M. Campana, D. Pel, J. Richter, "Ultrasonic Thin-Wire Thermometry for Nuclear Applications," Temperature: Its Measurement and Control in Science and Industry, Vol. 5, Part 2, pp. 1191-1196, 1982.

155. H.A. Tasman, H.E. Schmidt, "The Ultrasonic Thermometer-Construction, Application, and Operating Experience," High Temperatures- High Pressures, Vol. 4 pp. 477-481, 1972.

156. H.A. Tasman, H.E. Schmidt, J. Richter, M, Campana, G. Fayl, "The TRESON Experiments: Measurement of Profiles in Nuclear Fuels by Means of Ultrasonic Thermometers," High TemperaturesHigh Pressures, Vol. 9 pp. 387-406, 1977.

157. L.C. Lynnworth, "Use of Ultrasonics for High-Temperature Measurements," Presented at American Society for Nondestructive Testing Meeting, Mar. 20, 1968, Boston, MA.

158. E.P. Papdakis, L.C. Lynnworth, D.R. Patch, E.H. Carnevale, "Ultrasonic Thermometry in LMFBR Systems," Final Report NYO-3906-13, Panametrics Inc. 1972. 
159. L.C. Lynnworth, "Temperature Profiles Using Multizone Ultrasonic Waveguides," Temperature: Its Measurement and Control in Science and Industry, Vol. 5, Part 2, pp. 1181-1190, 1982.

160. L.C. Lynnworth, E.H. Carnevale, "Ultrasonic Thermometry Using Pulse Techniques," Temperature: Its Measurement and Control in Science and Industry, Vol. 4, Part 1, pp. 715-732, 1972.

161. A. Benjaminson et al, "The Development of the Quartz Resonator as a Digital Temperature Sensor

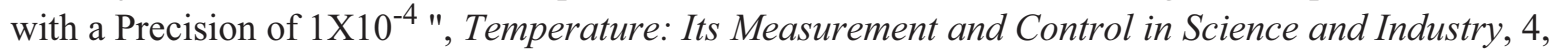
pp. 701-708, 1972.

162. A.A. Fathimani, J.F. Bell, “A New Resonant Thermometer for Nuclear Reactor Applications," J. Phys. E: Sci. Instrum., 11, pp. 588-596, 1978.

163. M.J. Roberts, D.E. Holcomb, R.A. Kisner, "Signal Processing Algorithm Implementation for In Vessel Level Measurement," Sept. 2006, https://inlportal.inl.gov/portal/server.pt/gateway/ PTARGS-0-2-3310-277-2604-43/ http\%3B/inlpublisher\%3B7087/publishedcontent/publ ish/communities/inl-gov/about- inl/gen-iv-technical-documents/si gnal-processing-algorighm.pdf.

164. Y. Dain, R. M. Lueptow, "Acoustic attenuation in three-component gas mixtures-Theory," $J$. Acoust. Soc. Am., 109, pp.1955, 2001.

165. Y. Dain, R. M. Lueptow, “Acoustic attenuation in a three-gas mixture: Results," J. Acoust. Soc. Am., 110, pp. 2974, 2001.

166. P. Ramuhalli, M. S. Good, et al, Ultrasonic Characterization of Cast Austenitic Stainless Steel Microstructure: Discrimination between Equiaxed- and Columnar-Grain Material - An Interim Study, Richland, Washington, Pacific Northwest National Laboratory, 2009.

167. D. S. Kupperman, K. J. Reimann, et al., "Ultrasonic Characterization and Microstructure of Stainless Steel Weld Metal" Nondestructive Evaluation: Microstructural Characterization and Reliability

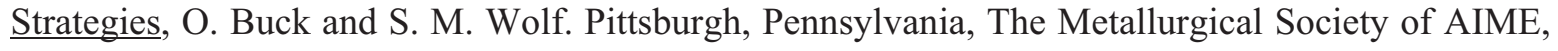
Warrendale, Pennsylvania: 199-216, 1981.

168. D. S. Kupperman, K. J. Reimann, et al., "Ultrasonic NDE of Cast Stainless Steel," NDT International 20(3): 145-152, 1987.

169. C. J. Yu, J. C. Conway, et al., "Ultrasonic Characterization of the Effect of Cold Work and Grain Size in Copper and 68:32 Brass Sheets." Journal of Materials Science, 27(19), pp. 5174-5180, 1992.

170. M. Vasudevan, P. Palanichamy, "Characterization of Microstructural Changes During Annealing of Cold Worked Austenitic Stainless Steel Using Ultrasonic Velocity Measurements and Correlation with Mechanical Properties." Journal of Materials Engineering and Performance, 11(2), pp. 169-179, 2002.

171. T. Jayakumar, A. Kumar, et al. (2008). Ultrasonic Characterization of Austenitic Stainless Steels. Proceedings of the 34th Annual Review of Progress in Quantitative Nondestructive Evaluation, Volume 27. D. O. Thompson and D. E. Chimenti. Golden, Colorado, American Institute of Physics, Melville, New York. AIP Conf. Proceedings Volume 975, pp. 1162-1169.

172. Sagar et al., "Precipitation Hardening Study of Ageing of Maraging Steel Using Ultrasonic Technique," Proc. National Seminar on Non-Destructive Evaluation, Hyderabad, 2007 
173. J. Stella, J. Cerezo, et al. (2009). "Characterization of the Sensitization Degree in the AISI 304 Stainless Steel Using Spectral Analysis and Conventional Ultrasonic Techniques." NDT \& E International 42(4): 267-274.

174. D. Frenet, P. Calmon, et al., "Modeling of Surface Acoustic Waves Reflected on Fluid-Loaded Solids. Application to Measurements on Anisotropic Materials with a Phased-Array Broadband Transducer," Review of Progress in Quantitative Nondestructive Evaluation, Volume 19, 2000, pp.1017-1024.

175. V. Buckin, B. O'Driscoll, et al., "Ultrasonic Spectroscopy for Material Analysis. Recent Advances." Spectroscopy Europe 15(1): 20-25, 2003.

176. E.P. Papadakis, "Correction for Diffraction Losses in the Ultrasonic Field of a Piston Source." The Journal of the Acoustical Society of America, 31(2), 1959, pp. 150-152.

177. E.P Papadakis, "Ultrasonic Diffraction Loss and Phase Change in Anisotropic Materials," The Journal of the Acoustical Society of America, 40(4), 1966, pp. 863-876.

178. G.S. Darbari, R. P. Singh, et al. (1968). "Ultrasonic Attenuation in Carbon Steel and Stainless Steel at Elevated Temperatures," Journal of Applied Physics, 39(5), 1968, pp. 2238-2245.

179. E.P. Papadakis, "Buffer-Rod System for Ultrasonic Attenuation Measurements," The Journal of the Acoustical Society of America, 44(5), 1968, pp. 1437-1441.

180. E.P. Papadakis, E. P., "Absolute Measurements of Ultrasonic Attenuation Using Damped Nondestructive Testing Transducers," Journal of Testing and Evaluation (JTEVA), 12(5), 1984, pp. 273-279.

181. X. Liu, S. Takamori, et al., "Diffraction Correction in the Measurement of Ultrasonic Attenuation," Materials Science and Engineering: A, 442(1-2), 2006, pp. 527-531.

182. G. P. P. Gunarathne, K. Christidis, "Material Characterization in Situ Using Ultrasound Measurements," IEEE Transactions on Instrumentation and Measurement, 51(2), 2002, pp. 368-373.

183. H. Willems, K. Goebbels, "Characterization of Microstructure by Scattered Ultrasonic Waves," Tenth World Conference on Non-Destructive Testing, 1A-30, 1982, pp. 39-45.

184. N. Feuilly, O. Dupond, et al., "Relation Between Ultrasonic Backscattering and Microstructure for Polycrystalline Materials," Proceedings of the 35th Annual Review of Progress in Quantitative Nondestructive Evaluation, 28, 1096, 2009, pp. 1216-1223.

185. J. Moysan, G. Corneloup, "Ultrasounds Back-Scattering Measurements for New Anisotropy Indicator Construction,"15th World Conference on Nondestructive Testing, October 15-21, 2000, Rome.

186. P. Barat, S. De, et al., "Fractal Property of Backscattered Acoustic Signals from Polycrystalline Aluminium," Physics Letters A, 245(1-2), 1998, pp. 91-96.

187. J.A. Scales, A. E. Malcolm, "Laser Characterization of Ultrasonic Wave Propagation in Random Media," Physical Review E, 67, 2003, pp. 7.

188. A.E. Malcolm, J. A. Scales, et al., "Extracting the Green Function from Diffuse, Equipartitioned Waves," Physical Review E, 70, 2004, pp. 4. 
189. R.L. Weaver, "On Diffuse Fields in Solid Media," Journal of Acoustical Society of America, 71(6), 1982, pp. 1608-1609.

190. J.A. Turner, R. L. Weaver (1995). "Time Dependence of Multiply Scattered Diffuse Ultrasound in Polycrystalline Media," The Journal of the Acoustical Society of America, 97(5), 1995, pp. 2639-2644.

191. G. Ghoshal, J. A. Turner, "Diffuse Ultrasonic Backscatter in a Two-Dimensional Domain," Acta Mech, 205, 2009, pp. 35-49.

192. R.L. Weaver, O. I. Lobkis (2001). "On the Emergence of the Green's Function in the Correlations of a Diffuse Field," Journal of Acoustical Society of America, 110(6), 2001, pp. 3011-3017.

193. F. C. Sgard, N. Atalla, et al. "A Numerical Model for the low Frequency Diffuse Field Sound Transmission Loss of Double-Wall Sound Barriers with Elastic Porous Linings," Journal of Acoustical Society of America, 108(6), 2000, pp. 2865-2872.

194. R. L. Weaver, O. I. Lobkis, "Temperature Dependence of Diffuse Field Phase," Ultrasonics, 38, 2000, pp. 491-494.

195. J. Becker, L. Jacobs, J. Qu, "Characterization of cement-based materials using diffuse ultrasound," $J$. Eng. Mechs., 39, 2003, pp.1478-84.

196. S.K. Ramamoorthy, Y. Kane, et al., "Ultrasound Diffusion for Crack Depth Determination in Concrete," Journal of Acoustical Society of America, 115(2), 2004.

197. R. L. Weaver W. Sachse, "Diffusion of Ultrasound in a Glass Bead Slurry," Journal of Acoustical Society of America, 97(4), 1994, pp. 2094-2102.

198. J.H. Cantrell, W. T. Yost, "Nonlinear Ultrasonic Characterization of Fatigue Microstructures." International Journal of Fatigue, 23(Supplement 1), 2001, pp. 487-490.

199. L. Adler and C. Mattei, "Impacts of Nonlinear Acoustics on Nondestructive Evaluation and Acousto-Optics," Proceedings of the 15th International Symposium on Nonlinear Acoustics - Nonlinear Accustics at the Turn on the Millennuum, Göttingen, Germany, AIP(DE), 1999, pp. 317-320.

200. S.S. Kulkarni, J. D. Achenbach, "Structural Health Monitoring and Damage Prognosis in Fatigue." Structural Health Monitoring, 7(1), 2008, pp. 37-49.

201. L. Ostrovsky, P. A. Johnson, et al., "The Mechanism of Nonlinear Response in Highly Nonlinear Solids," Proceedings of the 15th International Symposium on Nonlinear Acoustics - Nonlinear Accustics at the Turn on the Millennuum, Göttingen, Germany, AIP(DE), 1999, pp. 75-84.

202. S.N. Jerebtsov, A. A. Kolomenskii, et al., "Characterization of a Polycrystalline Material with Laser-Excited Nonlinear Surface Acoustic Wave Pulses," International Journal of Thermophysics, 25(2), 2004, pp. 485-490.

203. http://stackoverflow.com/questions/4495000/multi-threading-in-matlab

204. http://www.instructables.com/id/Matlab-Multithreading-EASY/ 


\section{APPENDIX A}

This appendix provides additional design information about the two DOE MTRs (ATR and HFIR) where DOE-NE irradiations are performed. In addition, design information is provided about the MITR, where the ultrasonic transducer irradiation will be performed.

\section{A.1 ATR}

\section{A.1.1. Reactor Design and Characteristics}

As shown in Figure A-1, the ATR core consists of 40 curved plate fuel elements in a serpentine arrangement around a $3 \times 3$ array of primary testing locations, or nine large high-intensity neutron flux traps. The unique ATR control device design permits large power variations among its nine flux traps using a combination of control cylinders (drums) and neck shim rods. The beryllium control cylinders contain hafnium plates that can be rotated toward and away from the core. Hafnium shim rods, which withdraw vertically, are inserted or withdrawn for minor power adjustments. Within bounds, the power level in each corner lobe of the reactor can be controlled independently to allow for different power and flux levels in the four corner lobes during the same operating cycle. The ratio of fast to thermal flux can be varied from 0.1 to 1.0. In addition to the nine large volume (up to $1.22 \mathrm{~m}$ long and up to $127 \mathrm{~mm}$ diameter) high-intensity neutron flux traps, there are 66 irradiation positions inside the reactor core reflector tank, and there are two capsule irradiation tanks outside the core with 34 low-flux irradiation positions. A Hydraulic Shuttle Irradiation System (HSIS), more commonly referred to as the "Rabbit", was also recently installed in the ATR to restore the reactor's capability to perform irradiations of small capsules in the B-7 position of the reactor for materials research, rapid activations, and isotope production.

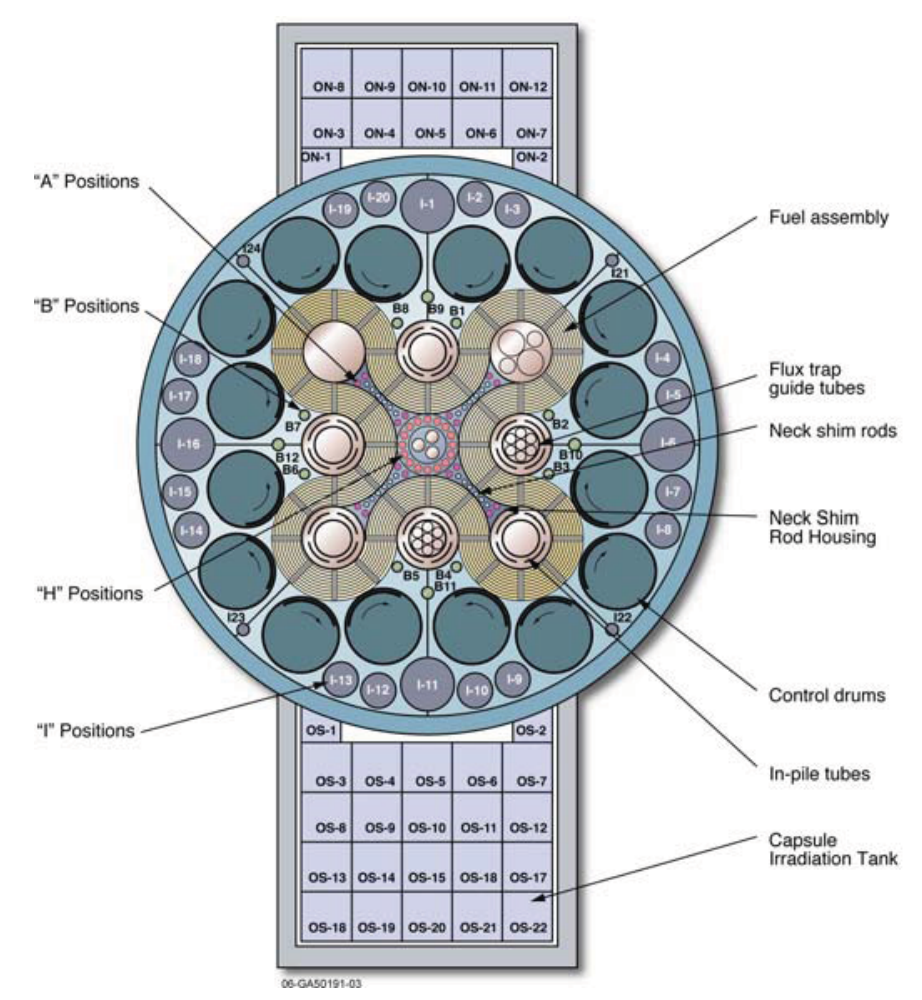

Figure A-1.ATR core cross section showing irradiation locations. 


\section{A.1.2. Test Configurations and Conditions}

Irradiated samples are enclosed in test capsules that are then typically placed in a basket to facilitate positioning within the reactor. This section provides summary information about the three ATR primary test configurations, which are conceptually shown in Figure A-2, and the HSIS. More detailed information can be found in References 1 and 2.
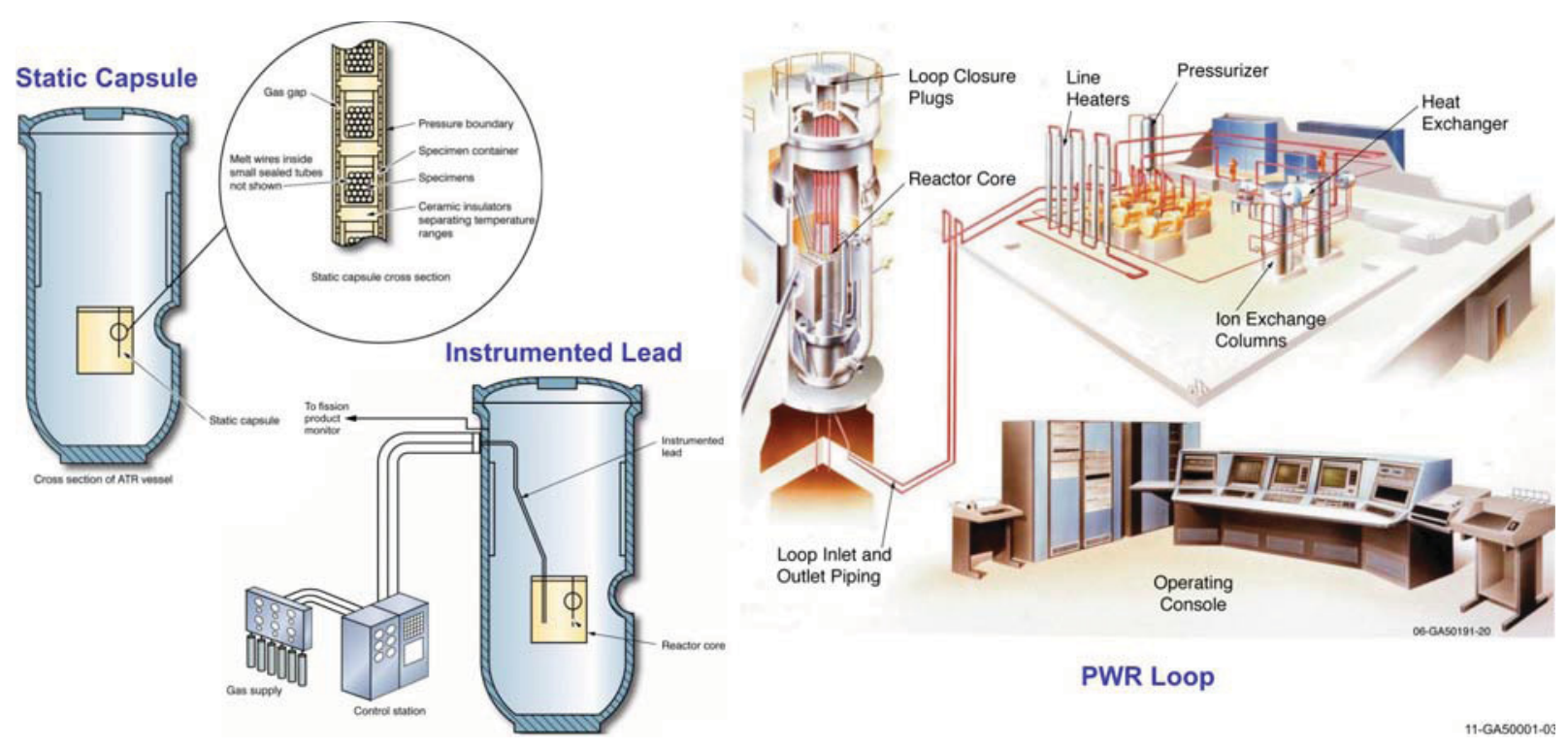

Figure A-2.Schematic diagrams illustrating ATR irradiation locations.

- Static Capsule Experiments - These capsules may contain a number of small samples or engineered components. Static capsule experiments may be sealed or may contain material that can be in contact with the ATR primary coolant (such capsules are in an open configuration without being sealed). Capsules may be any length, up to $122 \mathrm{~cm}$ (48 in.) and may be irradiated in any core position, including the flux traps. Irradiation temperature may be selected by providing a gas gap in the capsule with a known thermal conductance. Peak temperatures may be measured using a series of melt wires, temperature-sensitive paint spots, or silicon carbide temperature monitors. Accumulated neutron fluences may be verified using flux wires.

- Instrumented Lead Experiments - Active control of experiments and data from test capsules during irradiation is achieved using core positions with instrumentation cables and temperature control gases in ATR instrumented lead experiments. Such experiments can have instrumentation, such as thermocouples, connected to individual capsules or single specimens. This instrumentation can be used to control and sample conditions within the capsule. For example, temperature control in individual zones is performed by varying the gas mixture (typically helium and neon) in the gas gap that thermally links the capsule to the water-cooled reactor structure. In addition to temperature, instrumented lead experiments can be configured to monitor the gas around the test specimen. In a fueled experiment, the presence of fission gases due to fuel failures or oxidation can be detected via gas chromatography. Instrument leads allow real time display of experimental parameters in the control room.

- Pressurized Water Loop Experiments - Six of the nine ATR flux traps used for materials and fuels testing are equipped with pressurized water loops (at the NW, N, SE, SW, and W locations). Each of the water loops can be operated at different temperatures, pressures, flow rates, or water chemistry requirements. These loops can operate above the standard temperatures and pressure of 
a commercial Pressurized Water Reactor (PWR) power plant. Each ATR pressurized loop is instrumented to measure and control coolant flows (both helium and water), temperatures, pressures and sample test data.

Rabbit Tests - The HSIS, or rabbit, enables insertion and removal of experiment specimens during ATR during operational cycles. The HSIS is installed in the B-7 reflector position, which is one of the higher flux positions in the reactor with typical thermal and fast $(>1 \mathrm{MeV})$ fluxes of $2.8 \times 10^{14} \mathrm{n} / \mathrm{cm}^{2} / \mathrm{sec}$ and $1.9 \times 10^{14} \mathrm{n} / \mathrm{cm}^{2} / \mathrm{sec}$, respectively. The titanium experiment capsules, or shuttles, are approximately $16 \mathrm{~mm}$ in diameter x $57 \mathrm{~mm}$ in length with interior usable dimensions of $14 \mathrm{~mm}$ in diameter $\mathrm{x} 50 \mathrm{~mm}$ long. Up to 14 capsules can be used for irradiations simultaneously, although one does not need to fill all 14 capsules for a test. The maximum allowable weight of each shuttle contents is 27.0 grams.

\section{A.2 HFIR}

\section{A.2.1. Reactor Design and Characteristics}

The reactor core, illustrated in Figure A-3, consists of a series of concentric annular regions, each approximately $61 \mathrm{~cm}$ in height. The flux trap is $\sim 12.7 \mathrm{~cm}$ in diameter, and the outer fueled region is $\sim 43.5 \mathrm{~cm}$ in diameter. The fuel region is surrounded by a concentric ring of beryllium reflector approximately $30.5 \mathrm{~cm}$ in thickness. The beryllium reflector is in turn backed up by a water reflector of effectively infinite thickness. In the axial direction, the reactor is reflected by water. The reactor core assembly is contained in a $2.44 \mathrm{~m}$ diameter pressure vessel, which is located in a $5.5 \mathrm{~m}$ cylindrical pool of water. Figure A-4 shows a cutaway of the reactor pressure vessel and its location in the reactor pool. Experiment facilities shown in this figure are discussed in Section A.2.2.

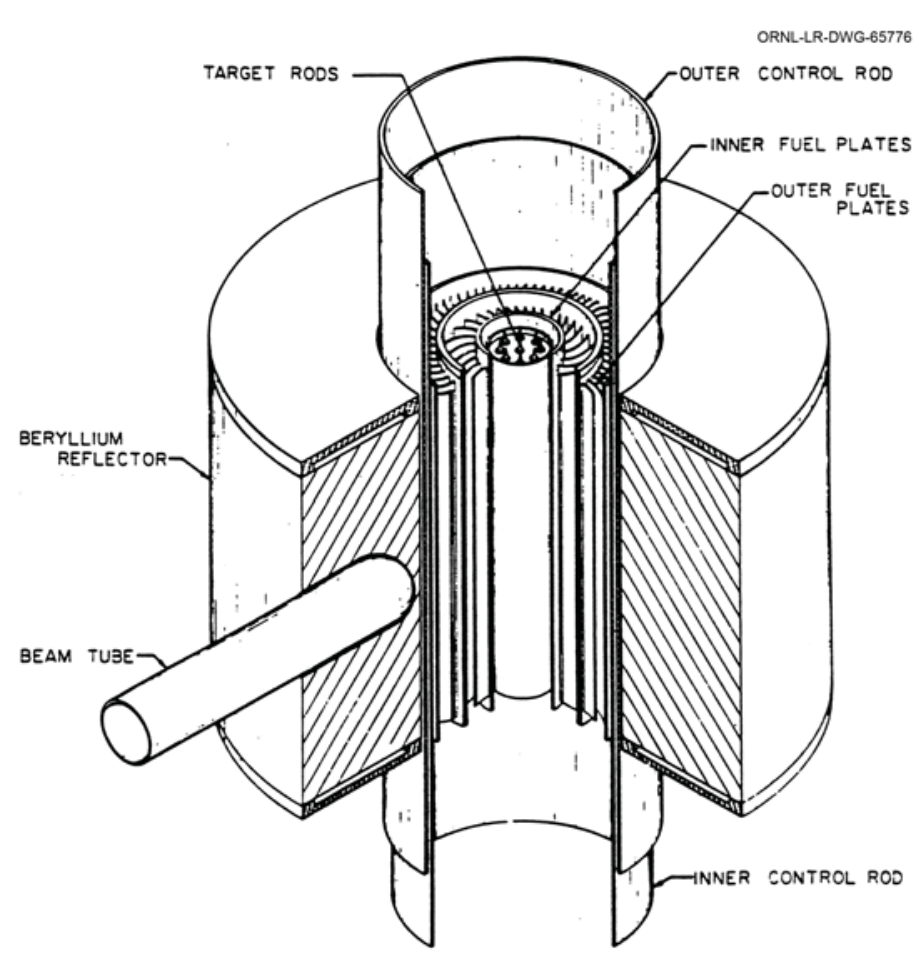

Figure A-3.Schematic of HFIR reactor core and beryllium reflector. 


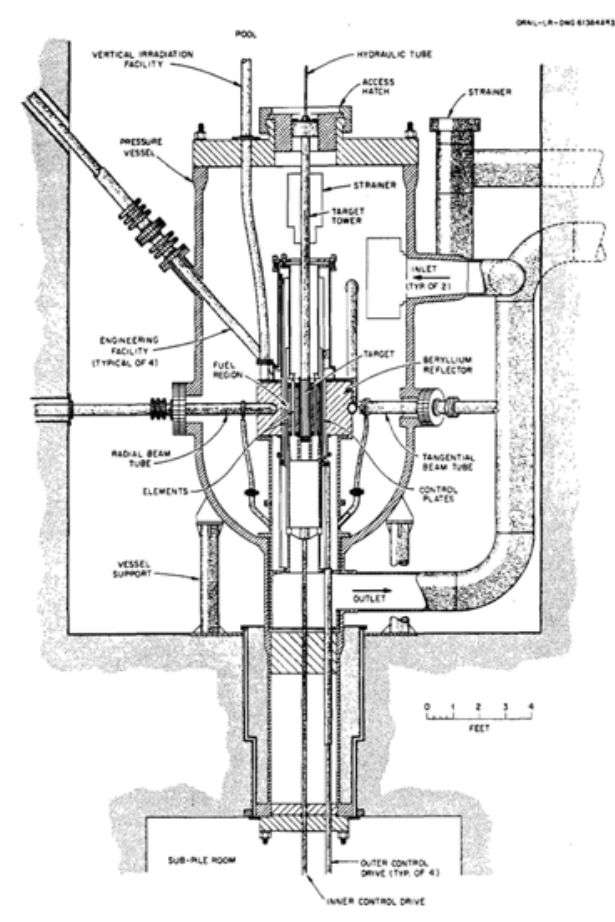

Figure A-4.Cross section through HFIR pressure vessel.

\section{A.2.2. Test Configurations and Conditions}

Several facilities within the HFIR core and reflector are available for experimental use. These include: (1) the flux trap, (2) three horizontal beam holes which originate in the reflector, (3) four slant access facilities which are located adjacent to the outer reflector at an angle with the vertical, and (4) 30 vertical facilities of various sizes located in the reflector. Figure A-5, a cross section of the HFIR, illustrates these experimental facilities.

Table A-1 contains the characteristics of the vertical irradiation facilities in HFIR. The facilities listed start with the flux trap (left column) and proceed outward to the large Vertical Experiment Facility (VXF) positions (right-most column). Going from the target region to the large VXF position, the fast flux decreases by a factor of 100 and the thermal flux (without shields) decreases by a factor of 5. Also given in Table A-1 are the characteristics for the Large Removable Beryllium Facility (RB*) position with and without thermal-neutron shields. Using the standard $\mathrm{RB}^{*} \mathrm{Eu}_{2} \mathrm{O}_{3}$ shield, the thermal neutron flux can be reduced by a factor of 50 without significantly affecting the fast flux, even after 8-10 cycles of operation. At beginning of life, the fast/thermal ratio is far higher. Thus, it is possible to tailor the neutron spectrum for specific experimental purposes and goals.

The target region has the highest reactor neutron flux (thermal flux $[\mathrm{E}<0.5 \mathrm{eV}]$ of $2.1 \cdot 10^{15} \mathrm{n} / \mathrm{cm}^{2} \cdot \mathrm{sec}$ and a fast flux $[\mathrm{E}>0.1 \mathrm{MeV}]$ of $1.1 \cdot 10^{15} \mathrm{n} / \mathrm{cm}^{2} \cdot \mathrm{sec}$ ). A schematic of the target region is given in Figure A-6. The flux trap contains 36 positions plus the hydraulic tube (rabbit irradiation). Target positions may be irradiated for a cycle or multiple cycles (a cycle averages $\sim 23$ days but may vary from 21-26 days, depending on the power level and experiments loaded in the core). The target region may accommodate two fully instrumented experiments (the E3 and E6 locations). 


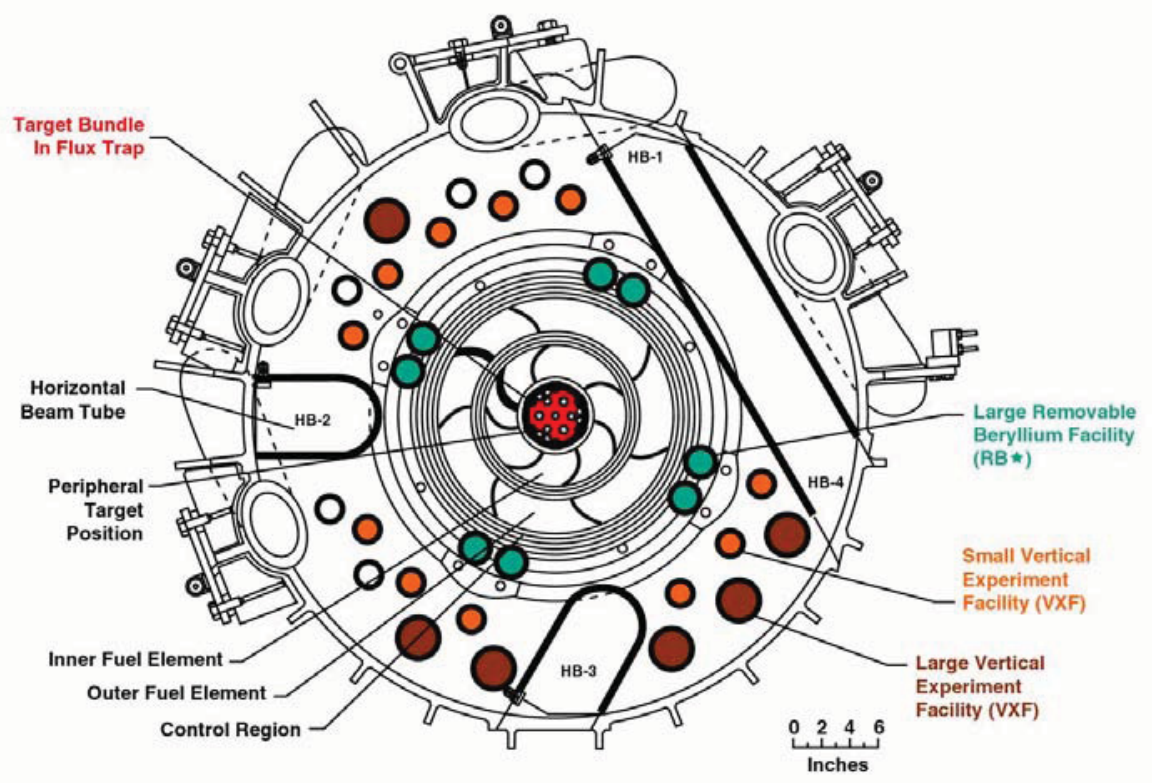

Figure A-5.Cross section through HFIR mid-plane.

Table A-1. Characteristics of vertical HFIR irradiation facilities.

\begin{tabular}{l|c|c|c|c|c}
\hline \multicolumn{1}{c|}{ Characteristic } & Target & $\begin{array}{c}\mathbf{R B}^{*} \\
\text { unshielded }\end{array}$ & $\begin{array}{c}\mathbf{R B}^{*} \text { with } \\
\mathbf{E u}_{\mathbf{2}} \mathbf{O}_{\mathbf{3}} \text { shield }\end{array}$ & $\begin{array}{c}\text { Small } \\
\mathbf{V X F}\end{array}$ & $\begin{array}{c}\text { Large } \\
\text { VXF }\end{array}$ \\
\hline Fast flux, E $>0.1 \mathrm{MeV}\left(10^{14} \mathrm{n} / \mathrm{cm}^{2} \cdot \mathrm{sec}\right)$ & 11 & 5.3 & 4.9 & 0.5 & 0.13 \\
Thermal flux, E $<0.1 \mathrm{MeV}\left(10^{14} \mathrm{n} / \mathrm{cm}^{2} \cdot \mathrm{sec}\right)$ & 21 & 11 & 0.19 & 7.5 & 4.3 \\
Peak displacements per atom $(\mathrm{dpa})$ per cycle, stainless steel & 1.8 & 0.67 & 0.58 & & \\
Typical capsule diameter $(\mathrm{mm})$ & 16 & 43 & 38 & 37 & 69 \\
Number of available positions & 36 & 8 & 2 & 16 & 6 \\
\hline
\end{tabular}

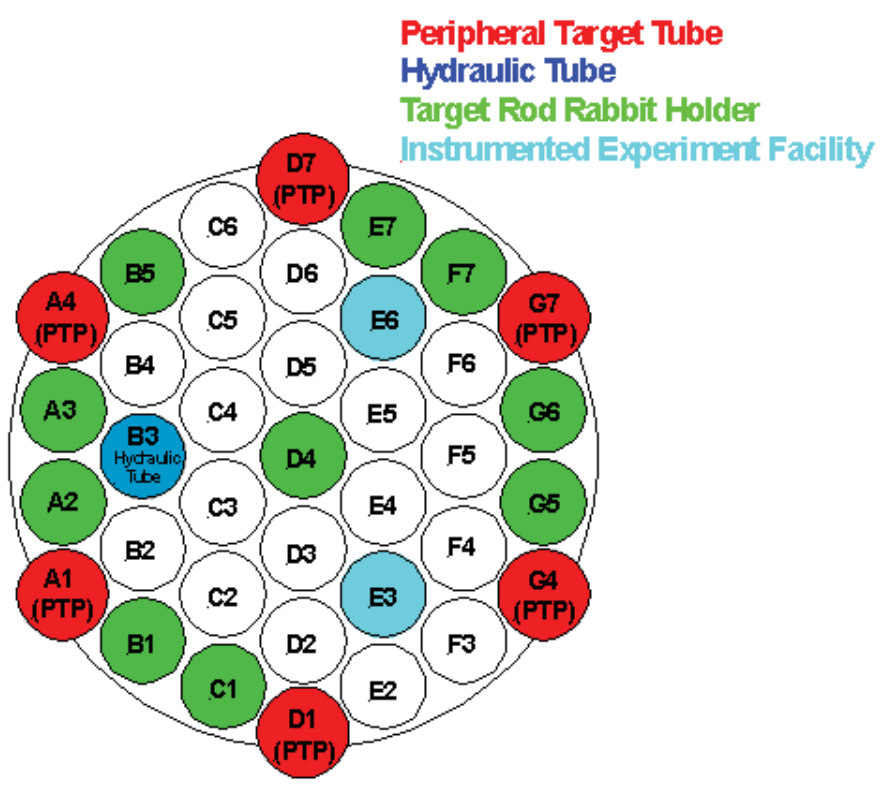

Figure A-6.HFIR flux trap schematic. 
The target region also contains a hydraulic facility (location B3) which offers the unique opportunity to irradiate experiments for very low doses with irradiation times as short as 1 minute or as long as the full cycle.

The primary vertical test positions in the reflector (outside the core) are the "RB", "small VXF", and the "large VXF" positions (see Figure A-5). The attributes (number of available positions, typical experimental capsule diameters, gamma heating and flux levels) for these positions are given in Table A-1. Shielded designs are routinely used for these positions with highly instrumented assemblies normally being inserted in the RB positions.

\section{A.3 MITR}

As shown in Figure A-7, the MITR ${ }^{30}$ reactor has two tanks: an inner one for the light water coolant/moderator and an outer one for the heavy water reflector. A graphite reflector surrounds the heavy water tank. The reactor utilizes flat, plate-type fuel elements. Each rhomboidal fuel element consists of fifteen plates of $\mathrm{UAl}_{\mathrm{x}}$ cermet clad with 6061 aluminum alloy. Longitudinal fins on the fuel plates increase the heat transfer area. The core contains 27 fuel element positions and is normally configured with 24 fuel elements and 3 positions available for in-core experiments. The close-packed hexagonal core design maximizes the thermal neutron flux in the heavy water reflector region where the re-entrant thimbles of the beam ports are located. The light-water core, heavy-water reflector, and graphite region are all separately cooled. Each transfers heat to a secondary coolant that dissipates it to the atmosphere via two cooling towers.

The MITR operates at atmospheric pressure. Primary coolant, at a nominal flow rate of approximately $125 \mathrm{~kg} / \mathrm{s}$, enters the bottom of the core tank through the core shroud, flows upward through the fuel elements and then exits at the outlet piping located about $2 \mathrm{~m}$ above the top of the core. The primary coolant core inlet temperature is approximately $42{ }^{\circ} \mathrm{C}$, and the coolant outlet temperature is about $50{ }^{\circ} \mathrm{C}$. The hexagonal core structure is about $380 \mathrm{~mm}$ across with an active fuel length of about $560 \mathrm{~mm}$. The compact core has an average power density of about $70 \mathrm{~kW} / 1$, with fast, thermal, and gamma fluxes similar to those of a commercial light water reactor (LWR).

The MITR is equipped with a wide variety of sample irradiation facilities, with fast and thermal neutron fluxes up to $10^{14}$ and $5 \times 10^{13} \mathrm{n} / \mathrm{cm}^{2} \mathrm{~s}$. These facilities are described in the following section. The MITR operates 24 hours a day, 7 days per week. A typical fuel cycle lasts about 4-6 weeks followed by a 1 week refueling and maintenance outage. 


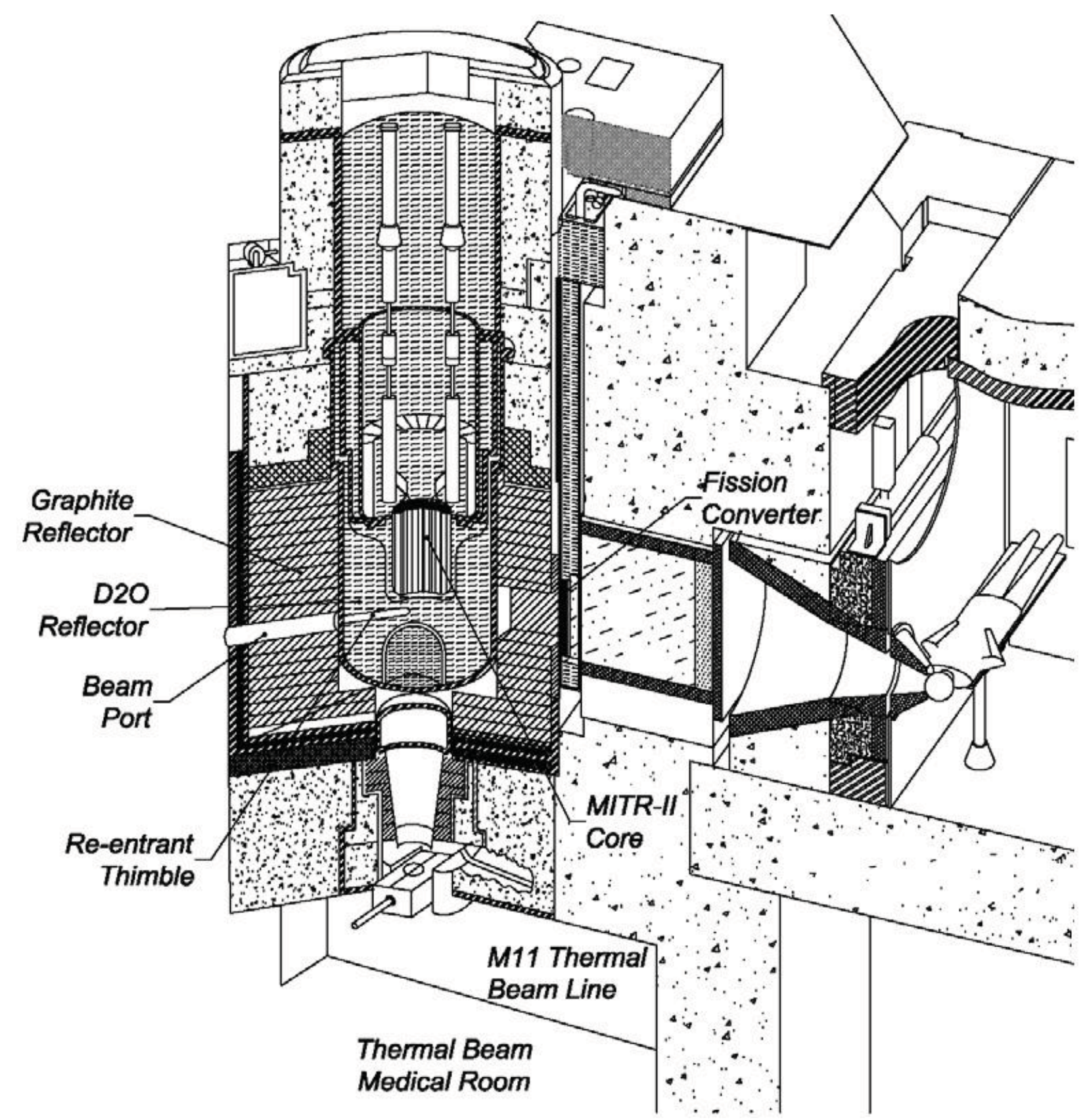

Figure A-7.Cutaway schematic of the MITR. 
NEET In-Pile Ultrasonic Sensor Enablement-FY 2012 Status Report

September 2012 